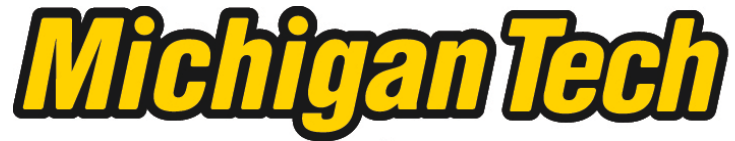 \\ Michigan Technological University Create the Future Digital Commons @ Michigan Tech
}

Dissertations, Master's Theses and Master's Reports - Open

Dissertations, Master's Theses and Master's

Reports

2011

\section{Orbits design for Leo space based solar power satellite system}

Neelima Krishna Murthy Addanki

Michigan Technological University

Follow this and additional works at: https://digitalcommons.mtu.edu/etds

Part of the Mechanical Engineering Commons

Copyright 2011 Neelima Krishna Murthy Addanki

\section{Recommended Citation}

Addanki, Neelima Krishna Murthy, "Orbits design for Leo space based solar power satellite system", Master's Thesis, Michigan Technological University, 2011.

https://doi.org/10.37099/mtu.dc.etds/343

Follow this and additional works at: https://digitalcommons.mtu.edu/etds

Part of the Mechanical Engineering Commons 


\title{
ORBITS DESIGN FOR LEO SPACE BASED SOLAR POWER SATELLITE SYSTEM
}

\author{
By \\ Neelima Krishna Murthy Addanki
}

\begin{abstract}
A THESIS
Submitted in partial fulfillment of the requirements for the degree of MASTER OF SCIENCE

(Mechanical Engineering)
\end{abstract}

MICHIGAN TECHNOLOGICAL UNIVERSITY

2011

Copyright $(\mathbb{C}$ Neelima Krishna Murthy Addanki 
This thesis, "Orbits Design for LEO Space Based Solar Power Satellite System," is hereby approved in partial fulfillment of the requirements for the Degree of MASTER OF SCIENCE IN MECHANICAL ENGINEERING

Department of Mechanical Engineering-Engineering Mechanics

Signatures:

Thesis Advisor

Dr.Ossama O AbdelKhalik

Department Chair

Dr. William W. Predebon

Date 
This thesis is dedicated to my loving parents 


\section{TABLE OF CONTENTS}

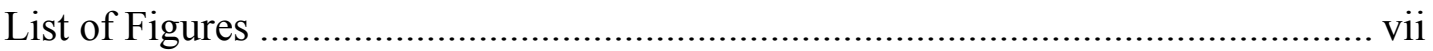

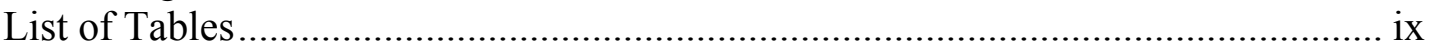

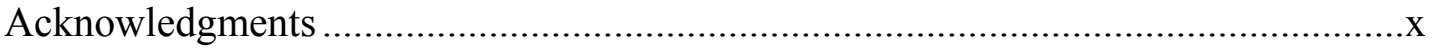

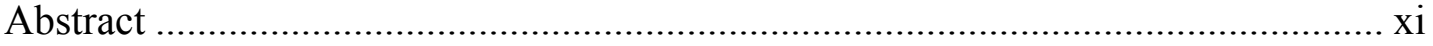

1. BACKGROUND AND LITERATURE REVIEW ......................................

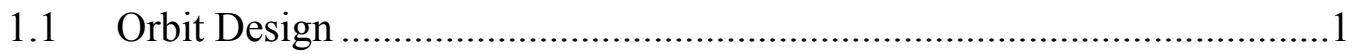

1.1.1 Equation of motion ..................................................................

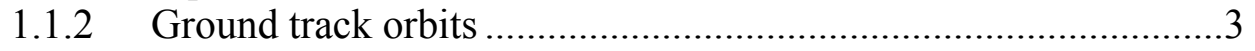

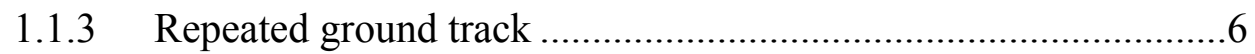

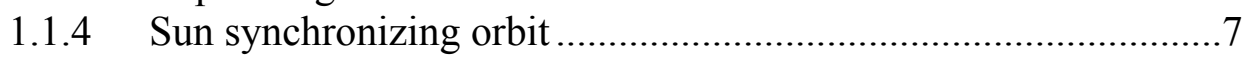

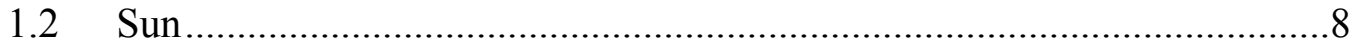

1.2.1 Birth of Our Sun.................................................................. 8

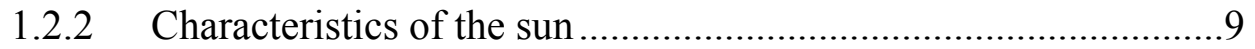

1.2.2.1 Orbit mechanics of sun .................................................

1.2.2.2 Size comparison and chemical composition of Sun .......9

1.2.2.3 Layers of Sun ............................................................10

1.2.2.3.1 Core ......................................................... 10

1.2.2.3.2 Radiative zone...........................................11

1.2.2.3.3 Convective zone.......................................11

1.2.2.3.4 Photosphere..............................................11

1.2.2.3.5 Corona..................................................... 11

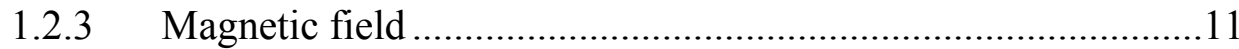

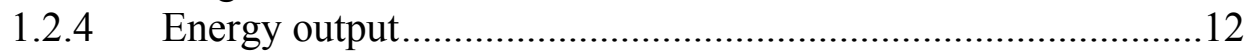

1.3 Space based power satellite systems (SSP) …………............................13

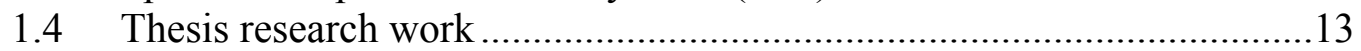

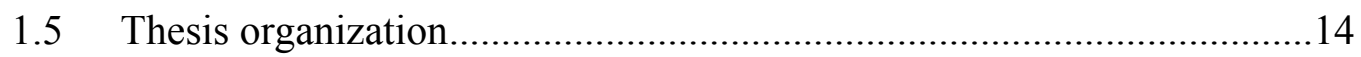

2. PROPOSED SOLAR POWER SATELLITE SYSTEM ……......................15

2.1 The Architecture of the Proposed Space based Solar Power Grid ............15

2.2 Orbit Determination for Repeated Sun-Synchronizing Orbit....................17

2.2.1 Selection of a Ground Track....................................................17

2.2.2 Orbit Perturbations................................................................... 18

2.2.3 Algorithm for ground track …………………........................19

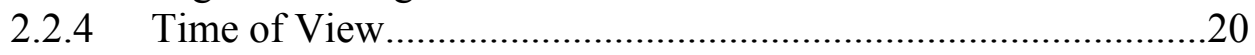

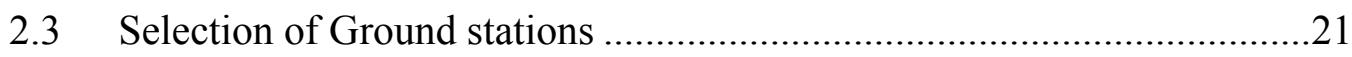

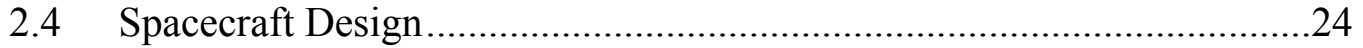

2.4.1 Space craft dynamical analysis for the SBSPG .........................24

2.4.2 Concept of Relaying ………………………….......................25

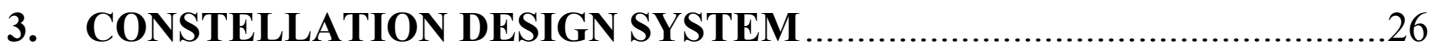

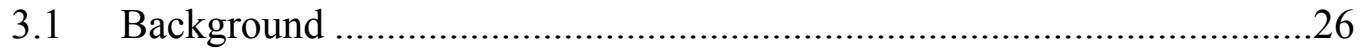




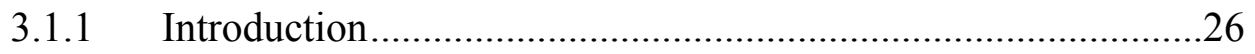

3.1.2 Constellation patterns...............................................................2

3.1.2.1 Flower Constellation...................................................28

3.1.2.2 Geosynchronous Constellation .....................................28

3.1.2.3 Walker constellation .................................................29

3.1.3 Coverage in adjacent planes......................................................30

3.2 SPS Constellation Design....................................................................

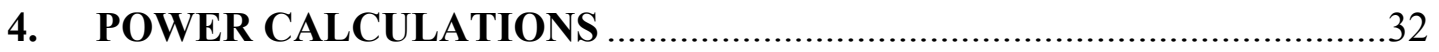

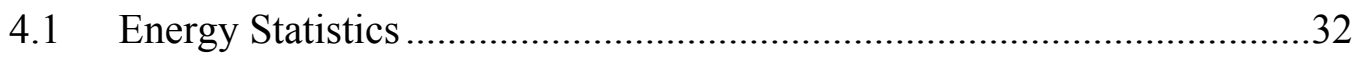

4.1.1 Renewable energy resources .....................................................33

4.1.1.1 Installed Geothermal Power capacity …………...........33

4.1.1.2 Hydro Electric Consumption.........................................34

4.1.1.3 Solar Cumulative installed photovoltaic (PV) power .35

4.1.1.4 Wind/ Cumulative installed wind turbine capacity.....36

4.1.2 Non -Renewable Energy Resources ............................................37

4.1.2.1 Coal Consumption \& Production ...................................37

4.1.2.2 Natural Gas Consumption \& Production.....................39

4.1.2.3 Oil Consumption .........................................................40

4.1.2.4 Nuclear Consumption.................................................4

4.1.2.5 Ethanol Production ....................................................42

4.2 Benefits of SBS Power over other fuels .................................................42

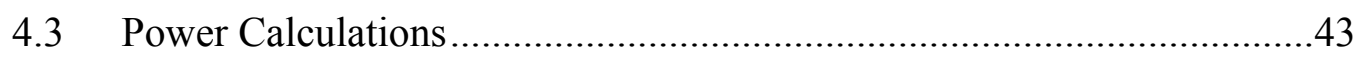

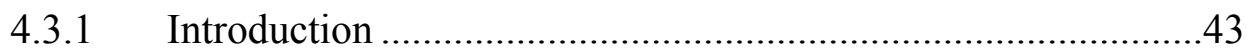

4.3.2 Power calculations for the designed space craft.........................43

4.3.3 Power collected by the SOPHU ..............................................4

4.3.4 Converting Watts (W) to decibels (dB) ...................................4

4.3.5 Calculating the losses during the entire transmission ................45

4.3.6 Calculating the Power transmitted in $\mathrm{dB}$...................................46

4.3.7 Calculating the Power transmitted in Watts (W) ........................47

4.4 Power transmission vs. Altitude ...............................................................47

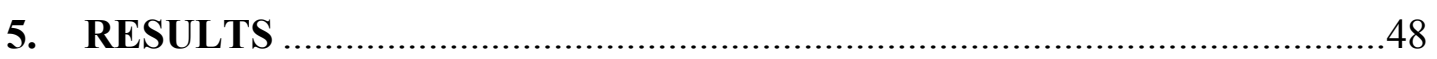

5.1 Best Suitable Orbit Elements calculations .............................................

5.2 RAAN Selection for the second orbit...................................................59

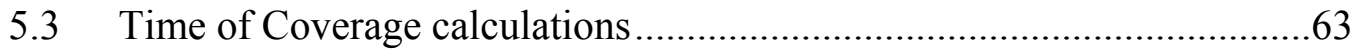

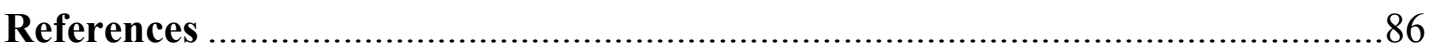




\section{List of Figures}

Figure 1.1 Geometry for two bodies in an inertial reference frame xyz...................... 2

Figure 1.2 Spacecraft in an elliptical path ........................................................ 3

Figure 1.3 Ground track for various inclinations................................................... 4

Figure 1.4 Ground track for varying Altitudes ....................................................... 4

Figure 1.5 Ground track for varying argument of perigee........................................... 5

Figure 1.6 Ground track for varying Right Ascending Node RAAN ........................... 5

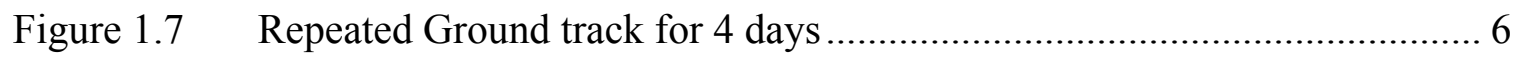

Figure 1.8 Ground track of Sun-synchronizing orbit............................................ 7

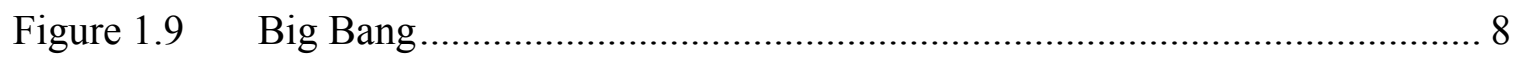

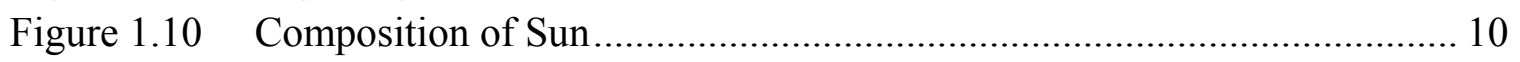

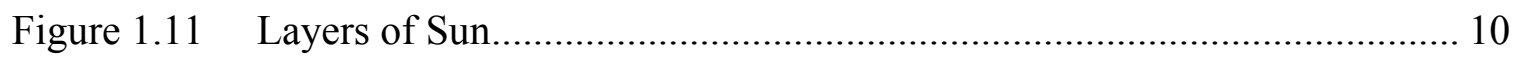

Figure 2.1 the Architecture of the Space Based Solar Power Grid for 2 Orbits ......... 15

Figure 2.3 3D Constellation Design for 3 orbits................................................ 16

Figure 2.2 3D Constellation Design for 2 orbits...................................................... 16

Figure 2.4 the Architecture of the Space Based Solar Power Grid with 3 Orbits ...... 16

Figure 2.5 Repeated sun-synchronous ground track simulating for a period of 6days ..

Figure 2.6 Perturbation calculations due to Earth's Rotation ................................... 18

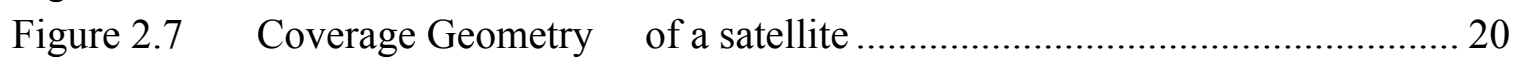

Figure 2.8 US census Regions and Divisions ..................................................... 21

Figure 2.9 Ground stations selected on the US map .............................................. 22

Figure 2.10 Ground stations selected on the World map........................................... 23

Figure 2.11 the proposed structure for one grid unit .................................................. 24

Figure 2.12 Relaying the Collected Energy by SOPHU B to PCBS through LEO

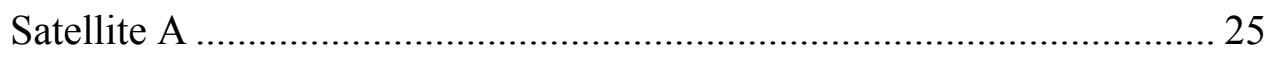

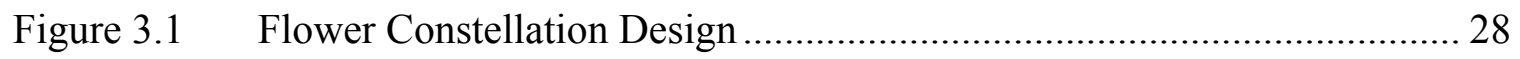

Figure 3.2 Geo Synchronizing Constellation Design ............................................ 28

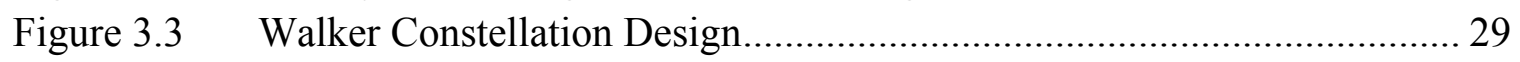

Figure $3.4 \quad$ Coverage in adjacent planes ............................................................... 30

Figure 3.5 Constellation Design for the proposed Space Base Solar Power Satellite

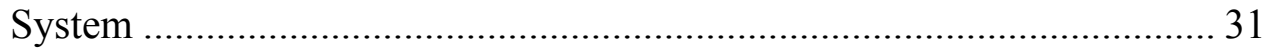

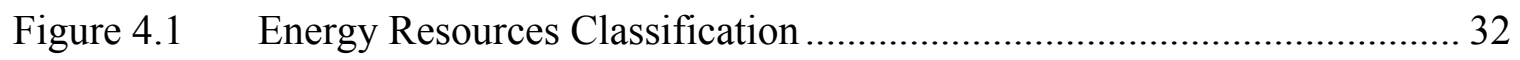

Figure 4.2 US Geothermal Power capacity (in Megawatts) ……………………...... 33

Figure 4.3 World's Geothermal Power Capacity in 2009 ......................................... 33

Figure 4.4 US Hydro Electric Consumption (in Million tones oil equivalent)........... 34

Figure 4.5 World's Hydro Electric Consumption in 2009........................................ 34 
Figure 4.6 US Solar installed photovoltaic (PV) power (in Megawatts) .................... 35

Figure 4.7 World Solar installed photovoltaic (PV) power in 2009 .......................... 35

Figure 4.8 US installed Wind turbine power (in Megawatts) .................................... 36

Figure 4.9 World installed Wind turbine power in 2009.......................................... 36

Figure 4.10 US Coal Consumption in 2009 (in Million tones oil equivalent)............. 37

Figure 4.11 US Coal Production in 2009 (in Million tones oil equivalent)................. 37

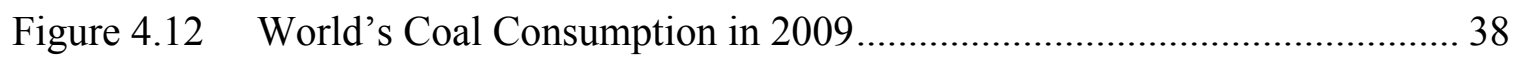

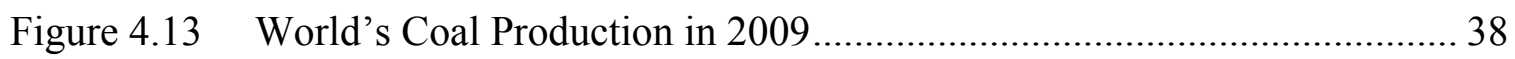

Figure 4.14 US Natural Gas Production (in Million tons oil equivalent)..................... 39

Figure 4.15 US Natural Gas Consumption (in Million tones oil equivalent) ............... 39

Figure 4.16 US Oil Consumption (in Million tones oil equivalent) ............................. 40

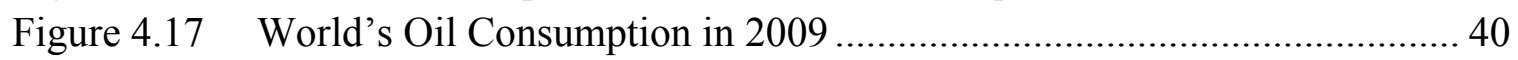

Figure 4.18 US Nuclear Consumption (in Million tones oil equivalent)...................... 41

Figure 4.19 World Nuclear Consumption in 2009 (in Million tones oil equivalent) ... 41

Figure 4.21 US Ethanol Production (in thousand tons of oil equivalents) .................. 42

Figure 4.20 World Ethanol Production in 2009 (in thousand tons of oil equivalents).....

Figure 4.22 Power transmission from SOPHU to PCBS............................................. 44

Figure 5.1 Ground trace for 5 days sun synchronous repeating orbit........................ 50

Figure 5.2 Ground trace for 5 days sun synchronous repeating orbit with perturbations

Figure 5.3 Ground trace for 19 days visiting maximum number of Ground stations....

Figure 5.4 Number of Ground Stations Visited .....................................................61

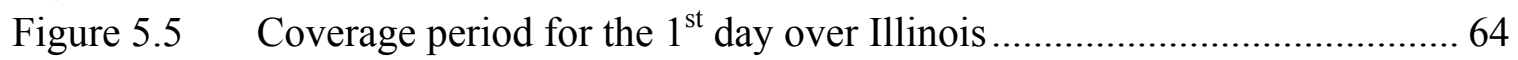

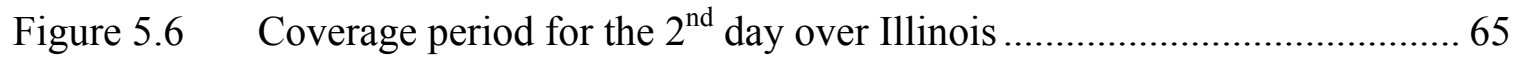

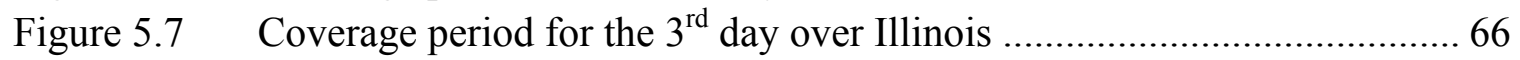

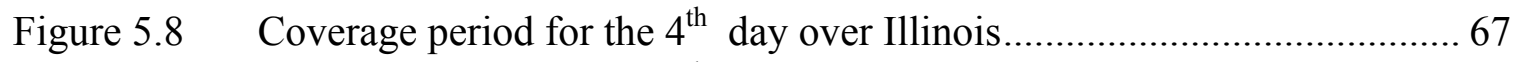

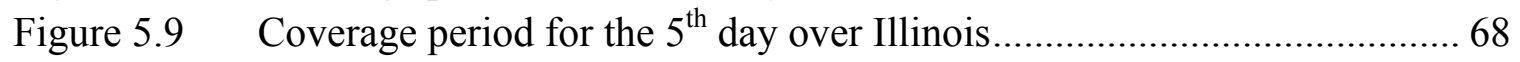

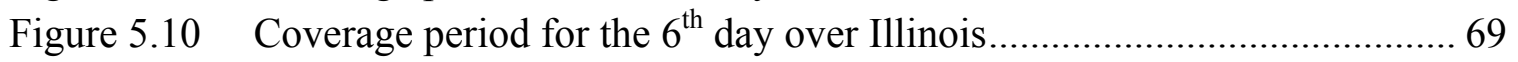

Figure 5.11 Coverage period for the $7^{\text {th }}$ day over Illinois.......................................... 70

Figure 5.12 Coverage period for the $8^{\text {th }}$ day over Illinois.......................................... 71

Figure 5.13 Coverage period for the $9^{\text {th }}$ day over Illinois.......................................... 72

Figure 5.14 Coverage period for the $10^{\text {th }}$ day over Illinois.......................................... 73

Figure 5.15 Coverage period for the $11^{\text {th }}$ day over Illinois......................................... 74

Figure 5.16 Coverage period for the $12^{\text {th }}$ day over Illinois......................................... 75

Figure 5.17 Coverage period for the $13^{\text {th }}$ day over Illinois......................................... 76

Figure 5.18 Coverage period for the $14^{\text {th }}$ day over Illinois........................................ 77

Figure 5.19 Coverage period for the $15^{\text {th }}$ day over Illinois......................................... 78

Figure 5.20 Coverage period for the $16^{\text {th }}$ day over Illinois........................................ 79 
Figure 5.21 Coverage period for the $17^{\text {th }}$ day over Illinois......................................... 80

Figure 5.22 Coverage period for the $18^{\text {th }}$ day over Illinois....................................... 81

Figure 5.23 Coverage period for the $19^{\text {th }}$ day over Illinois.......................................... 82

Figure 5.24 Coverage for the 48 ground stations selected in the US........................... 85 


\section{List of Tables}

Table $1.1 \quad$ Trajectory motion based on the application............................

Table 2.1 Residential Average Monthly Bill by Census Division, And State, 2009 ...

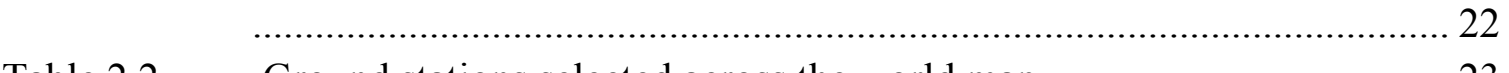

Table 2.2 Ground stations selected across the world map ……………………....... 23

Table $4.1 \quad$ Power Transmission vs. Altitude ……………...................................... 47

Table 5.1 User Requirements for the Sun Synchronous Repeated Ground Track

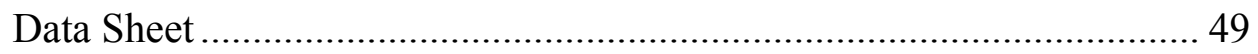

Table 5.2 Ground trace for 5 days sun synchronous repeating orbit with

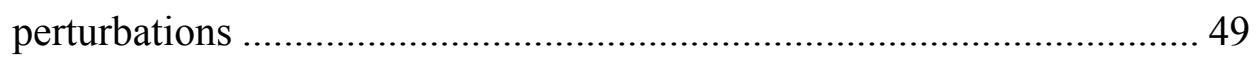

Table 5.3 Power downloaded at different Sun-synchronous altitudes..................... 55

Table 5.4 Results for the Complete set of ground tracks ........................................ 57

Table 5.5 Data sheet for orbital elements selection .............................................. 58

Table 5.6 Maximum Number of Ground Stations Visited............................................ 61

Table 5.7 Maximum Number of Ground Stations Visited....................................... 62 


\section{ACKNOWLEDGEMENTS}

This Thesis gave me an opportunity to work on one of the most challenging topics today. First and foremost, my sincere regards to my advisor Dr.Ossama AbdelKhalik. I am very grateful for him for giving me this opportunity to work under His guidance. His outstanding knowledge helped me achieve my goals. His devotion to work inspired me and drove in me a new passion to acquire knowledge. Without his support and encouragement I would not have completed this thesis. I would also like to thank my supervision committee members, Dr.Sayed Zekavat and Dr. Bo Chen. My loving parents, A. Krishna Murthy and N. J. Annapurna and my sister A. Prathima have always supported me through every step of my life. Their boundless faith in me is a constant driving force that inspired me. I would like to thank all the staff at International Program Services and at the Mechanical Engineering and Engineering Mechanics Department for helping me out with all issues I faced. Special thanks to all my friends

Neelima Krishna Murthy Addanki 


\section{ABSTRACT}

Space Based Solar Power satellites use solar arrays to generate clean, green, and renewable electricity in space and transmit it to earth via microwave, radiowave or laser beams to corresponding receivers (ground stations). These traditionally are large structures orbiting around earth at the geo-synchronous altitude.

This thesis introduces a new architecture for a Space Based Solar Power satellite constellation. The proposed concept reduces the high cost involved in the construction of the space satellite and in the multiple launches to the geo-synchronous altitude. The proposed concept is a constellation of Low Earth Orbit satellites that are smaller in size than the conventional system.

For this application a Repeated Sun-Synchronous Track Circular Orbit is considered (RSSTO). In these orbits, the spacecraft re-visits the same locations on earth periodically every given desired number of days with the line of nodes of the spacecraft's orbit fixed relative to the Sun. A wide range of solutions are studied, and, in this thesis, a two-orbit constellation design is chosen and simulated. The number of satellites is chosen based on the electric power demands in a given set of global cities.

The orbits of the satellites are designed such that their ground tracks visit a maximum number of ground stations during the revisit period. In the simulation, the locations of the ground stations are chosen close to big cities, in USA and worldwide, so that the space power constellation beams down power directly to locations of high electric power demands. The $\mathrm{j} 2$ perturbations are included in the mathematical model used in orbit design.

The Coverage time of each spacecraft over a ground site and the gap time between two consecutive spacecrafts visiting a ground site are simulated in order to evaluate the coverage continuity of the proposed solar power constellation. It has been observed from simulations that there always periods in which s spacecraft does not communicate with any ground station. For this reason, it is suggested that each satellite in the constellation be equipped with power storage components so that it can store power for later transmission.

This thesis presents a method for designing the solar power constellation orbits such that the number of ground stations visited during the given revisit period is maximized. This leads to maximizing the power transmission to ground stations. 


\section{BACKGROUND AND LITERATURE REVIEW}

\subsection{Orbit Design}

Astronomy has always been very interesting and a very well know science since the ancient times. Aristotle, Ptolemy, Nicholaus Copernicus, Tyco Brahe, Johannes Kepler, Galileo Galibi, Sir Isaac Newton, Leonardo Da Vinci are some of the renounced astronomers since the ages. Astronomers believed that earth is always the centre of the solar system for ages. This is called geocentric. But it was accepted that Sun is the centre of our solar system (heliocentric) in the $16^{\text {th }}$ century, proposed by Nicholaus Copernicus. A lot of technology was been invented since then, but the basics remain the same. Griffin \& French in 1991 described Astrodynamics as the "study of motion of man-made objects; subject to both natural and artificial force". Orbit dynamics is "the study of the motion of all orbiting bodies".

Orbit design[3] includes simply means finding the right values for the five orbit elements called the Kepler's elements. This chapter describes more about selection of these five orbital elements.

\subsubsection{Equation of motion}

The Newtonian law is used to derive a two body equation of motion for initial analyses of the motion of bodies.

$$
\ddot{\vec{r}}=\frac{\mu}{r^{2}} \frac{\vec{r}}{r}
$$

$\boldsymbol{\mu}$ is the gravitational constant. $\overrightarrow{\boldsymbol{r}}$ is the position vector of the satellite. This equation assumes that (1) the mass of the satellite is very small compared to the mass of the body attracted (2) the coordinate system chosen is inertial (3) the gravitational force is along the line joining the centers (4) both the bodies are symmetric. To explain this problem below is a schematic representation of the two body problem. 


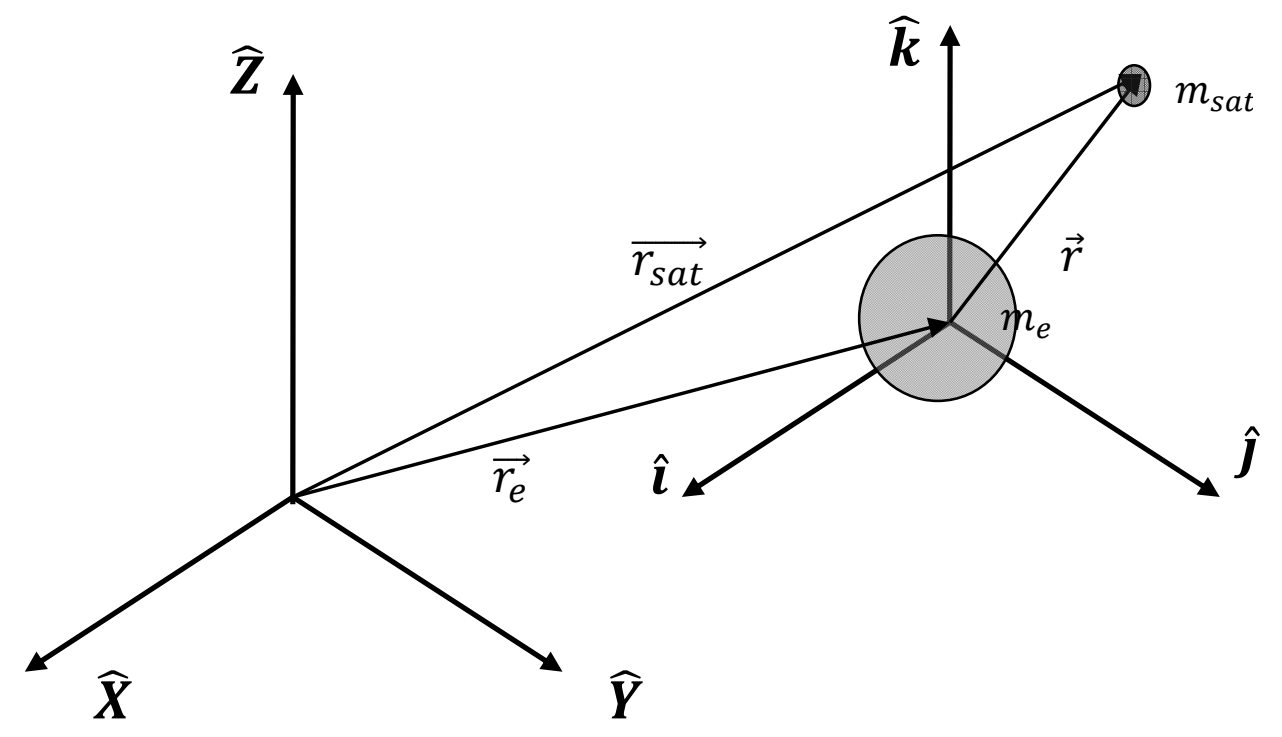

Figure 1.1 Geometry for two bodies in an inertial reference frame $\mathrm{xyz}$

In figure 1.1, $\mathrm{XYZ}$ is the inertial frame of reference and ijk are the earth centered frame of reference. Using the Newton's law $\mathrm{F}=\mathrm{ma}$ the equation of motion is determined from the above frame of reference. The solution to this equation is either, circular, elliptical, parabolic or hyperbolic trajectory. In this thesis topic elliptical and circular orbits are used. The trajectory is defined by five orbital elements. These classic orbital elements area to identify (1) The orbit plane (inclination, i); Right Ascension of Ascending node RAAN, $\Omega$ ) (2) The orbit in plane (argument of perigee, $\omega$ ) (3) The shape of orbit (eccentricity, e; semi major axis, a) (4) Identify the position of the spacecraft on orbit (true anomaly, $\theta$ ). From these five classic orbital elements motion of the satellite is determined. By varying these orbital elements we can achieve either various orbits. Some of them are sun synchronous, geosynchronous, polar orbits, etc. Trajectories are based on the orbit shape which are defined as following

Table 1.1

Trajectory motion based on the application

\begin{tabular}{|c|c|c|c|}
\hline Trajectory & Eccentricity & Semi-major axis & Energy \\
\hline Circular & $\mathrm{e}=0$ & $\mathrm{a}=\mathrm{r}$ & $\mathrm{h}<0$ \\
\hline Ellipse & $\mathrm{e}<0$ & $\mathrm{a}>\mathrm{r}$ & $\mathrm{h}<0$ \\
\hline Parabola & $\mathrm{e}=1$ & $\mathrm{a}=\infty$ & $\mathrm{h}=0$ \\
\hline hyperbola & $\mathrm{e}>1$ & $\mathrm{a}<0$ & $\mathrm{~h}>0$ \\
\hline
\end{tabular}




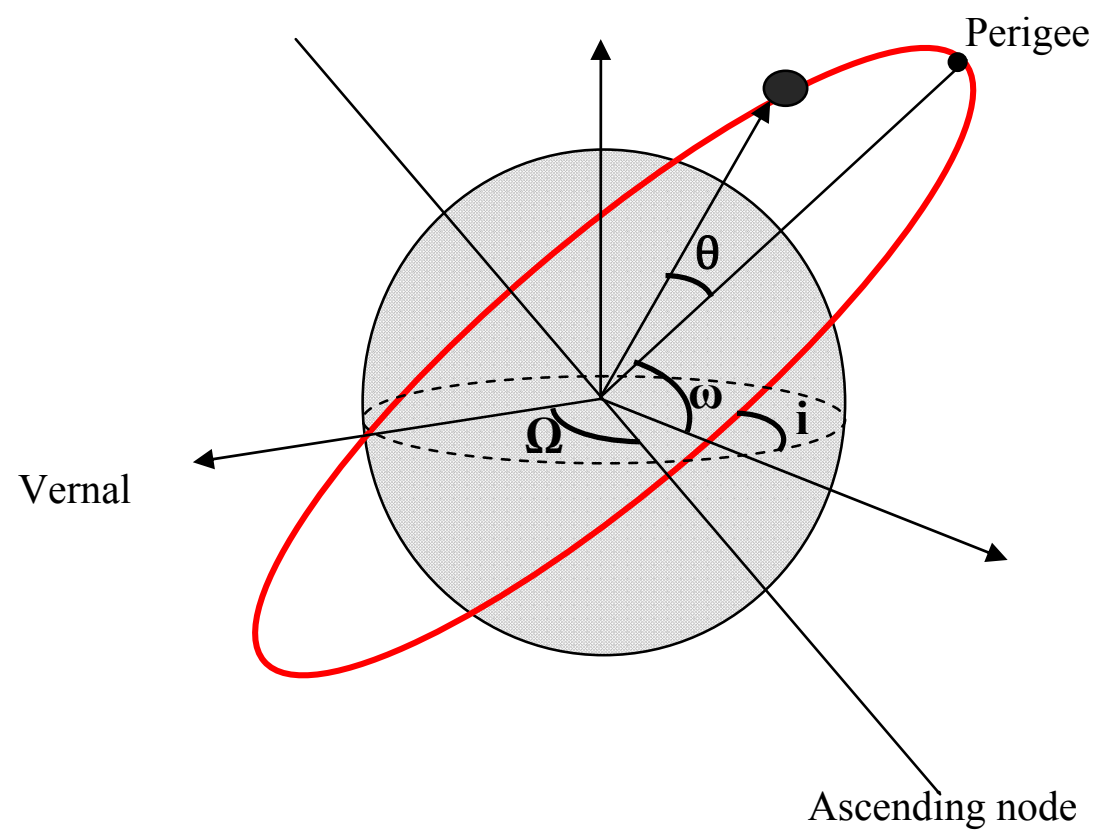

Figure 1.2 Spacecraft in an elliptical path

In this thesis, elliptical and circular orbits are more specified. In figure 1.2, the Kepler's Orbital elements are shown. In the following sections, a detailed description of these satellite paths on earth is given which are called the ground tracks.

\subsubsection{Ground track orbits}

Ground tracks[4] are the locus of points formed by the points on the Earth directly below a satellite as it travels through its orbit. By seeing where a satellite is at any time, we can obtain useful information. To determine ground tracks for a satellite's orbit, we combine both Kepler's equations of motion with the conversion of a position vector to its sub-satellite point. This combination helps us in plotting the ground track by determining the position and location relative to a ground site.

The ground track varies with the five orbital elements described in 1.1.2. Greater the inclination of the orbit, the ground track passes more at the north and south poles. The geographic latitudes covers from $-i$ to $+i$ which is $-90^{0}$ to $+90^{\circ}$. If the argument of perigee $(\omega)$ is zero then, the track is at the equatorial plane. As $\omega$ increases the track moves farther from the equatorial plane.

Figure 1.3 shows the variation in the progression of the spacecraft for various inclinations for an inclination of $0^{0}$ to $90^{\circ}$ the plot is shown. Depending upon the type of application the inclinations are decided. If the orbit needs to cover near equator, then lower inclinations are chosen and vice versa. 


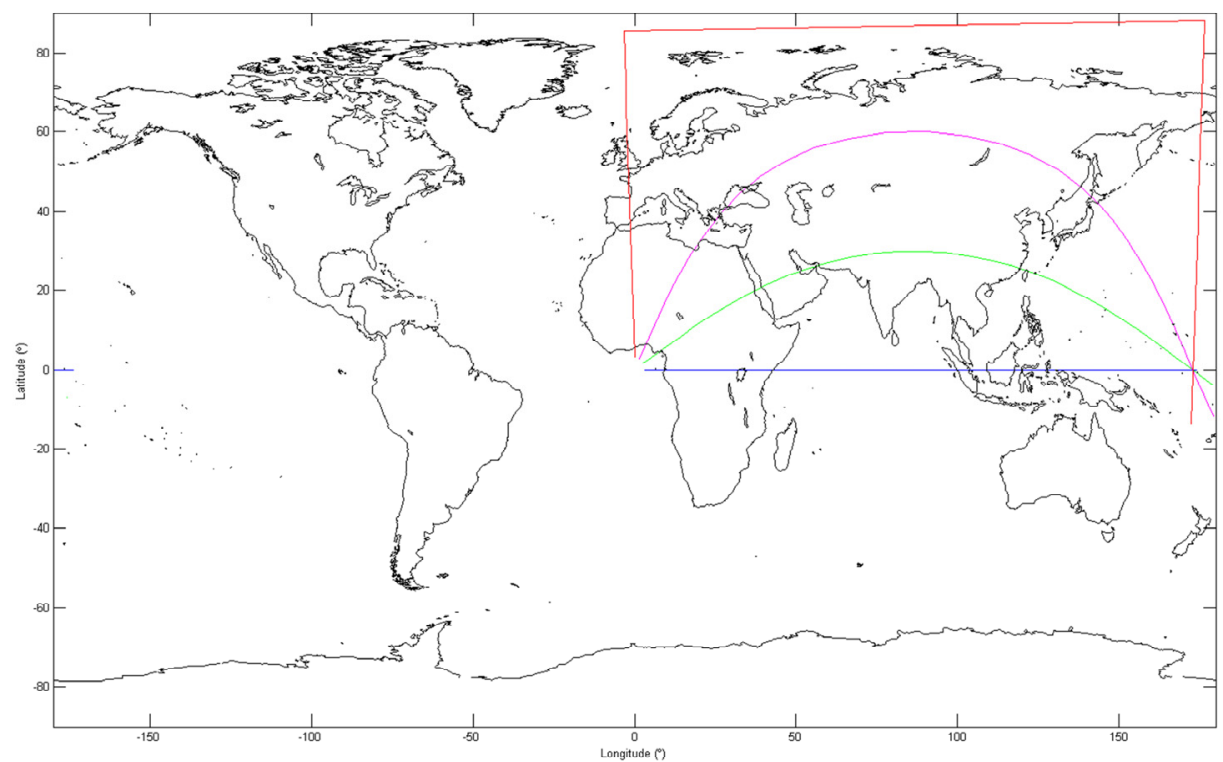

Figure 1.3 Ground track for various inclinations

Figure 1.4 shows the variation in the progression of the spacecraft for various altitudes. For an altitude of $100 \mathrm{kms}, 5000 \mathrm{kms}$ and $10000 \mathrm{kms}$ are plotted. As the altitude increases the spacecraft field of view increases and the ground track length decreases.

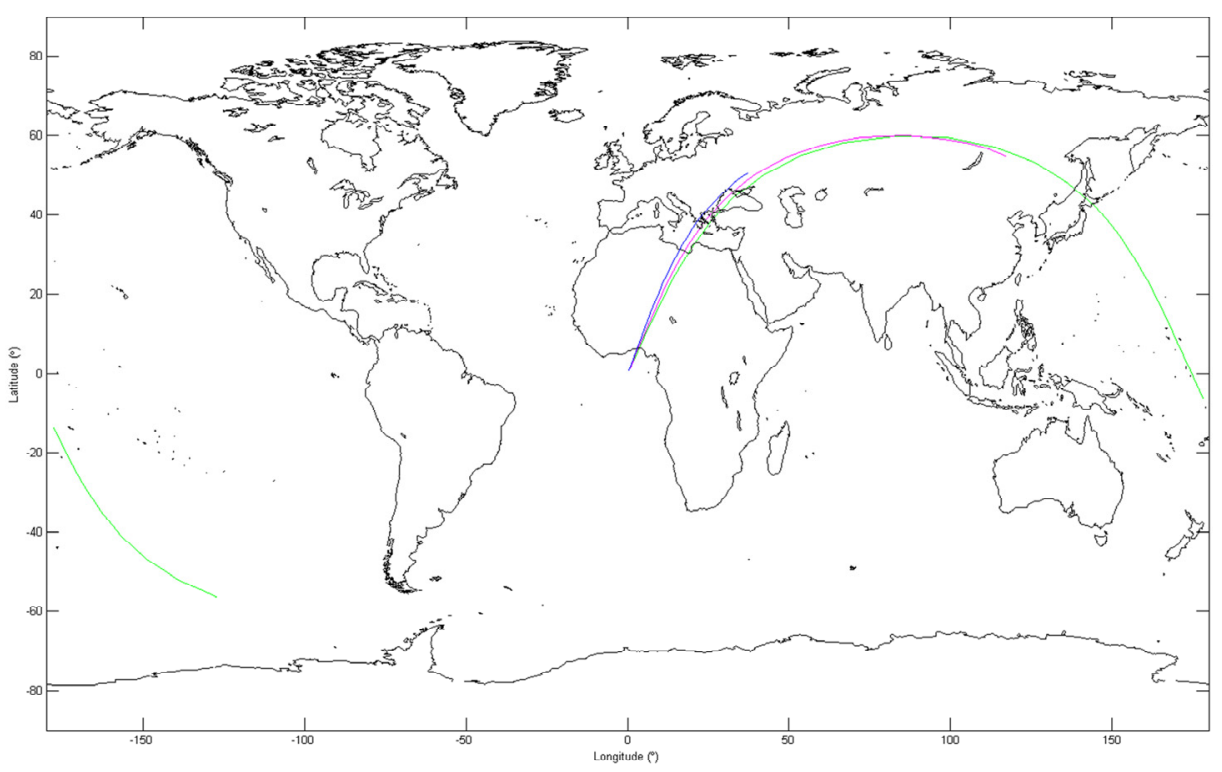

Figure 1.4 Ground track for varying Altitudes 
Figure 1.5 shows the variation in the progression of the spacecraft for various arguments of perigees $(\omega)$. For $\omega 0^{\circ}, 30^{\circ}, 60^{\circ}, 90^{\circ}$ ground tracks are plotted. As $\omega$ increases the spacecraft initial position of the spacecraft varies in terms of both latitude and longitude.

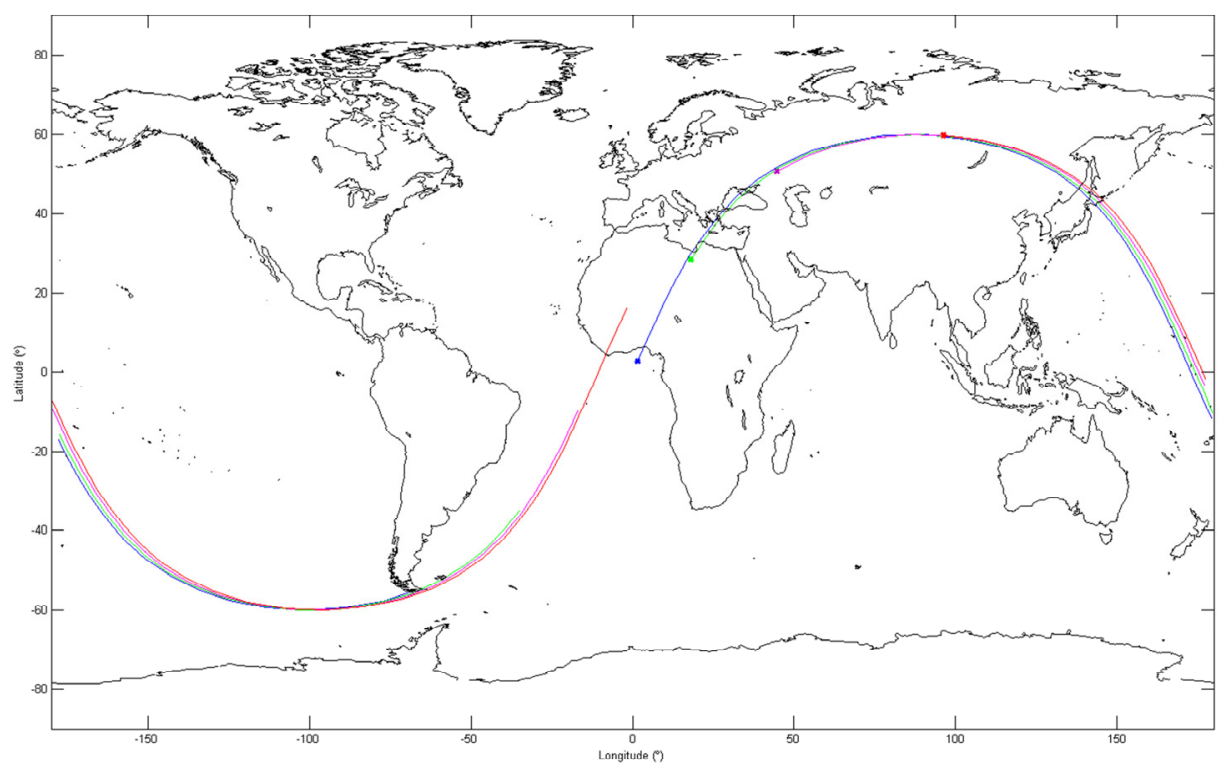

Figure 1.5 Ground track for varying argument of perigee

Figure 1.6 shows the variation in the progression of the spacecraft for various Right Ascension of Ascending nodes RAAN $(\Omega)$. For $\Omega 0^{\circ}, 30^{\circ}, 60^{\circ}, 90^{\circ}$ ground tracks are plotted. As $\Omega$ increases the spacecraft initial position (longitude) of the spacecraft.

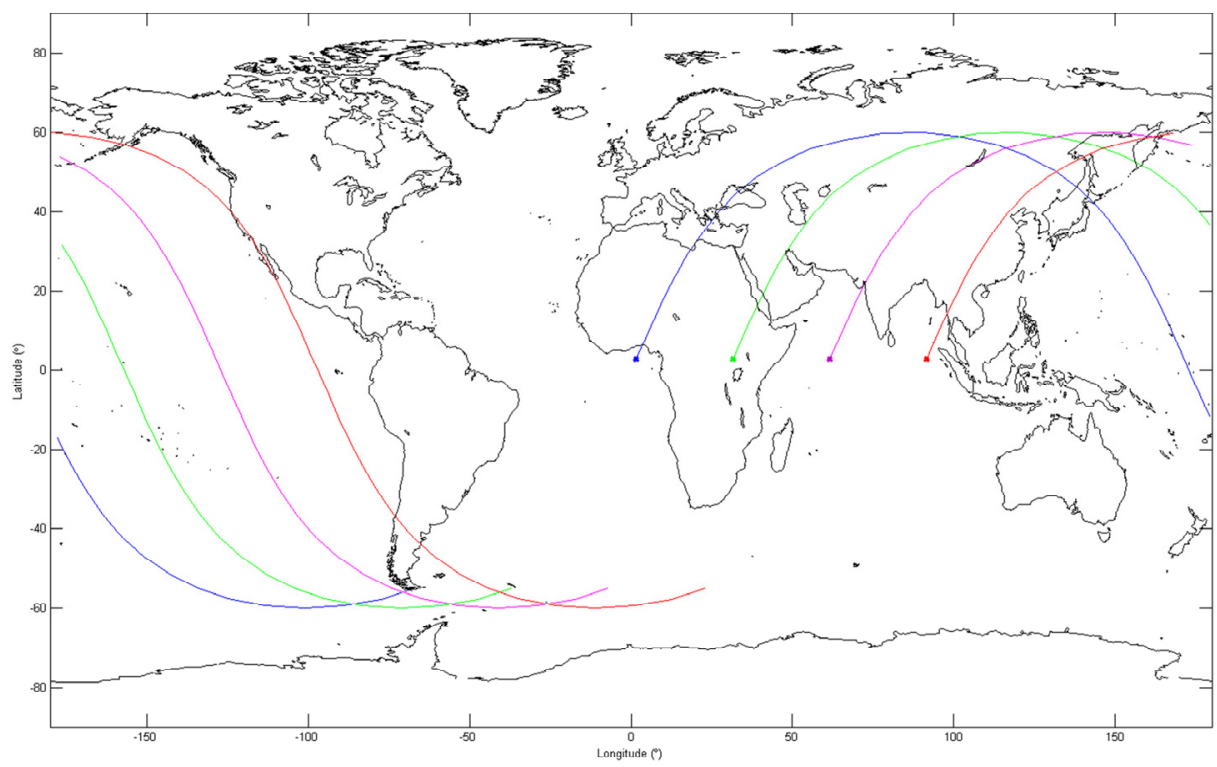

Figure 1.6 Ground track for varying Right Ascending Node RAAN 


\subsubsection{Repeated ground track orbits}

Repeated Ground track orbits[5] are those which retrace their ground track over a certain time interval. Here is a repeated ground track for the orbital elements mentioned in fig 1.2.

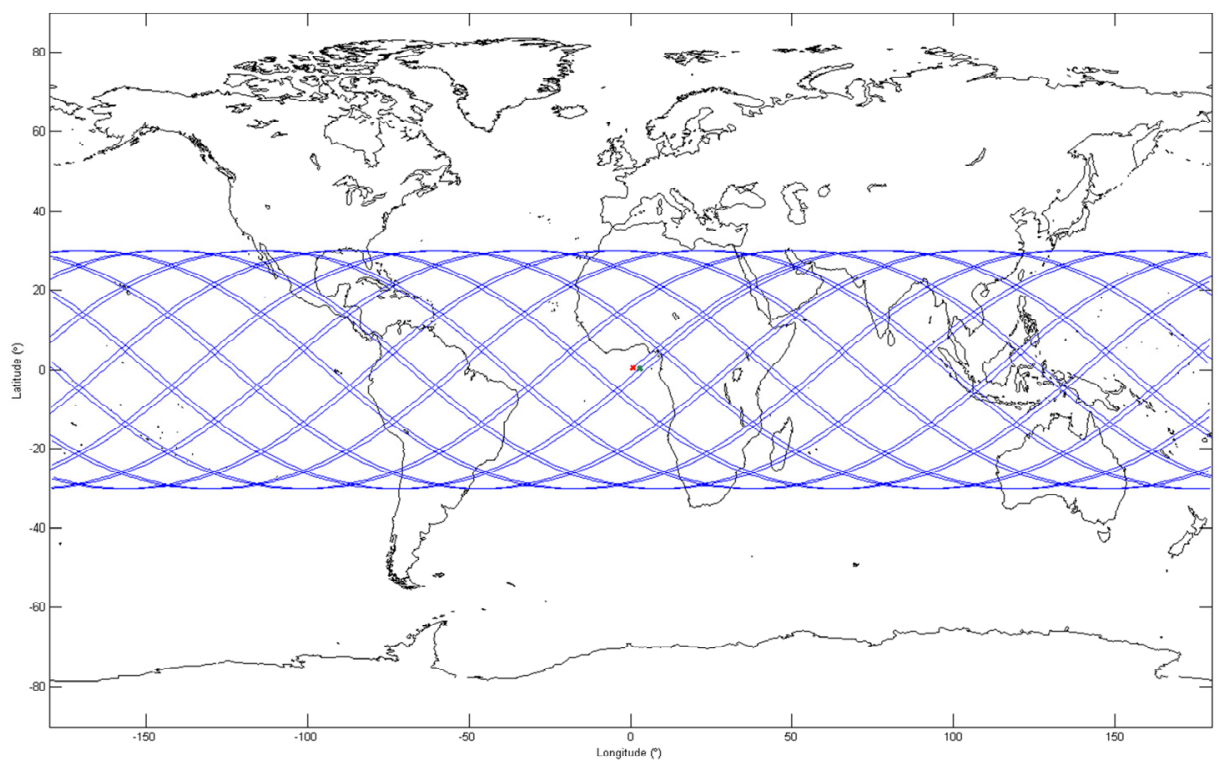

Figure 1.7 Repeated Ground track for 4 days

Repeated-ground track orbits are those which retrace their ground track over a certain time interval. As this is a special application where the ground stations needs to be visited for every certain time interval, the repeated ground track orbits are chosen. The selection of this repeated ground track depends primarily on the orbital period (n) and the number of days to repeat.

$$
n=2 \prod \sqrt{\frac{a^{3}}{\mu}}
$$

The condition for this repeated ground track is the orbital period should be an integer. In order to understand this, an example is illustrated as following. If an satellite makes 15.25 orbits in one day it takes 3 more days for the orbital period to become an integral value. His means after 4 days the satellite makes 61 orbits to come back to the same point. This means the repeated orbital period is 4 days. In equation form this can be written as

$$
k=\frac{m}{n}
$$

Where $\mathrm{k}=$ any integer, $\mathrm{m}$ is the number of orbits to repeat, $\mathrm{n}$ is the orbital period/day. In the figure 1.7 a ground track is plotted for $j=4, m=61$ and $n=4$. The spacecraft comes back to the same initial position after 4 days represented as the red dot. 


\subsubsection{Sun synchronizing orbit}

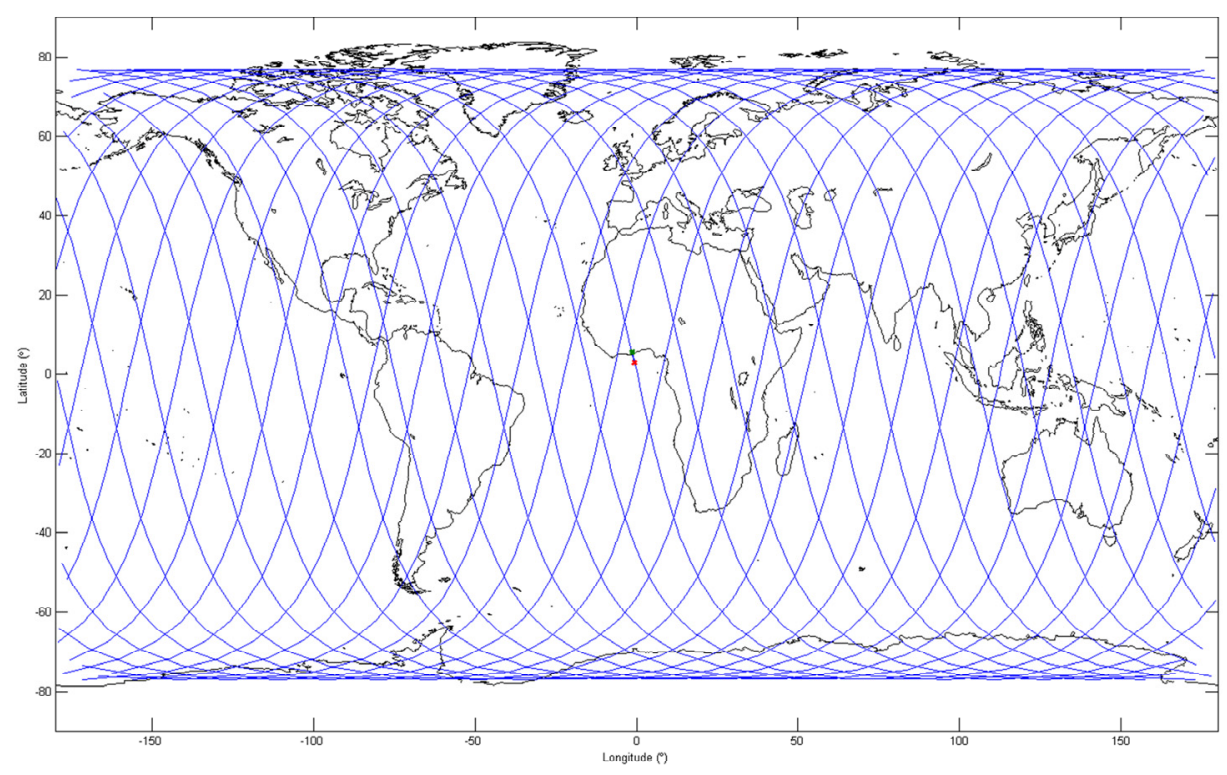

Figure 1.8 Ground track of Sun-synchronizing orbit

Sun-synchronous[6] orbit maintains a constant orientation towards the Sun over time and hence called Sun-synchronous. This orbit is specially chosen when a constant source of solar radiation for the solar cells is required to maintain the viewing condition when observing the Earth. In this thesis we need a constant orientation towards Sun as the whole idea is to trap Solar Radiations into a Solar cell and then beam to the Earth's surface at desired Ground Stations using either microwave or radio wave beams.

For Low-Earth satellites, the dominant motion of $\Omega$ is caused because of the $\mathrm{j} 2$ effect. Hence the orbit for which the nodal rate matches the average rate of Sun's motion projected on to the equator, the satellite's line of nodes will maintain a constant angular separation with respect to the Sun[7]. The angle of separation ranges from $0^{0}$ to $360^{\circ}$ by selecting appropriate $\Omega$. This, concept when applied to formulas looks as follows

$$
\dot{\Omega}_{\text {Desired }}=\dot{\Omega}_{\text {Sunsync }}=\frac{360^{\circ}}{365.242} \mathrm{deg} / \mathrm{day}
$$

From the above equation if math is applied, an equation for the Sun synchronizing orbit is derived as follows. Figure 1.8 is one such ground track plot derived from the equation. More about Sun-synchronous orbits are discussed in chapter 2.

$$
a^{7 / 2}=\frac{3 R_{e}^{2} J_{2} \sqrt{\mu}}{2 \dot{\Omega}_{\text {Sunsync }}\left(1-e^{2}\right)^{2}} \cos (i)
$$




\subsection{Sun}

\subsubsection{Birth of Our Sun}

Sky has no limits. The universe is never ending and is still expanding. In order to describe the universe, I choose to start with the catechism event of the great "Big Bang." According to the Big Bang theory, there was a huge matter in the space, which exploded approximately 13.7 billion years ago. During this time of everything was hot and beyond any form of measurement. In the first second of the explosion super hot gas very often referred as to plasma, was formed. At this point matter was so unstable and is referred as quarks $(\mathrm{Q})$ which further cooled down to form neutrons $(\mathrm{n})$ and protons $(\mathrm{p})$, the basic particles of an atom. For a few thousand millions years universe remained extremely hot. Later it cooled down the hot plasma could form nuclei that could hold electrons. Either two or three such electrons (e) with nuclei form hydrogen and helium atoms respectively. This is when the universe remained in the dark ages.

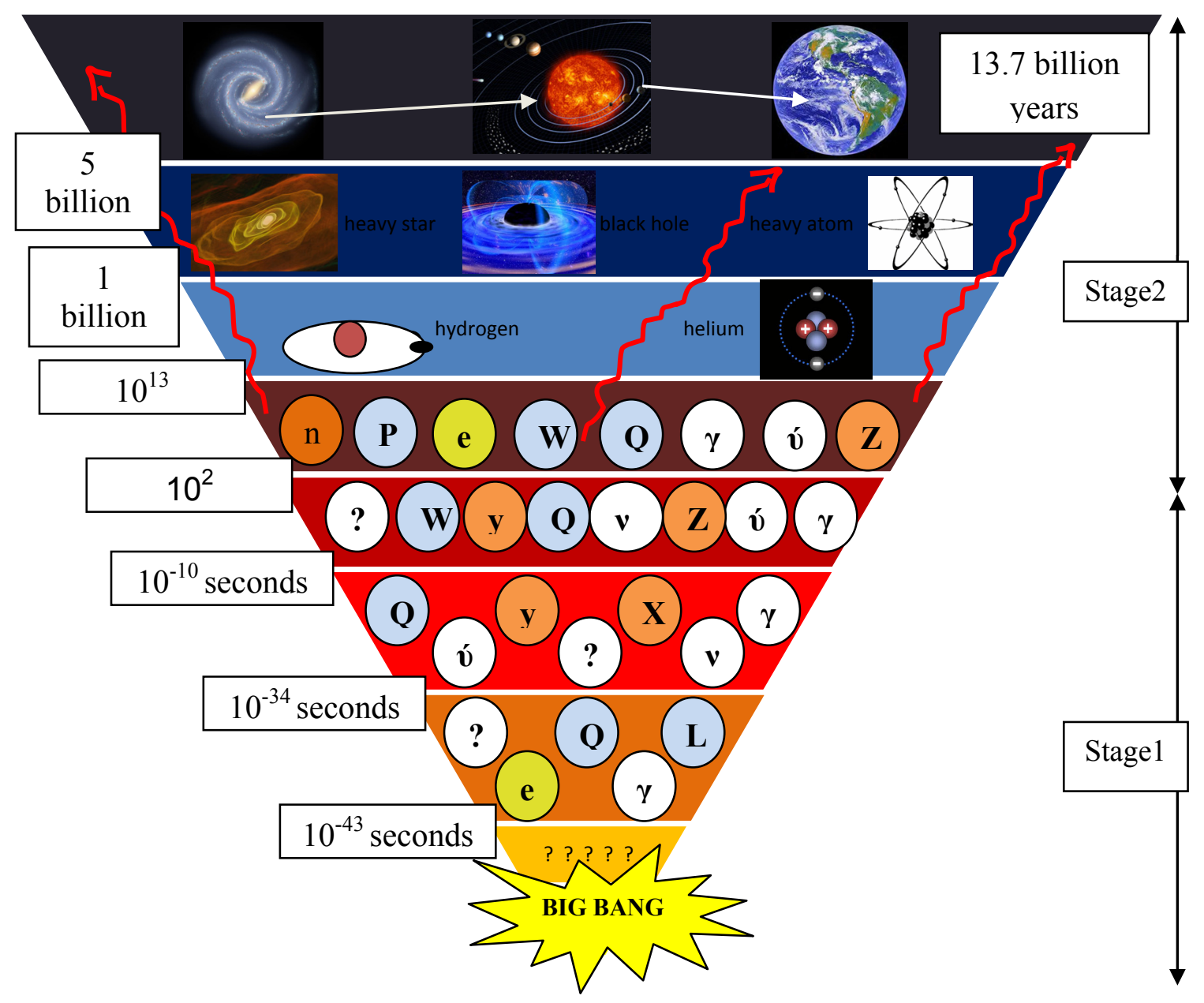

Figure 1.9 Big Bang 
After this, there formed the cosmic waves which include the whole band of waves including radio waves, microwaves, etc[8]. As shown in the above figure 1.9, the history of the universe can be classified roughly into two stages. In stage 1 the radiation due to the explosion dominated the matter hence named as the radiation dominated era. During this stage all the basics of matter was formed due to the high temperatures and pressures. Bosons (W, Z), positron (v́), neutron (n), electrons (e), quarks $(\mathrm{Q})$, gamma rays $(\gamma)$, $\mathrm{x}-$ rays $(\mathrm{X})$, mesons $(\mathrm{Q})$, ions and many other such particles were formed during this stage and are the roots for the formation of our universe today. It's approximately estimated that the temperature from around $10^{29} \mathrm{~K}$ are cooled to present time $3 \mathrm{~K}$. The stage 2 can be classified as the era in which matter is dominating. As the temperature cooled down, the basic atoms like hydrogen and helium formed. This expansion further lead to the formation of galaxies, meteors, comets, planets, asteroids and many other celestial bodies. Some of them remained as stars, which are giant plasma bodies. Even today we can experience the cosmic waves which were once a part of the greatest blast ever none to the mankind the" big bang". One of such stars formed is the ruler of our planetary system, the Sun. After 13.7 billion year approximately after the blast the present earth is estimated to form. Here is some more description about our magnificent Sun.

\subsubsection{Characteristics of the sun}

\subsubsection{Orbit mechanics of sun}

As we are discussing about orbit mechanics, here are a few facts about the orbit mechanics of the Sun. The Sun revolves around our galactic core in an estimated elliptical orbit. It is estimated that before the sun lost all its fuel it makes 31 revolutions around the centre of our Milky Way galaxy. Sun is approximately 26,000 light years away from the galactic core and revolves at an astonishing speed of $782,000 \mathrm{~km} / \mathrm{hr}$. It is calculated approximately that it takes 226 million years to complete one revolution. Till date, Sun is supposed to make approximately 20.4 revolutions in 4.6 billion years. Sun is very tiny in our Milky Way galaxy. There are many other huge stars when compared to sun. It's estimated that our sun is formed 4.6 billion years ago. Sun completely runs out of its fuel in another 7 billion years[9], after that it becomes a white dwarf. This means, Sun is going to make approximately another 31 revolutions around the centre of the galaxy before it runs out of its fuel.

\subsubsection{Size comparison and chemical composition of Sun}

The hot glowing ball Sun is a huge giant gas ball. Imagine a huge ball of gases which are denser at the core and lighter at the surface, that is who the sun approximately looks like. The mass of the sun is $99.8 \%$ in the solar system. The mass of the sun is $1.98892 \times 10^{30}$ kilograms which is 332,900 times more than the mass of the earth. The radius of sun is 695,500 kilometers and the radius of earth is 6378.1 kilometers. The radius of sun is greater than 109 times than that of earth. To visualize more than $10^{6}$ earths together make one sun. The hydrogen and helium atoms which were the primitive elements formed after the "Big Bang", are the main components of our Sun. 


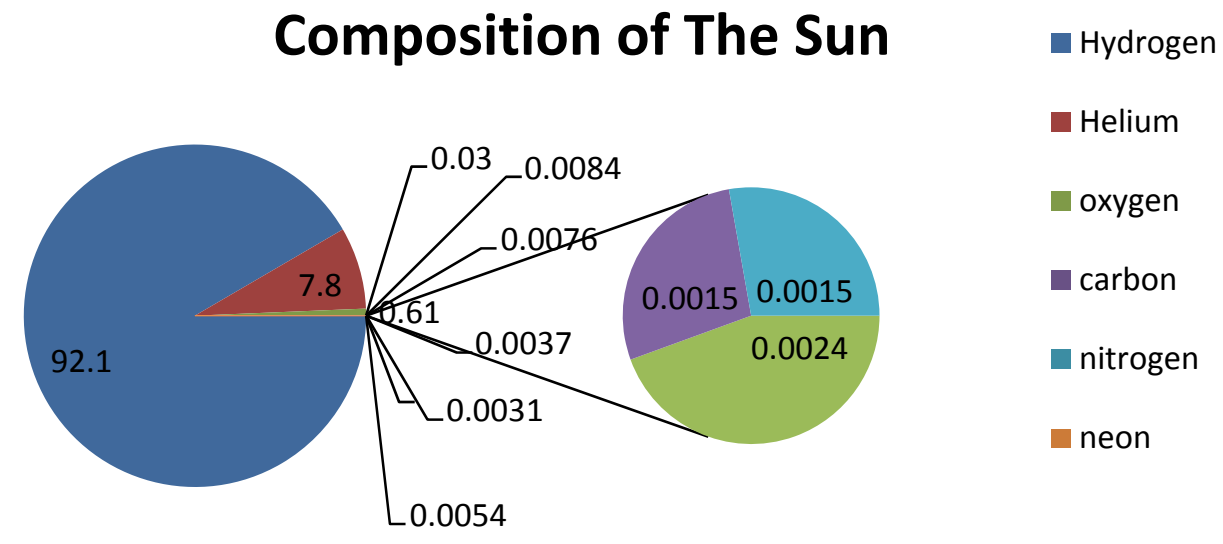

Figure 1.10 Composition of Sun

\subsubsection{Layers of Sun}

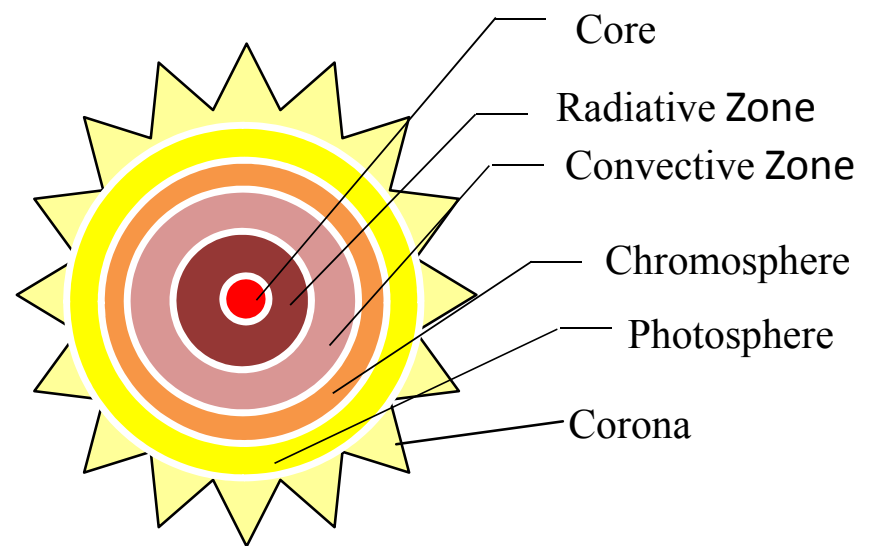

Figure 1.11 Layers of Sun

As we already discussed about the size, composition and the origin of our Sun, let us discuss about the layers of the sun

\subsection{Core}

The core is the innermost part of the sun and is about 15 million degrees Kelvin and a high pressure of 200 billion times that of the atmospheric pressure on earth. The density is around $150 \mathrm{gm} / \mathrm{cm}^{3}$. At this temperature the constituents of the atoms are very unstable and hence destroy and form the basic elements like protons, neutrons, electrons. Neutrons do not have any charge and hence escape the core but the protons and electrons which have opposite charges attract each other to form the plasma. At this high temperature, the electrons and protons inside this plasma slam each other thus creating the nuclear fusion, releasing a huge amount of energy which is the main source of the 
sun's energy. This is how hydrogen and helium atoms after reaching equilibrium liberate a huge amount of energy.

\subsection{Radiative zone}

Around the core is the Radiative zone. This is named so because the energy transfer is due to radiation. The density at this point is $0.2 \mathrm{gm} / \mathrm{cm}^{3}$ and the temperature varies from 8 million Kelvin to 2 million Kelvin. The material is 0.2 to 0.7 solar radii and is very dense and hot. Heat is transferred by the ions of hydrogen and helium and photons are emitted.

\subsection{Convective zone}

The convective zone has a thickness of 0.7 to 0.1 sun radii. The temperature is around $5800 \mathrm{~K}$ and is the lightest of all the three zones with a density very close to zero. More than $66 \%$ of the sun's volume is convective zone but is less than $2 \%$ of the mass of the sun. Thermal convection happens when the energy is carried for the Radiative zone to the photosphere

\subsection{Photosphere}

This zone emits light and hence named photosphere and is about $500 \mathrm{kms}$ thick. The bottom is at $6600 \mathrm{~K}$ and the top is at $4400 \mathrm{~K}$. The density is 1 millionth gm/ $\mathrm{cm}^{3}$ which is extremely lighter. This is the visible part of the sun's zones.

\subsection{Corona}

This is the plasma atmosphere around the sun which has a surface area much bigger than that of sun. It consists of loops and streams of particles, ionized gas. Sunspots, solar winds etc are a part of this region.

\subsubsection{Magnetic field}

Sun's magnetic field is extremely complex. The magnetic field of sun is due to the movement of the convectional cells. Any electrically charged particles can create a magnetic field as we know that because of the high temperature the protons, electrons (convectional cells) are highly excited and hence help in creating a magnetic field. We generally describe magnetic field in forms of loops around the north and south poles. When magnetic field is complicated it forms twists and kinks. This is due to (1) sun rotates rapidly at the equator than that of at the higher latitude and (2) inner parts of the sun rotates rapidly than at the surface. In some places magnetic field is thousand times stronger than other which results in the formation of magnetic clouds, clusters. Simply the magnetic field can be visualized like a hairy ball. The sunspot cycle is for every 11 years, which says that the number of sunspots varies every 11 years. The north and south 
poles of sun interchange every 22 years which is stated very commonly as a flip. Sun takes 25 days to rotate at the equator and little more than 28 days at the higher latitudes. The equatorial surface gravity is $274 \mathrm{~m} / \mathrm{s}^{2}$ which is $28 \mathrm{x}$ earth's surface gravity. The escape velocity of sun is $2,223,720 \mathrm{~km} / \mathrm{h}$ which is $55 \mathrm{x}$ earth escape velocity.

\subsubsection{Energy output}

In this chapter all I discussed is about Sun, Its origin, its structure, the temperature, etc. Now I would like to discuss about the energy of the sun. In the following sections detailed analysis of the source of energy, amount of energy are discussed.

As the thesis topic is to get energy form Sun, here is a brief description of the energy available at the surface of the sun and on earth's surface. As we discussed about the nuclear fusion in the above sections, here are the calculations required for the energy output at the core.

As per the proton-proton cycle, when one hydrogen atom converts into helium atom lot of energy is liberated in the form of gamma rays. The energy liberated is the difference between the nuclei of the hydrogen and helium.

$$
4{ }_{1}^{1} H \rightarrow{ }_{2}^{4} \mathrm{He}+\text { energy }
$$

Mass of one hydrogen nuclei $=6.693 * 10^{-27} \mathrm{kgs}$

Mass of one helium nuclei $\quad=6.645 * 10^{-27} \mathrm{kgs}$

$$
0.048 * 10^{-27} \mathrm{kgs}
$$

The energy emitted per each reaction can be calculated by the Einstein's formula, $E=m c^{2}$

$\mathrm{E}=\left(0.048 * 10^{-27} \mathrm{~kg}\right) *\left(3 * 10^{8} \mathrm{~m} / \mathrm{s}^{2}\right)^{2} \quad=0.043 * 10^{-11} \mathrm{~J}$

$10^{38} /$ seconds will transform 5 million tons of mass into energy every second

\section{$0.043 * 10^{-11} \mathrm{~J} * 10^{38} /$ second $=0.432 * 10^{27} \mathrm{~W}$}

Therefore, Sun radiates $0.432 * 10^{27} \mathrm{~W}$ which is also named as luminosity but receives only $2 /$ billionth part of it. Hence it earth receives $0.864 * 10^{18} \mathrm{~W}$.

Mean Distance to Earth: 149.60 million km (92.96 million mi) (1 astronomical unit) the radiation is approximately $1362 \mathrm{~W} / \mathrm{m}^{2}$. Earth radiates $70 \%$ of received energy back to space, $51 \%$ is absorbed by land and sea. $23 \%$ of evaporation and precipitation (water cycle) wind and ocean currents use $1 \%$ photo synthesis $0.023 \%$. This means we can collect only $7-10 \%$ of the suns energy on the earth surface because of all the reflections 
and absorptions by the clouds and atmosphere. In other words sun radiosity of sun energy is $1364 \mathrm{~W} / \mathrm{m}^{2}$ out of this earth receives $343 \mathrm{~W} / \mathrm{m}^{2}$ of this $103 \mathrm{~W} / \mathrm{m}^{2}$ is reflected and the reset $168 \mathrm{~W} / \mathrm{m}^{2}$ is absorbed by the earth. The green house gases help in absorbing energy into atmosphere [1]. So if the energy is captured before the rays reach the earth surface we can capture a huge amount of energy as there is no atmosphere in the space.

\subsection{Space based power satellite systems (SSP)}

Space based power satellite system is first proposed in 1968 by Dr. Peter Glaser [8]. The proposed system was a large SSP system which can beam $10 \mathrm{GW}$ of power to the earth's surface using microwave beams using large receiving antennas on a 36 square miles area on the earth. The system is located at geosynchronous orbit. The structure included a solar panel of dimension $1.6 \mathrm{~km} * 1.6 \mathrm{~km}$ with a $100 * 100$ row of solar cells.

In 1975 NASA JPL[10] demonstrated Wireless Power Transmission from space named The Goldstone Demo. This was a huge success and hence led to the future study of the project. In 1998 Japan space agency (JAXA) started a study on SSPS and in 1999 NASA's began Space Solar Power Exploratory Research and Technology program (SERT). Companies like ISRO[11], Solaren, Space Energy INC, power sat corporation, Boeing, are launching a demo system to study the system completely. It is believed that by 2050 clean energy will be transmitted to earth. The LEO[12] satellite system was proposed by Dr. Narayan Komerath[13] which is relatively close to this thesis topic. Dr. Narayan[14] describes mostly concerns about the transmission system, cost, etc. This thesis topic describes in detail the constellation design of these satellite systems.

\subsection{Thesis research work}

The amount of energy resources available presently will vanish soon in the coming hundred years. This leads us to the search of a new, reliable, cheap, clean and green energy[15]. Sun has been the main source of energy for our planetary system ever since we know[16]. Knowing that the sun produces energy for another 4 to 5 billion years[17], our design is proposed to extract power from space and beam on to the earth's surface which prevents all the additional losses due to atmosphere, day[18] and night, etc and can provide power $24 / 7$.

This design involves a constellation of satellites working together in Low Earth Orbit (LEO) [19]. A description of the dynamics and the structure of the satellite are described in chapter 2. The collected solar energy is stored in a solar cell in the satellite[20] and is beamed to earth either in the form of microwave or radio wave beams whenever the satellite sees the ground station. 
In order to design the constellation for Low earth orbit space based solar power satellite system we need to answer (1) how many satellites are required (2) the orbits in which these satellites are placed (3) how many satellites are placed in a single orbit (4) number of ground sites required to download the power (5) the positions of these ground sites. These are the major questions involved in the design of the orbits for SSP system[21]. An effort to answer these questions is made in this thesis.

\subsection{Thesis organization}

Chapter 1 introduces the necessity, concepts and methodologies involved for the calculation of optimal orbit design of space based solar power (SSP). A detailed description about ground tracks, sun synchronizing repeated ground tracks[22] are discussed. The amount of power produced by sun can be used for the coming 5 billion years evidently making it one of the most suitable options as alternative energy source. Detailed description of my present and future work is also discussed.

Chapter 2 explains our proposed solar power satellite system. It describes more specifically about the LEO based SSP system chosen. In this chapter complete system design is described which answers questions like (1) no of orbits required (2) number of satellites in each orbit (3) no of ground stations required to get desired power distribution. The structure of the spacecraft, its dynamics are also discussed in this chapter

Chapter 3 further describes constellation design[23] of our LEO based SSP system as mentioned in chapter2. A background about constellation designs along with our design is described.

Chapter 4 presents power calculations. This chapter tells us why we choose solar power and describes more about the benefits of collecting power in space than on the earth's surface. A statistical data of the available energy resource, their usage and the availability of these resources in the coming years is also mentioned.

Chapter 5 involves simulations of the proposed SSP system by varying various orbital elements for the optimal design needed.

Chapter6 summarizes the observations and conclusions made during this study. Recommendations for future work are also presents in this chapter. 


\section{PROPOSED SOLAR POWER SATELLITE SYSTEM}

\subsection{The Architecture of the Proposed Space based Solar Power Grid}

A constellation is a set of satellites distributed over space intended to work together to achieve a common objective. The proposed Space Based Solar Power Grid (SSPG) aims for a constellation which can download 140GW of power at ground stations. Since each satellite can download an amount of $1 \mathrm{GW}$ of power we require a total of 140 satellites total. This Design problem has many solutions. In this section two of such solutions are discussed. Figure 2.1 shows the architecture of the system including the spacecraft structures. Figure 2.2 shows the $3 \mathrm{D}$ view of the system in Matlab. When these 140 satellites are distributed in 2 orbits there are 70 in each equally spaced. The orbit is at the centre of mass of one unit grid.

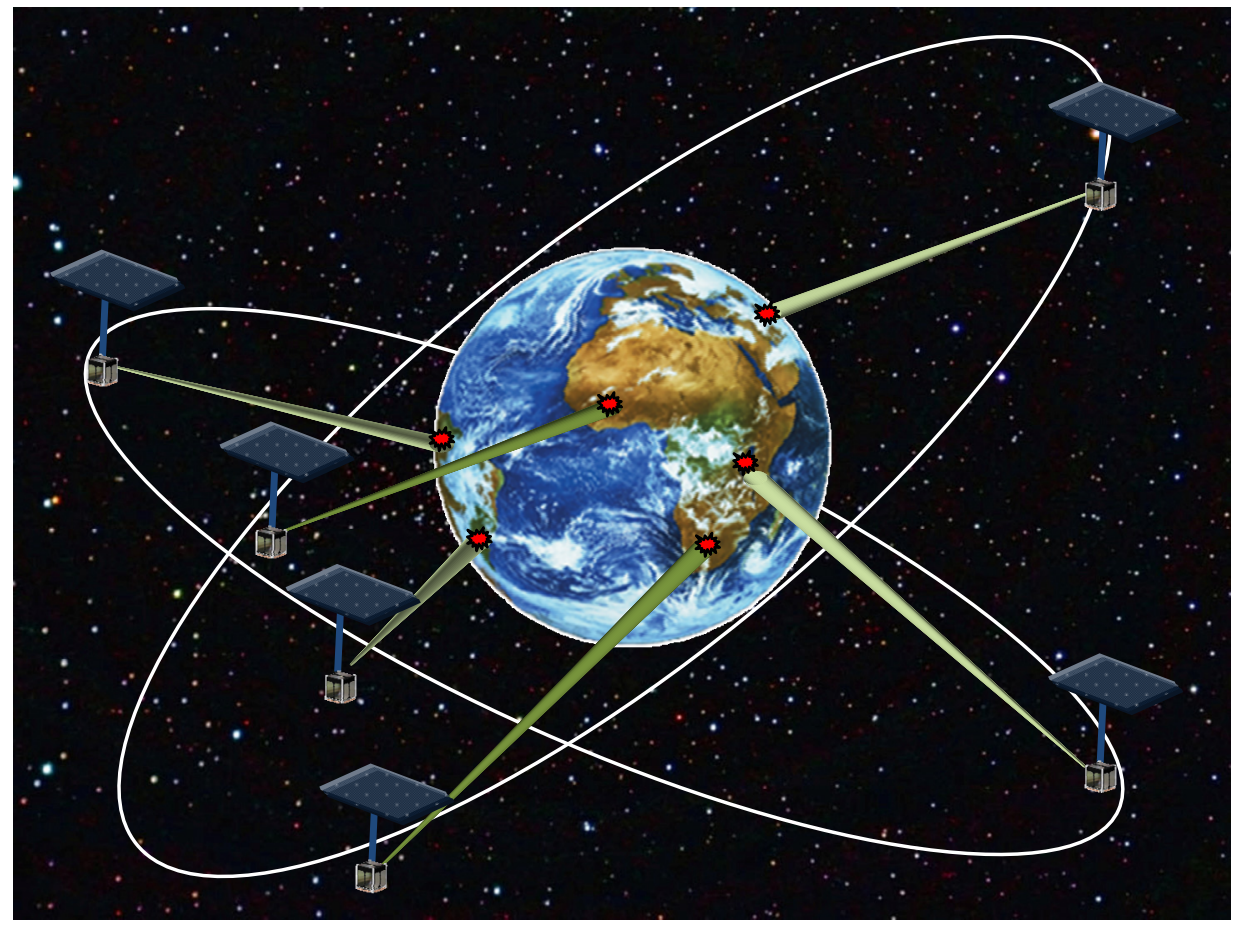

Figure 2.1 the Architecture of the Space Based Solar Power Grid for 2 Orbits 


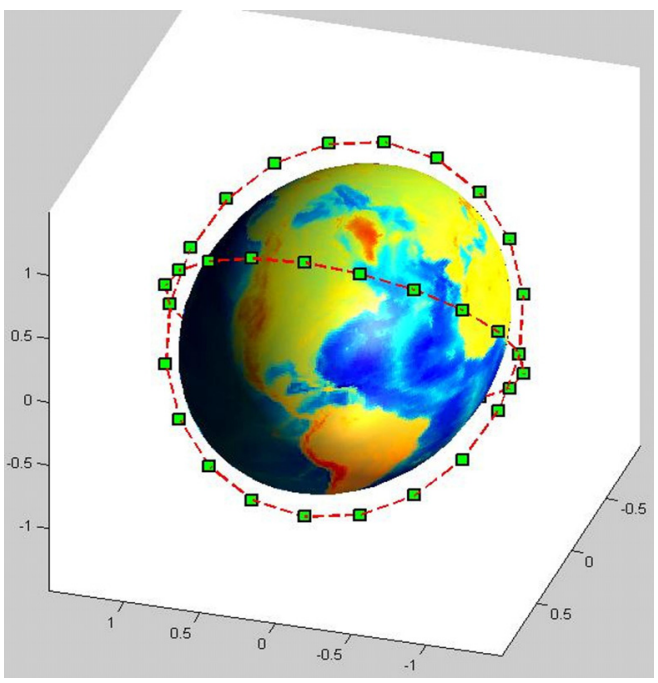

Figure 2.2 3D Constellation Design for 2 orbits

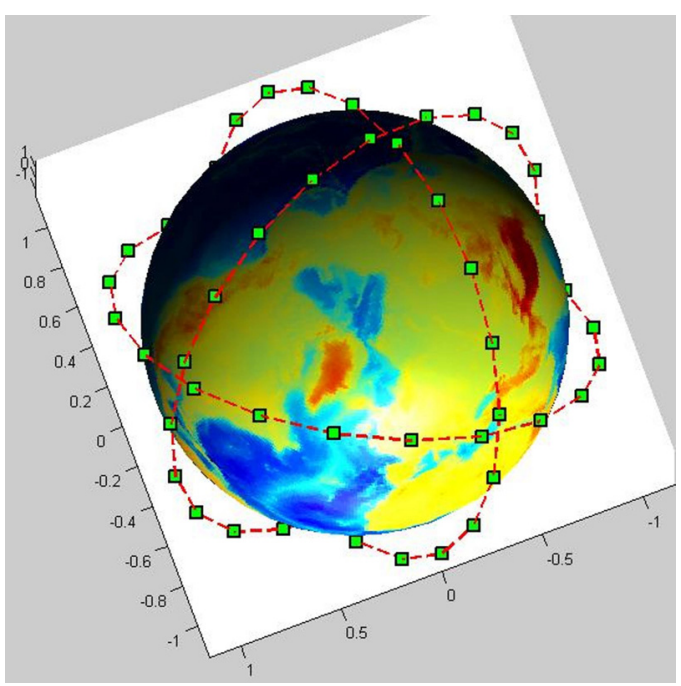

Figure 2.3 3D Constellation Design for 3 orbits

Figure 2.4 shows the architecture of the system including the spacecraft structures for 3 orbits. Figure 2.3 shows the 3D view of the system in Matlab. When these 140 satellites are distributed in 3 orbits there are 47 in each equally spaced.

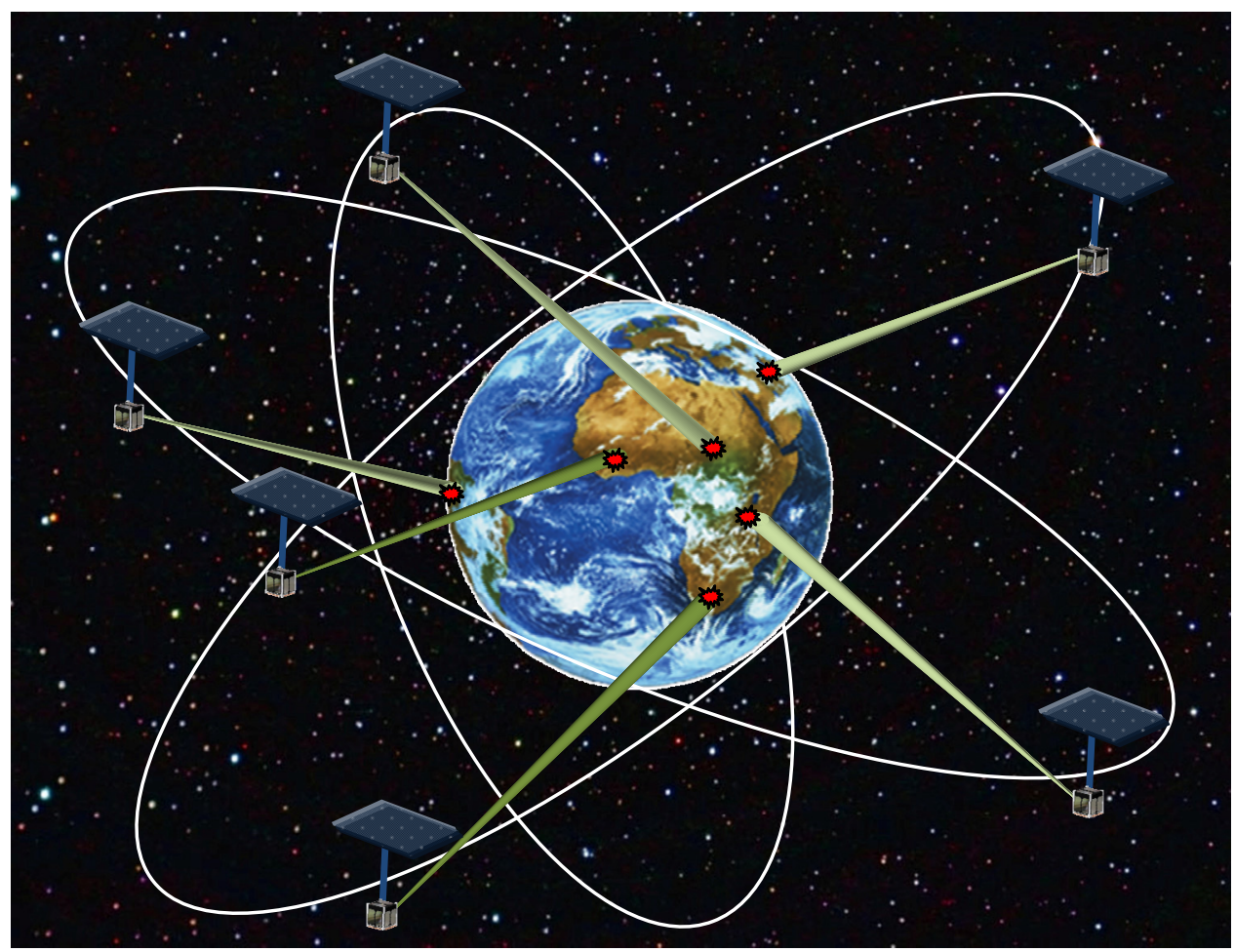

Figure 2.1 the Architecture of the Space Based Solar Power Grid for 3 Orbits 
Hence there are a lot other solutions for this design problem. But for simplicity a 2 orbit Design problem is considered which is discussed throughout this thesis.

\subsection{Orbit Determination for Repeated Sun-Synchronizing Orbit}

\subsubsection{Selection of a Ground Track}

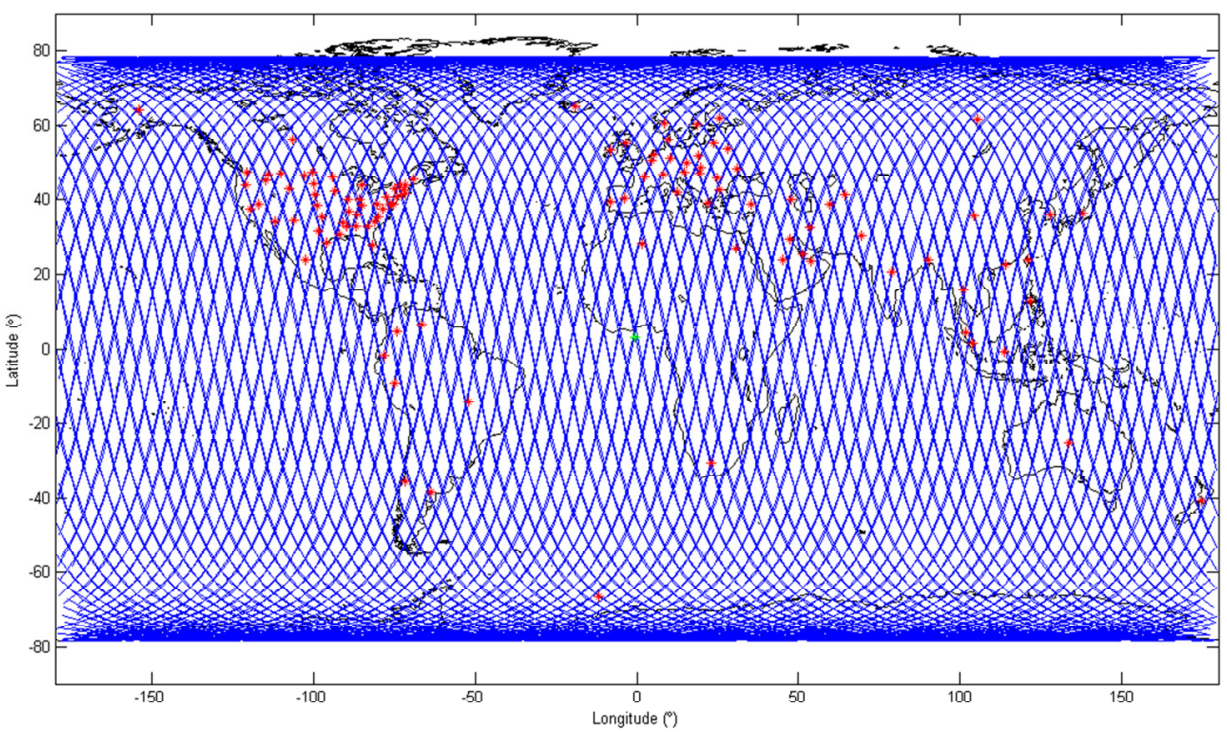

Figure 2.5 Repeated sun-synchronous ground track simulating for a period of 6 days

This section describes about the selection of a ground track[24] based on our application. The goal of the thesis is to design an orbit which passes through maximum number of ground stations. The red dots in Figure 2.5 are the ground stations and a ground track for 6 days with an altitude of $1395.579364 \mathrm{kms}$ and an inclination of 101.4026587 degrees is plotted. All the rest of the values are assigned as 0 . Once the ground track latitude and longitude are determined to plot the trace, the distance from the ground station to al the ground track points are calculated in spherical geometry. If the distance is in the permissible range (for example $50 \mathrm{kms}$ or $1^{0}$ ) then the ground track is considerable. This is repeated for all the ground stations and then the ground track which covers the maximum number of ground tracks is selected.

Since the ground track is a repeated sun-synchronous[25] the initial values semimajor axis (a) and eccentricity (e) are calculated from an excel sheet using the formulae's stated in chapter1 and then these values are used to plot a ground trace. Also perturbations should be included in order to make the trace a precise repeating ground track. The formulae's for perturbations and the method is discussed in section 2.2.2. 


\subsubsection{Orbit Perturbations}

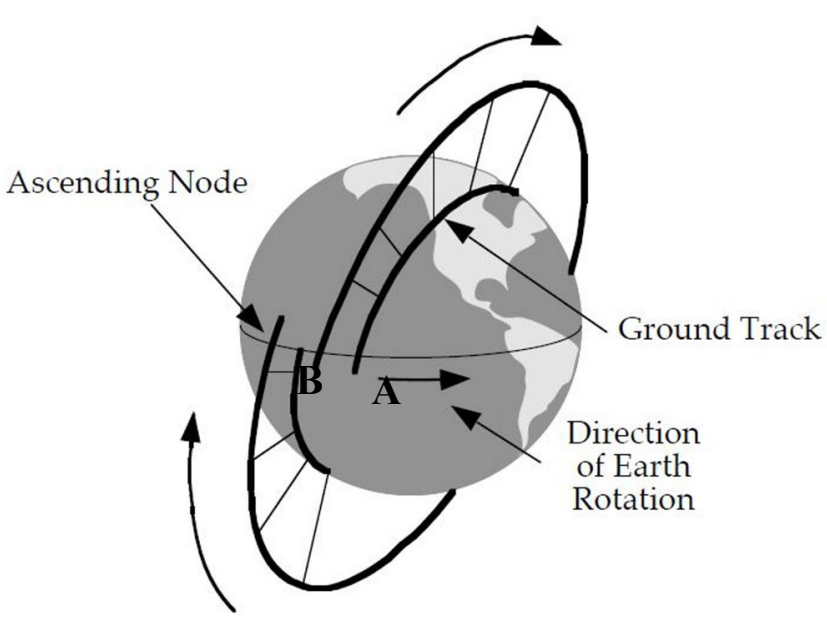

Figure 2.6 Perturbation calculations due to Earth's Rotation [2]
Considering a 3-Body problem, Perturbation plays a vital role in the determination of an accurate ground track of a satellite in practice. Perturbation refers to the change in the position of the satellite due to external forces like atmospheric drag, gravitational force, Radiations, Earth's rotation, etc.

Figure 2.6 shows the schematic representation of the ground trace of the orbit along with rotation of earth. The trace when started at point $\mathrm{A}$ is expected to come back at the same point after one revolution.

But because of the rotation of earth this trace reaches a point B on the earth's surface. In order to find the right ground trace over a time period $\mathrm{T}$, an increment of the rate of change of the orbital elements is applied as follows[26].

$$
\begin{aligned}
& n=\sqrt{\frac{\mu}{a^{3}}} \quad p=a\left(1-e^{2}\right) \quad \text { const }=k=1+\frac{3}{2} j_{2}\left(\frac{R_{E}}{p}\right)^{2}\left(\sqrt{1-e^{2}}\right)\left(1+\frac{3}{2} e\right) \\
& \dot{a}=\frac{\rho A C_{D} \sqrt{\mu a}}{m}\left[1-\left(\omega_{e} / n\right) \cos i\right]^{2} \\
& \dot{\Omega}=-k * \frac{3}{2} n j_{2}\left(\frac{R_{E}}{p}\right)^{2} \cos i \\
& \dot{\omega}=k * \frac{3}{4} n j_{2}\left(\frac{R_{E}}{p}\right)^{2}\left(4-5 \sin ^{2} i\right) \\
& \dot{M}=k * n
\end{aligned}
$$

Where a is $\mathrm{R}_{\mathrm{SAT}}$,

$$
\begin{aligned}
\mu & =398600 \mathrm{~km}^{3} / \mathrm{sec}, \\
\mathrm{e} & =\text { eccentricity } \\
\mathrm{i} & =\text { inclination }
\end{aligned}
$$$$
\mathrm{j} 2=\text { perturbation due to earth rotation }
$$

For Low Earth Orbits the j2 perturbation has a greater effect than the others. 


\subsubsection{Algorithm for ground track}

The following flow chart is a representation of the ground track algorithm. This in detail description of determination of the ground track latitude and longitude from the given orbital elements $\left\{\mathrm{a}, \mathrm{e}, \mathrm{i}, \Omega, \omega, \mathrm{M}_{\mathrm{o}}\right\}$ over a time period $\mathrm{T}$, with an interval of $\Delta \mathrm{T}$ stating at the Greenwich Meridian standard time (GMSTo) with initial time (Ti) final time (Tf).

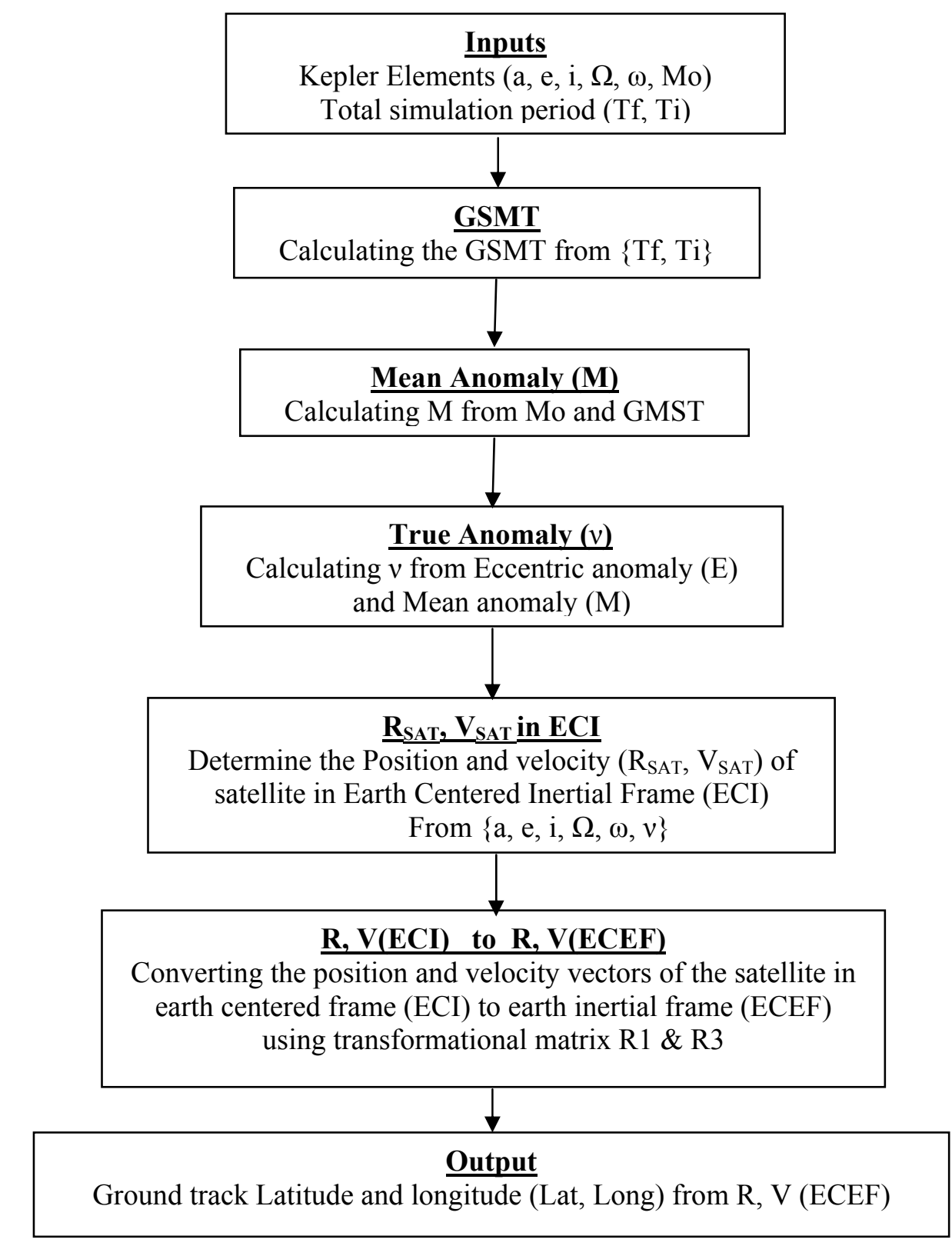




\subsubsection{Time of View}

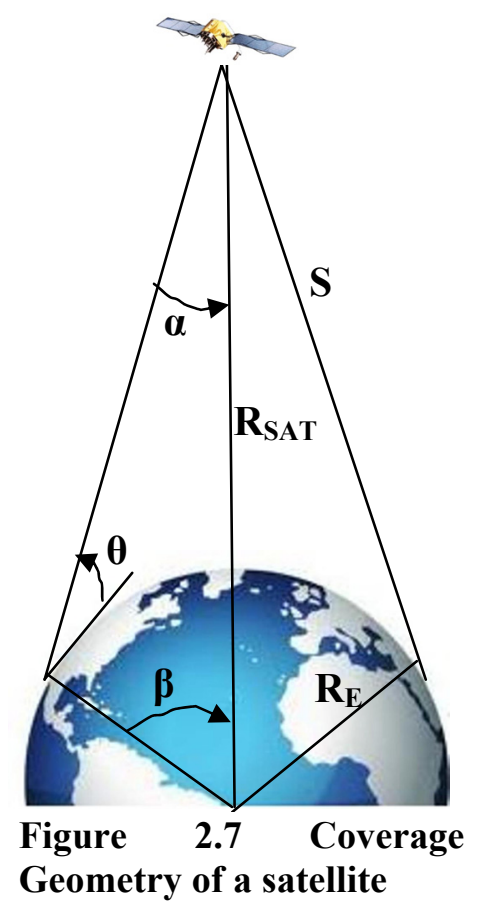

All the previous sections included the designing on ground track and selection based on various parameters. Once a right ground track is found, the next step is to find the time of view of a particular ground station as this is a major application in the current thesis topic. This section describes more about the method to find the time of view of the satellite at a particular ground station.

In order to find the time of view of a particular ground station, the geometry in spherical coordinate system is illustrated as shown in figure 2.7. The parameters which are important are:

(1) Nadir angle $(\alpha)$

(2) Earth central angle $(\beta)$

(3) Elevation angle $(\theta)$

(4) Slant range (S)

Once the orbital elements are found we determine the above stated four parameters from the following formulae's.

1. Earth central angle, $\beta=\frac{R_{E}}{R_{S A T}}$

Where $R_{S A T}=R_{E}+H, H$ is the altitude of the satellite and $R_{E}$ is the radius of earth

2. Either the Nadir angle $(\alpha)$ or the Elevation angle $(\theta)$ should be given as an initial value so that the other can be found as

$$
\alpha+\beta+\theta=90^{\circ}
$$

3. Once the angles are determined the Slant range and the area of access of coverage are determined.

Slant range, $\quad S=\sqrt{\mathrm{R}_{\mathrm{SAT}}{ }^{2}+\mathrm{R}_{\mathrm{E}}{ }^{2}-2 * \mathrm{R}_{\mathrm{SAT}}{ }^{2} * \mathrm{R}_{\mathrm{E}}{ }^{2} * \cos \beta}$

Access Area $A=2 \pi * \mathrm{R}_{\mathrm{E}}^{2}(1-\cos \beta)$

4. Time of view of the satellite $=$ abs ( Time of Rise- Time of Set $)$

5. Both the Time of Rise and the Time of Set are determined form the position of the satellite by using the orbital elements and also the Slant range.

More detailed description about the calculation of the time of view of a spacecraft over a particular ground station is discussed in chapter 5 including examples. 


\subsection{Selection of Ground stations}

Ground stations are assumed based on the statistics provided in chapter 4. According to the spacecraft design each spacecraft can download a $1 \mathrm{GW}$ power at a ground station. The ground stations are chosen according to the statistical data provided in chapter 4. An overall of 112 ground stations are chosen in which 42 stations belongs to the US and the rest throughout the world. This is explained in detailed as follows.

The power distribution by the Department of Energy (DOE) is estimated by different regions and divisions in the US. The main divisions are as shown in fig.2.8.

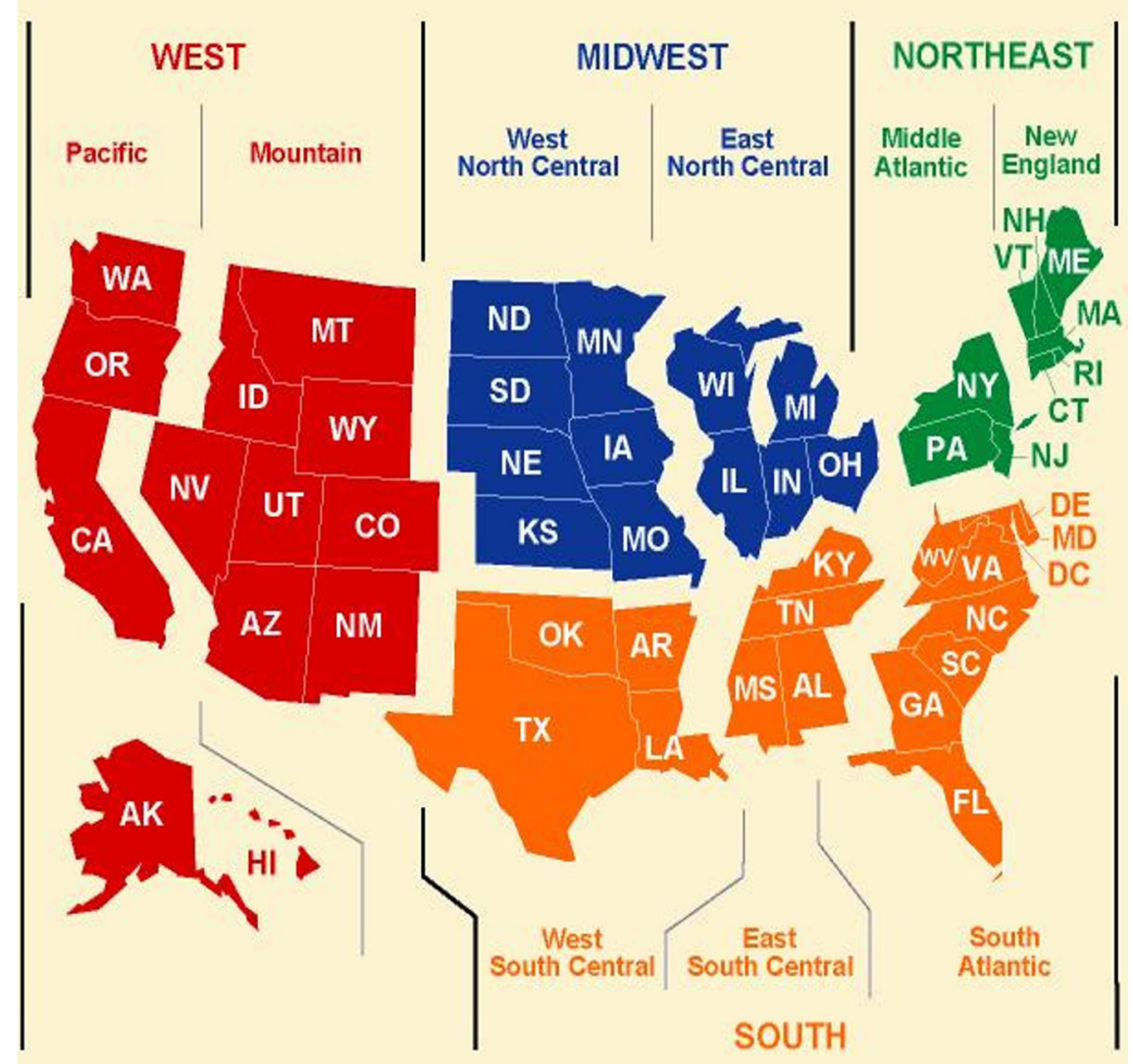

Figure 2.8 US census Regions and Divisions [1]

The major cities and divisions are considered as the ground stations where the $1 \mathrm{GW}$ power can be downloaded every time the ground station sees a space craft and plotted in Matlab as in figure 2.9. These are in total 48 ground stations in the United States. Also few other ground stations are considered in the rest of the world map and plotted in figure 2.10. These ground stations are also selected according to data described in chapter 4, section 4.2. All these ground stations are selected in the cities where the demand for power is more. 


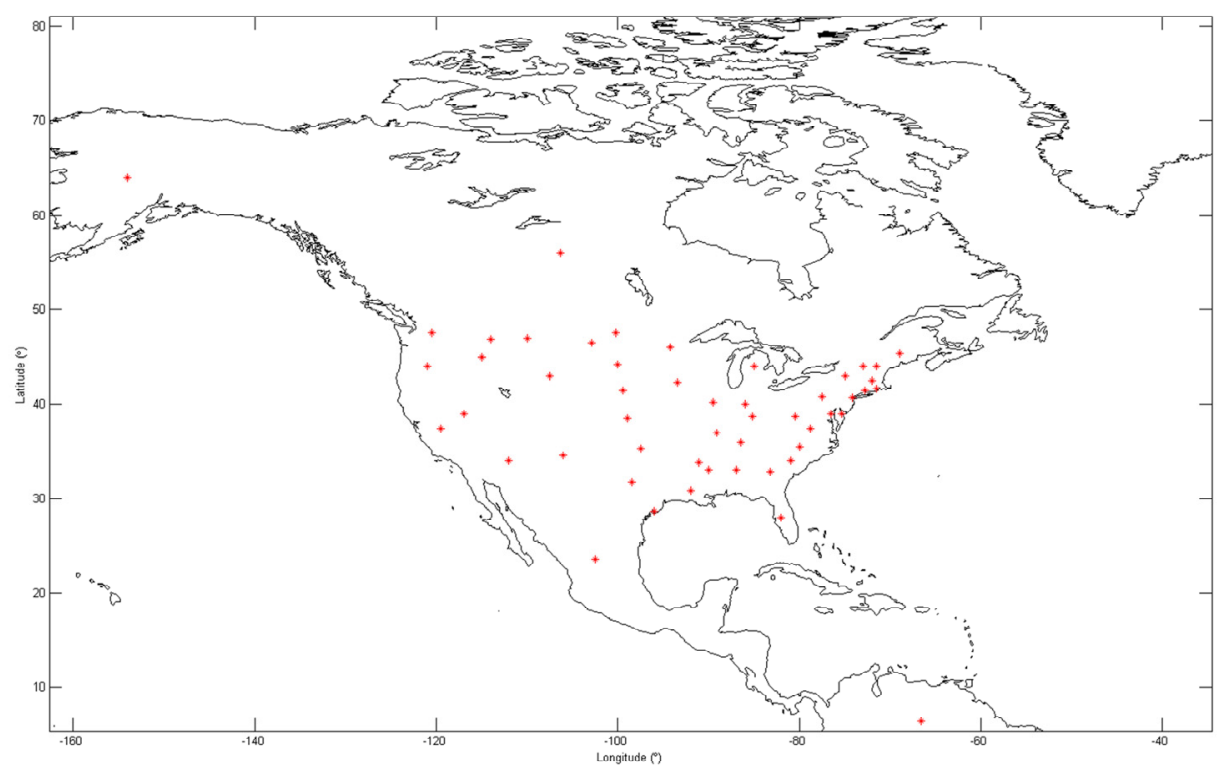

Figure 2.9 Ground stations selected on the US map

The table 2.1 shows statistical data (from DOE) of the average monthly power consumption by the residential section in the US according to 2009 census. This data is classified according to the divisions stated in figure 2.8. From the table it is evident that on an average $908 \mathrm{kWh} /$ month is consumed. Similarly Commercial and Industrial sections and on average it is noted that all the three sections including the US average consumption rate per month is $40 \mathrm{GW}$. So the thesis targets to download at least $40 \mathrm{GW}$ total. Hence a total number of 48 ground stations are picked according to fig. 2.8 and Table 1represented in fig 2.9.

Table 2.1

Residential Average Monthly Bill by Census Division, And State, 2009

\begin{tabular}{|c|c|c|c|c|}
\hline $\begin{array}{c}\text { Census Division } \\
\text { State }\end{array}$ & $\begin{array}{c}\text { Number of } \\
\text { Consumers }\end{array}$ & $\begin{array}{c}\text { verage Monthly } \\
\text { Consumption } \\
\mathbf{( k W h )}\end{array}$ & $\begin{array}{c}\text { Average Retail } \\
\text { Price } \\
\text { Cents per KWh) }\end{array}$ & $\begin{array}{c}\text { Average Monthly } \\
\text { Bill } \\
\text { Dollars and cents) }\end{array}$ \\
\hline New England & $6,136,238$ & 623 & 17.47 & $\$ 108.90$ \\
\hline Middle Atlantic & $15,582,581$ & 690 & 14.84 & $\$ 102.38$ \\
\hline East North Central & $19,531,947$ & 779 & 10.92 & $\$ 85.09$ \\
\hline West North Central & $9,001,636$ & 942 & 9.14 & $\$ 86.10$ \\
\hline South Atlantic & $25,669,340$ & 1,123 & 11.32 & $\$ 127.16$ \\
\hline East South Central & $7,972,331$ & 1,215 & 9.61 & $\$ 116.72$ \\
\hline West South Central & $14,390,523$ & 1,148 & 11.04 & $\$ 126.66$ \\
\hline Mountain & $8,867,490$ & 878 & 10.18 & $\$ 89.38$ \\
\hline Pacific Contiguous & $17,342,577$ & 703 & 12.15 & $\$ 85.43$ \\
\hline Pacific Noncontiguous & 682,512 & 632 & 21.31 & $\$ 134.59$ \\
\hline
\end{tabular}




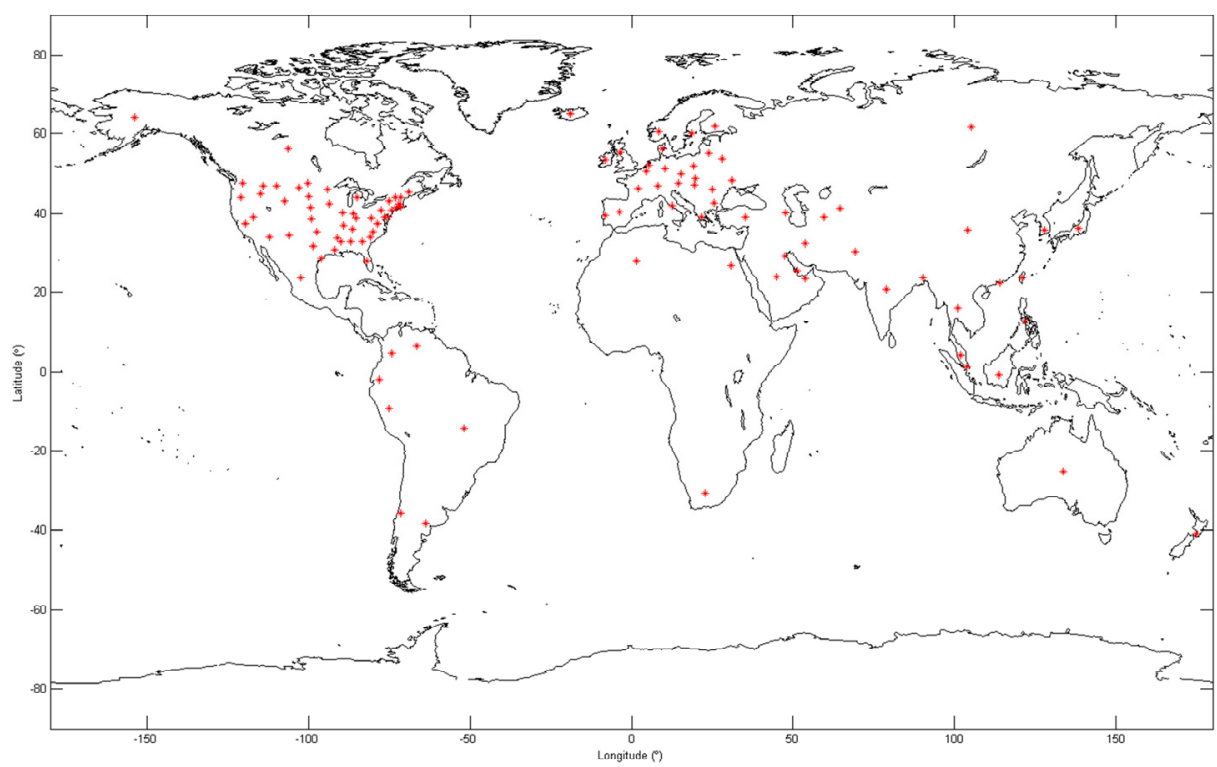

Figure 2.10 Ground stations selected on the World map

As stated earlier 112 ground stations are selected total. Out of these 112, 48 ground stations are selected in the US and the rest 74 are selected in countries which require energy according to statistics provided in chapter 4. As shown in figure 2.10 ground stations are chosen. The following is a list of ground stations considered throughout the World.

Table 2.2

Ground stations selected across the world map

\begin{tabular}{|l|l|l|l|l|}
\hline brazil & $\begin{array}{l}\text { Belgium \& } \\
\text { Luxembourg }\end{array}$ & Lithuania & Ukraine & $\begin{array}{l}\text { China \& } \\
\text { Hong Kong }\end{array}$ \\
\hline china & Bulgaria & Netherlands & United Kingdom & India \\
\hline Argentina & Czech Republic & Norway & Uzbekistan & Indonesia \\
\hline Canada & Denmark & Poland & Iran & Japan \\
\hline Mexico & Finland & Portugal & Kuwait & Malaysia \\
\hline Chile & France & Romania & Qatar & New Zealand \\
\hline Colombia & Germany & Russian Federation & Saudi Arabia & Pakistan \\
\hline Ecuador & Greece & Slovakia & $\begin{array}{l}\text { United Arab } \\
\text { Emirates }\end{array}$ & Philippines \\
\hline Peru & Hungary & Spain & Algeria & Singapore \\
\hline Venezuela & Iceland & Sweden & Egypt & South Korea \\
\hline Austria & Republic of Ireland & Switzerland & South Africa & Taiwan \\
\hline Azerbaijan & Italy & Turkey & Australia & Thailand \\
\hline Belarus & Kazakhstan & Turkmenistan & Bangladesh & Singapore \\
\hline
\end{tabular}




\subsection{Spacecraft Design}

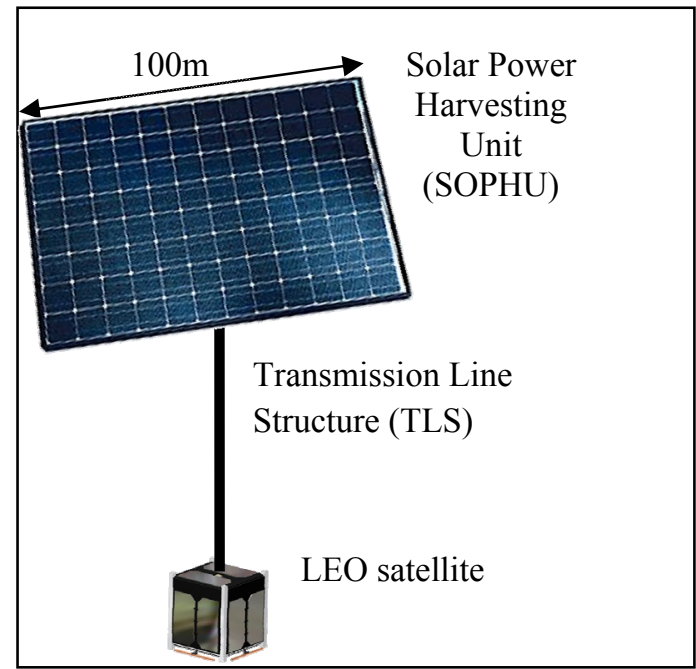

Figure 2.11 the proposed structure for one grid unit
The proposed Space Based solar grid is constructed in two-stage process.

1) A SOPHU (Solar Power Harvesting Unit) located at medium earth orbit (MEO) around $1000 \mathrm{~km}$ altitude and

2) A satellite at the LEO (around $200 \mathrm{~km}$ altitude) which is connected to the SOPHU via a light weight super conductive TLS (Transmission Line System).

The satellite at the Leo transmits the collected power to the PCBS (Power Collector Base Station) as shown in figure 2.11 , installed on the earth surface at all times. Thus providing continuous power to the city or town (ground station).

\subsubsection{Space craft dynamical analysis for the SBSPG}

The proposed SBSPG system consists of a large number of power collector/transmission units. Each unit has a structure that can be modeled mechanically as in figure 2.11. For the initial analysis the SOPHU is assumed to have an area of $100 \mathrm{~m}^{2}$ and a mass of $5000 \mathrm{kgs}$. The plate is connected to a small box of mass $500 \mathrm{kgs}$ and dimensions of $1 \mathrm{mx} 1 \mathrm{mx} 1 \mathrm{~m}$ representing the LEO satellite. The length of the connecting rod is assumed to be $300 \mathrm{~km}$ and mass less. The centre of mass of the small box is at altitude $200 \mathrm{~km}$ from the Earth Surface. The mass less assumption of the transmission line does not affect the dynamic stability of the system.

This assumption states that the area of solar panel in each SOPHU unit is about the same size as the international space station. This giant structure is assembled in the pace and an orbit control system is required to compensate the perturbations like drag and solar radiation pressure. Also the $300 \mathrm{~km}$ rod will be composed of pieces which are also assembled in space.

The proposed attitude control system consists of control moment gyros (CMG's) along the thrusters. Attitude thrusters will be used only to unload the CMG's when they are saturated. A vibration damping system is needed to guarantee the pointing accuracy to ground station. Because of the huge area of the solar panels, temperature increases and hence the efficiency of solar cells causing a structural deformation. Therefore Thermo control system is needed to maintain the temperature of the panels within the operational range. More description is mention in the reference[27]. 


\subsubsection{Concept of Relaying}

In figure 2.4 LEO satellite would function as a power distribution unit ${ }^{34}$. Therefore, leo satellites have two important roles: (1) to transmit the harvested energy by their associated SOPHU to an earth PCBS; and (2) to relay the harvested energy by the SOPHU of another nearby LEO satellite. For example, in Figure 2.12, LEO satellite B which is not in the visibility zone of any PCBS can transmit SOPHU B's harvested energy to the PCBS A through LEO satellite A. Moreover, if SOPHU A is in the earth eclipse and PCBS A needs power resources, even if LEO B might be in the visibility zone of a PCBS, it still can transmit (part of) the harvested energy of SOPHU B through LEO A to PCBS A to fulfill PCBS A's energy needs.

In addition, multiple LEO satellites might be available within the visibilty zone of one ground PCBS. In this case, those satellites should simultaneously transmit the harvested energy of their associated SOPHU to a ground PCBS. The submitted energy transmitted by these LEO satellites should arrive coherently at the PCBS in order to allow constructive addition of these signals at the PCBS. Therefore, propoer synchronization of multiple LEO satellites is also an important problem for the construction of space-based solar power grids.

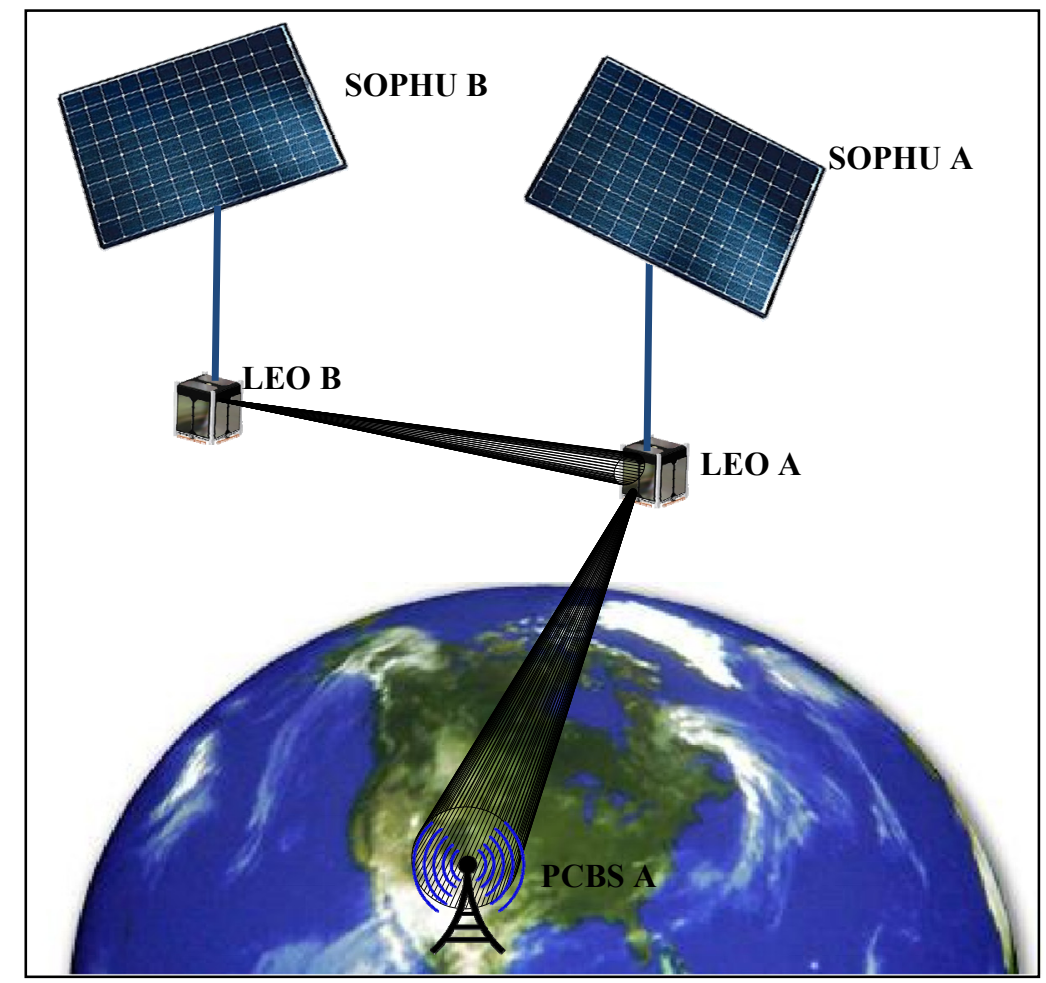

Figure 2.12 Relaying the Collected Energy by SOPHU B to PCBS through LEO Satellite A 


\section{CONSTELLATION DESIGN SYSTEM}

\subsection{Background}

\subsubsection{Introduction}

A constellation[28] is a set of satellites distributed over space intended to work together to achieve a common objective. The characteristics of a satellite drastically vary with the altitude, inclination and size. Most of the constellations are used for communications, navigations, surveillance, guiding and other similar applications[29] where the global earth coverage is difficult to achieve by other means. The constellation deign is expensive and hence satellites with lost costs are preferred.

The principle parameters for the constellation design are described as follows.

Coverage: Coverage is the principal performance parameter and is the primary reason for creating a constellation. Based on the application we can choose if we need continuous coverage or coverage for a particular area of interest. Altitude, minimum angle of elevation and constellation patterns is the major elements which determine the required coverage.

Number of satellites: Number of satellites is the principal cost driver. Hence the goal in a constellation design is to achieve maximum coverage with minimum number of satellites. Smaller constellation may require larger and complex satellites. For example a constellation with 20 satellites in LEO may or may not be cheaper than 3 or 4 satellites in Geosynchronous orbit. 
Launch options: A given coverage can be obtained with a fewer satellites at a higher altitude. But, when the mass increases due to the power and performance then lower altitudes are preferred.

Environment: constellation design is independent of factors like thermal, vacuum and zero-g but is largely dependent on radiation environment which increases if the spacecraft is in the Van Allen belt. This limits the life time of the components like solar arrays, cells and computers. Hence it is preferred that the satellite is either above or below the Van Allen belt.

Orbit perturbations (station keeping): The drag perturbation on the earth's satellite is dependent on the altitude and the earth's oblateness effect depends on inclination, altitude and eccentricity. These perturbations cause a drift of the position of the satellites and this can be avoided by keeping all the satellites at a same altitude and inclination.

Collision avoidance: The single largest threat to constellation design is the collision within a constellation which creates a cloud of debris within the system causing intercollisions. The only way to avoid this collision is by designing the entire system for collision avoidance.

Constellation buildup, replenishing, End of life: One of the important factor to be considered is the condition when a spacecraft fails and so is the end-of-life of a satellite. This is a major cost driver. After the end-of-life the satellite is removed from the constellation pattern to avoid collisions.

Number of orbit planes: moving satellites within a plane takes extremely small amount of propellant, where as changing the orbit planes takes very large amount of propellant. Hence constellation with a smaller number of orbit planes will have more performance as the system builds up. However depending on the constellation patter these orbital planes can also be determined.

\subsubsection{Constellation patterns}

Coverage plays a crucial role in the constellation pattern design. In order to design a constellation all the parameters stated in section 3.1.1. They are a wide variety of constellation patterns depending on full-coverage, systematic multiple coverage, phasing of co-rotating planes, minimum revisit time, etc. Among them, the most prominent patterns are Flower, Walker (delta/ Star), Geosynchronous, etc. These patterns and their prominences are discussed in the following sections. 


\subsubsection{Flower Constellation}

Flower constellations are constellations where every satellite covers a closed loop trajectory that is repeating, which is often axissymmetric. Figure 3.1 illustrates a clear pattern of flower constellation[30] design. The geometry of a flower constellation[31] can be either symmetric or unsymmetrical[32]. This is the one of the common forms of repeated ground track constellation[33]. Here in this figure it is a symmetric pattern with four

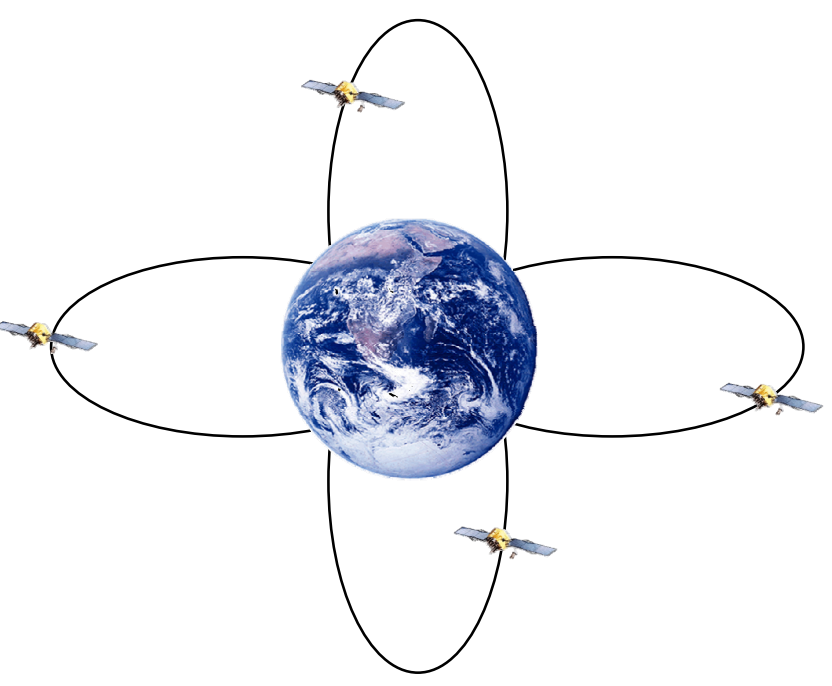

Figure 3.1 Flower Constellation Design petals (orbit planes). But they may vary (generally from 4-8).

The guiding parameters for these kinds of orbits are:

1. the number of petals (number of planes)

2. Repetition period for the orbit

3 . Number of satellites

4. argument of perigee $(\omega)$

5. Orbit inclination (i)

6. Altitude at the Perigee $\left(\mathrm{H}_{\mathrm{P}}\right)$

\subsubsection{Geosynchronous Constellation}

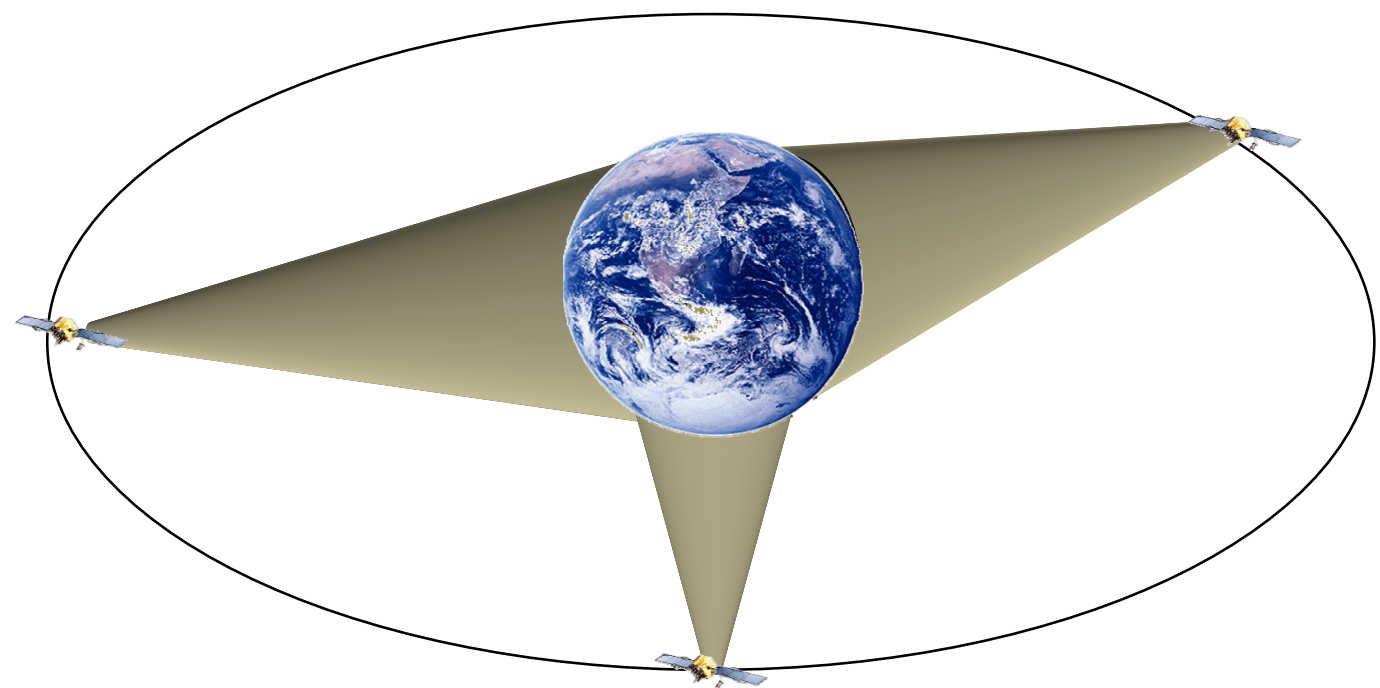

Figure 3.2 Geo Synchronizing Constellation Design 
The simplest of all the constellation patterns is the geosynchronous constellation. As the name says "Geo" means earth and "synchronous" means same time. This means the satellite which moves with the same angular velocity as that of earth so that it has a revolution period equal to the earth rotation period approximately $23 \mathrm{hrs} 56$ minutes sidereal time.

Figure 3.2 represents a geosynchronous constellation. This system just has 3 satellites in one plane which is located at an altitude of $35,000 \mathrm{kms}-36,000 \mathrm{kms}$. These constellations focus on the equatorial and the mid-latitude areas extremely well. But have a poor coverage at the poles. Due to the higher altitudes these orbits are often called as high energy orbits which are extremely in demand. These patterns are mostly used for communication, weather reporting, inspecting over the LEO satellites, etc.

\subsubsection{Walker constellation}

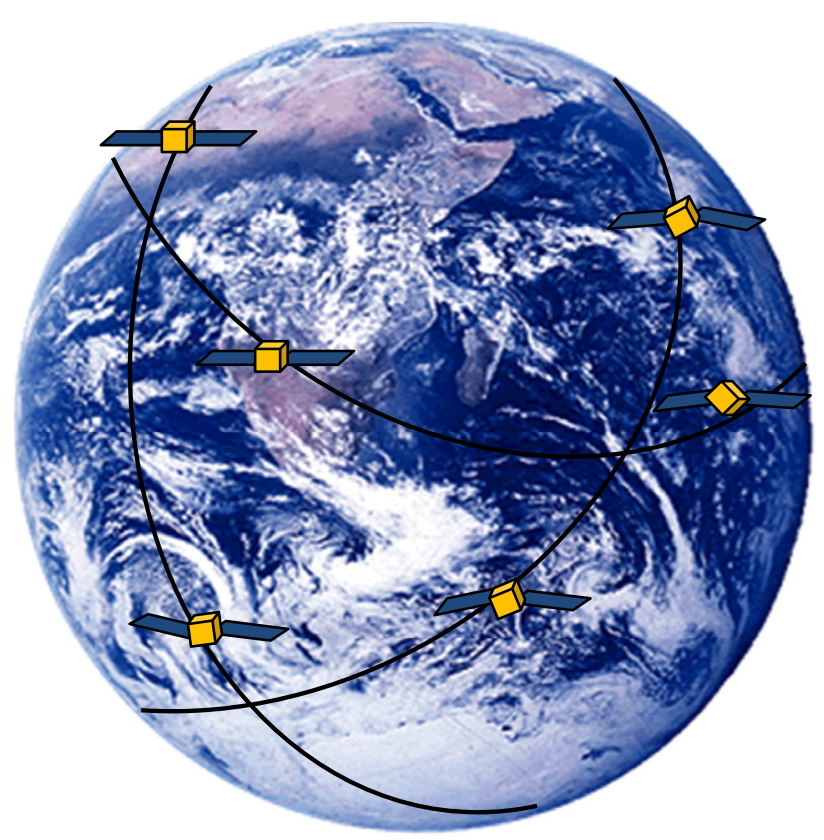

Figure 3.3 Walker Constellation Design

Walker constellations ${ }^{3}$ are the most symmetric of all patterns. The most common of these patterns are the star and delta Walker patterns. It was named Walker after John Walker. The constellation has "N" satellites distributed in "p" orbit planes. In this pattern all the orbits are assumed to be at same inclination (i) relative to earth. Hence the satellites are distributed uniformly (360/p around earth or $360 / \mathrm{n}$ around the orbit plane). Figure 3.3 illustrates the Walker Delta Pattern with three planes.

The only defining parameter that plays vital role is the phasing angle between the orbits. An example is illustrated as following.

If 15 satellites are distributed in 5 planes then in each plane we have $15 / 5=3$ satellites. 
Which means for every the satellites are spaced at $360 / 5=24$ deg or the in-plane phasing is $24 * 5=120 \mathrm{deg}$

But the nodal spacing is $24 * 3=72 \mathrm{deg}$.

Hence the phasing should be in between i.e., $24 * 4=96 \mathrm{deg}$

Hence the phasing angle between adjacent planes can be found thus making walker Constellation a simpler pattern.

\subsubsection{Coverage in adjacent planes}

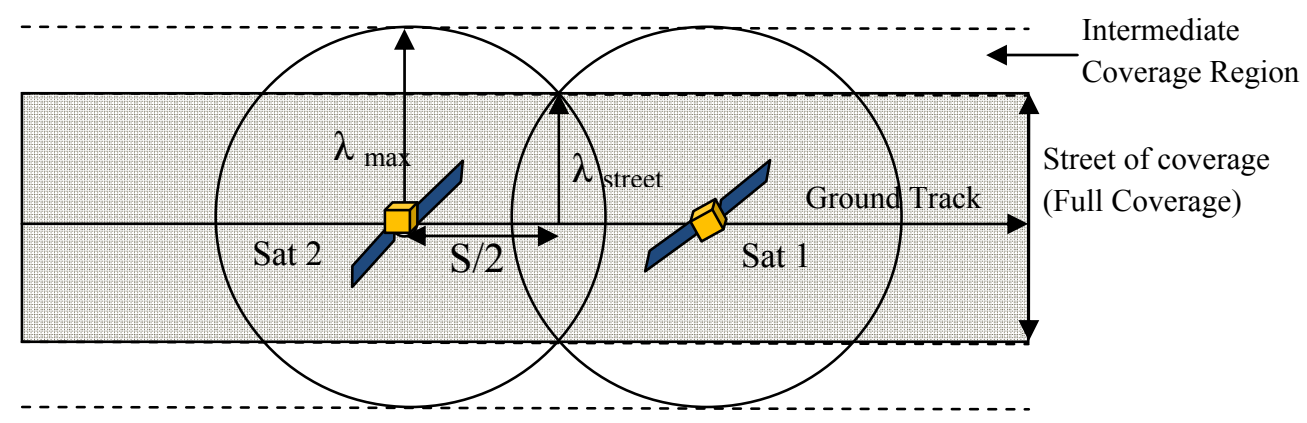

Figure 3.4 Coverage in adjacent planes

Another important parameter in the constellation design is the nodal spacing which is dependent on the swath width. Figure 3.4 shows the coverage pattern of two adjacent satellites. The circles represent the field of view of corresponding satellites. There are two important regions to be considered in this figure

1. Intermediate coverage region

2. Full coverage region ( street of coverage)

3. Overlapping region

Swath width is the perpendicular distance from the satellite to the coverage region.

Here $2 \lambda_{\max }$ is the maximum swath width region

And $\lambda_{\text {street }}$ is the minimum swath width region

In the minimum swath width region there is full coverage and decreases gradually as the swath width increases. So for example if an application involves sensor detection then minimum swath width is preferred. 


\subsection{SPS Constellation Design}

The Architecture of the SBSP is already discussed in chapter 2. But recollecting the architecture, as this chapter talks about constellation design Fig 3.5 shows briefly, the constellation patter. It's a simple design pattern consisting of 2 orbits with 70 spacecrafts in each .70 is chosen, so that the size of the solar panel is the same as the other proposed system. The orbit design is discussed in chapter 1, 2 and is future discussed in chapter 5 with results. This particular section is a brief introduction to specify the basic idea of the constellation pattern.

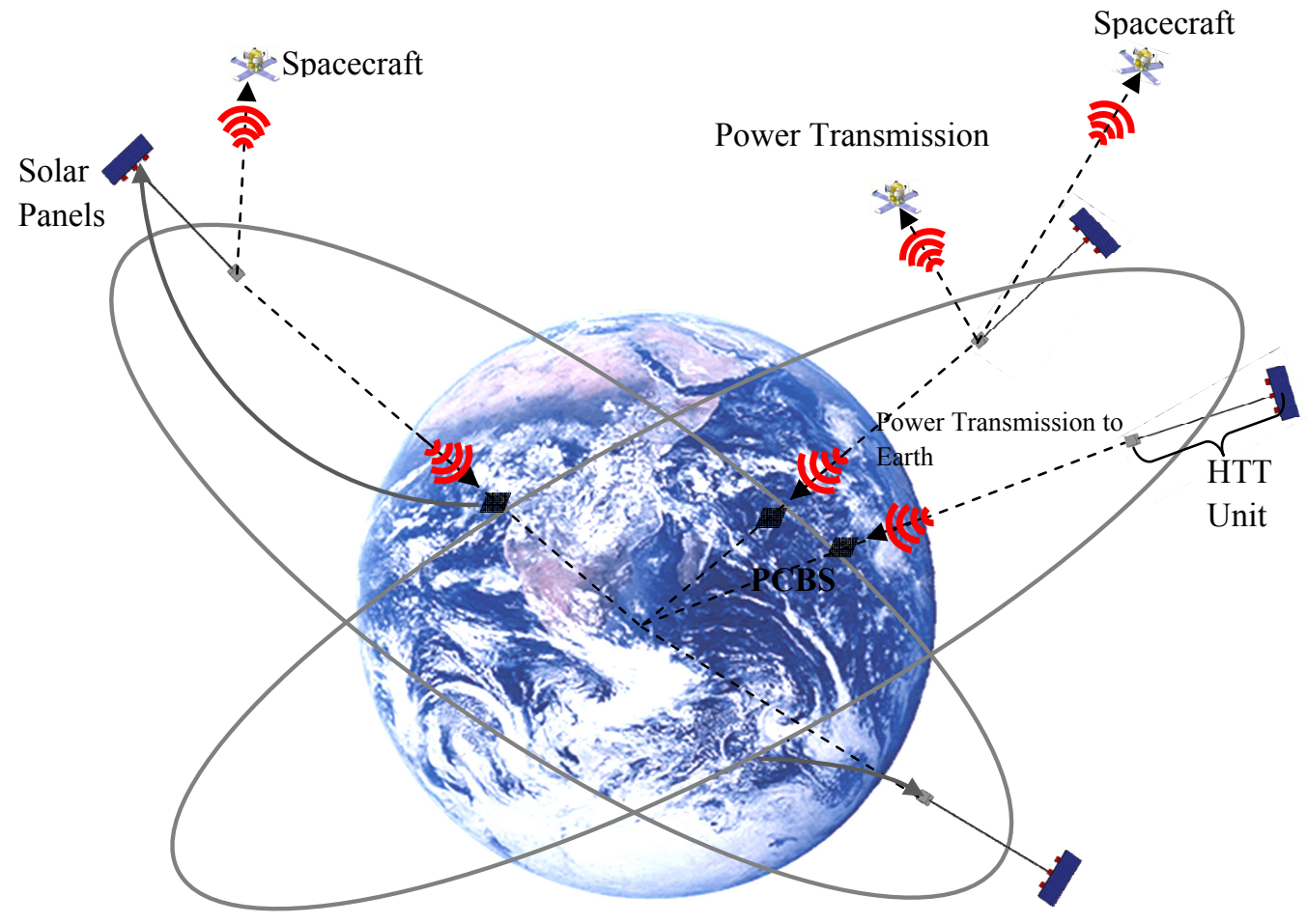

Figure 3.5 Constellation Design for the proposed Space Base Solar Power Satellite System 


\section{POWER CALCULATIONS}

In the first three chapters the orbit mechanics of the proposed system is discussed. Since the proposed system is designed targeting on the amount of solar power to be transmitted from the space to the earth surface, this chapter discusses why "solar Space" is more prominent when compared to the other existing systems.

The first few sections of thesis chapter talk about the energy growth due to the increase in the population demand both in the US and all over the globe. Then a detailed description based on statistics is disused. The later section focuses more on the power calculations for the Space Solar Power transmitted included losses and the space craft proposed in this thesis topic.

\subsection{Energy Statistics}

This section introduces a brief note about the various energy resources available and the World statistics for both production and consumption of different fuel according to EIA 2010. A brief introduction of energy is mention and in the later sections the forecasting of available energy resources is also stated.

Energy can be defined as that quantity which has the ability to perform work. Energy is always conserved. It can neither be created nor be destroyed. It can only change from one form to the other. Since the current topic is to discuss various types of energy resources available, The Chapter includes various types of energy resources available and the prominence of the project "Space based Solar Power."

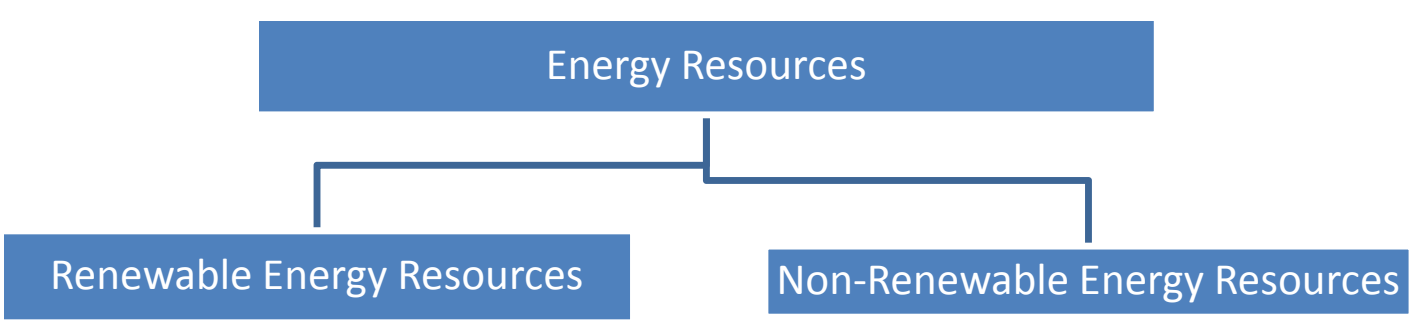

Figure 4.1 Energy Resources Classification 


\subsubsection{Renewable energy resources}

Renewable energy resources are those which naturally replenish. Solar Energy, tidal Energy, Hydro Electric Energy, Wind Energy, Biomass Energy, Geothermal heat Energy are the main sources of these renewable resources. These resources are also called clean and green as the amount of $\mathrm{CO}_{2}$ emissions are comparatively less. The current thesis topic focuses on one of such abundant energy resource "Solar Energy". A statistical review of these energies both in the US and in the world are discussed in section 4.2.

\subsubsection{Installed Geothermal Power capacity}

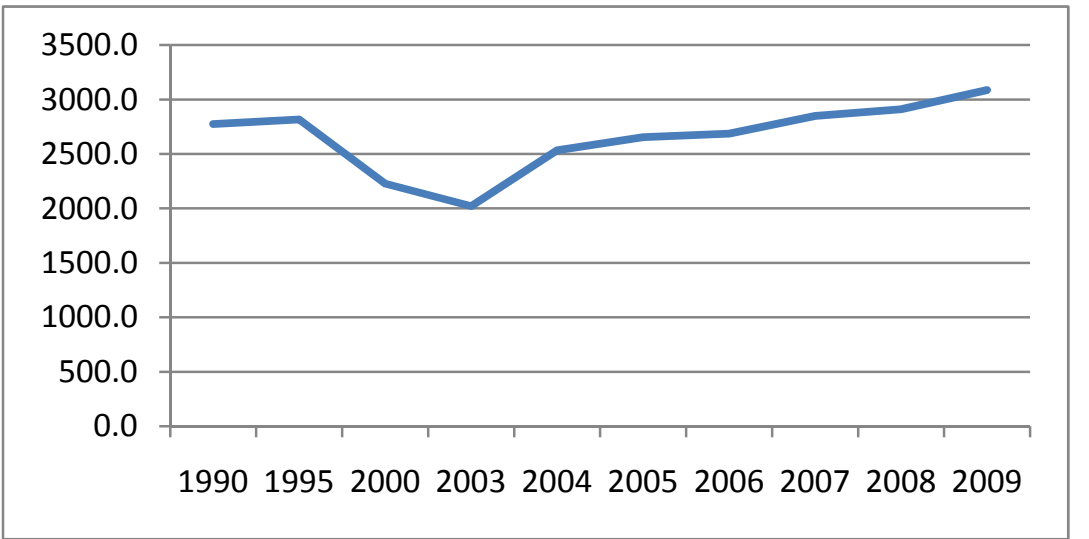

Figure 4.2 US Geothermal Power capacity (in Megawatts)

Geothermal Energy literally means Thermal energy from Earth. The main source of this energy is hot springs, heat developed in the formation of the planet like natural radioactive decay, tectonic plates, etc. As shown in figure 4.2 and 4.3 US[1] is one of the World's leading Geo thermal Energy

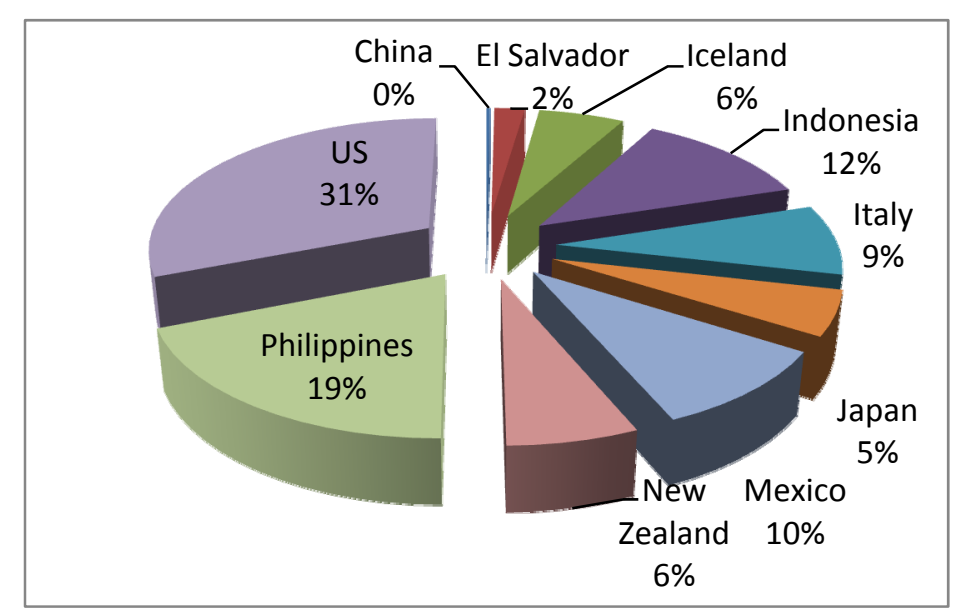

Figure 4.3 World's Geothermal Power Capacity in 2009 producers because of the geographical situations and a huge amount of hot spring. The Geothermal Power capacity in the US is More than $30 \%$. But this can satisfy only $0.3 \%$ of needs in US. Whereas, Philippines is the second largest producer but more than $27 \%$ of the national fuel consumption comes from geothermal power alone.

Figure 1 shows the geothermal power capacity in the US alone in Megawatts in the last decade. On average $3 \mathrm{GW}$ of power is from geothermal source. 


\subsubsection{Hydro Electric Consumption}

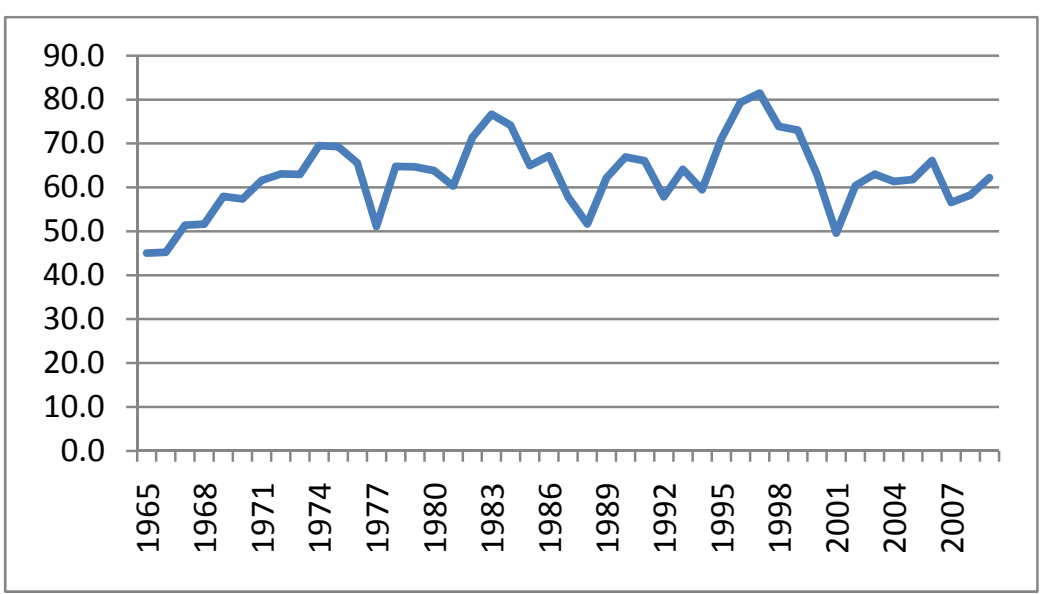

The term Hydro electricity means generating Electricity from water. This is the most ancient methods and also widely used renewable energy resource.

Figure 4.4 US Hydro Electric Consumption (in Million tones oil equivalent)

This potential energy of the dam water is used to turn the turbine and hence the generator to produce usable electric power. $3 \%$ of the total power in US comes from hydro-electric power. US consumes on an average 65 Million tones oil equivalent of Hydro electric power as shown in figure 4.4. As show in figure 4.5, Europe is one of the leading consumers of Hydro Electric power following South America, china and Canada respectively.

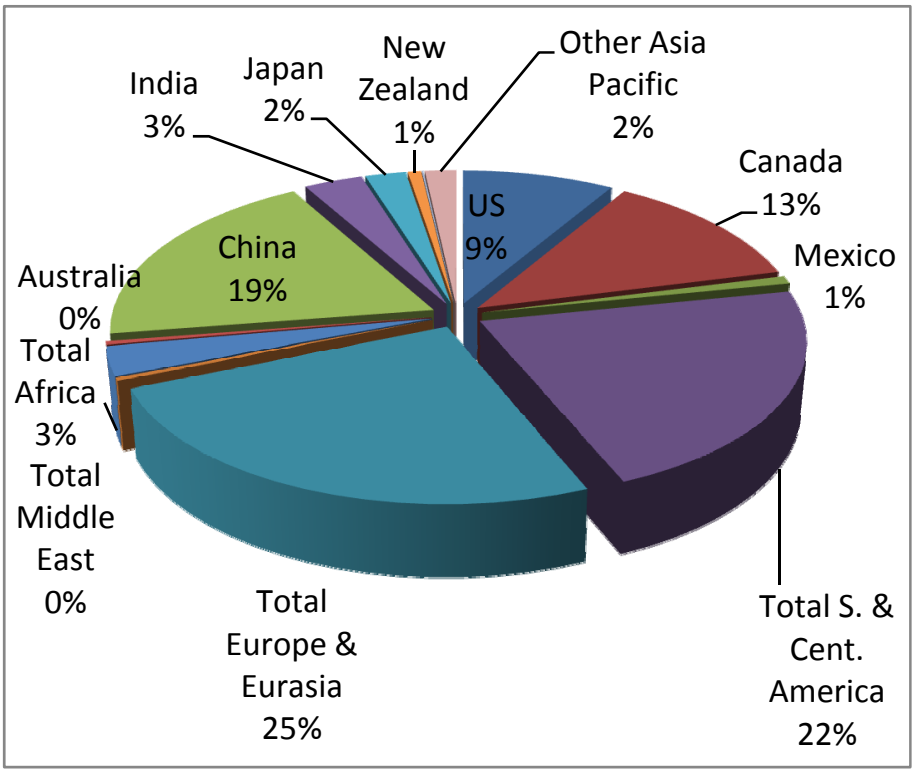

Figure 4.5 World's Hydro Electric Consumption in 2009
The World's leading producer is china following Canada, Brazil, and United States respectively. The only problem is this power installation takes a huge time and right geographical location for the construction of the dams. But once the construction is done, this is the presently know best renewable resource that can be easily manageable and most reliable. HydroElectricity contributes for over $20 \%$ of world's electricity and over $88 \%$ from the renewable resources. 


\subsubsection{Solar Cumulative installed photovoltaic (PV) power}

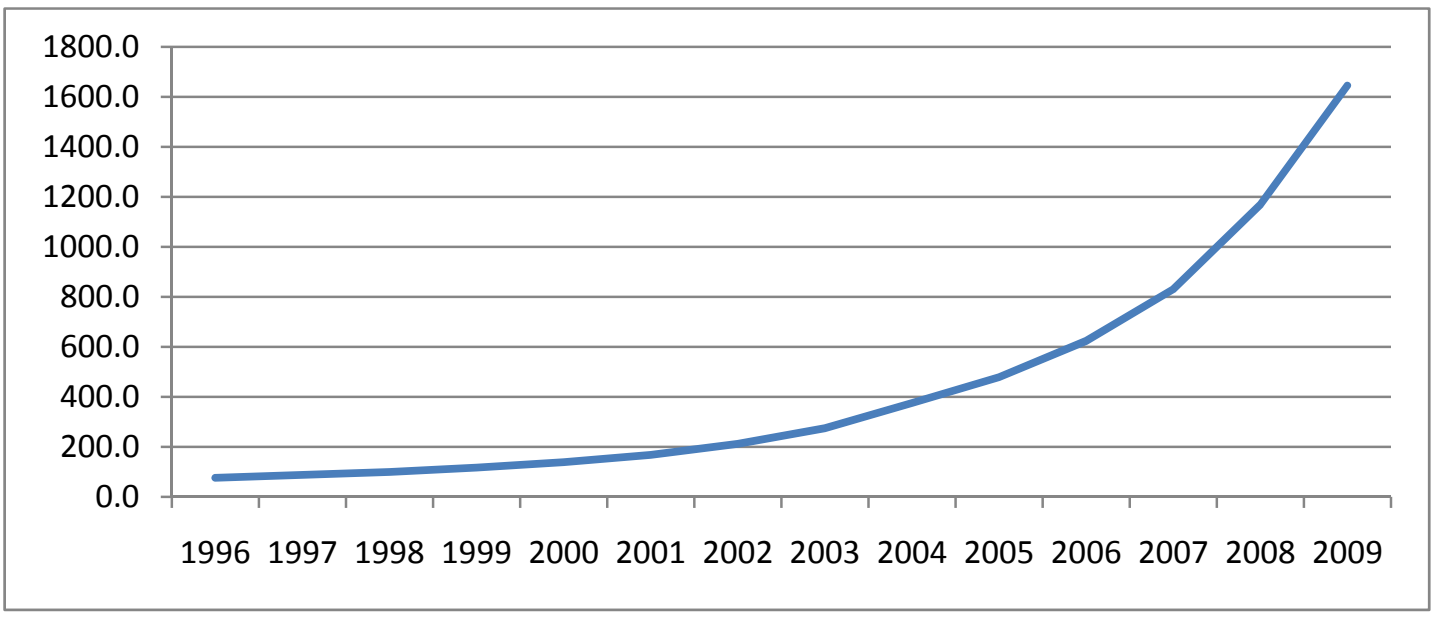

Figure 4.6 US Solar installed photovoltaic (PV) power (in Megawatts)

This section is very close to the current thesis topic. The conventional way to use solar energy is one of to collect the radiation from a solar panel and to convert it into usable form of electricity. Over the last decade the installation of solar power stations in US has been drastically increased to produce $100 \mathrm{MW}$ of power to $1.6 \mathrm{GW}$ of energy as shown in figure 4.6. This is not widely popular because it is the less reliable source of energy. Collecting Solar power on the earth's surface depends on various factors like day

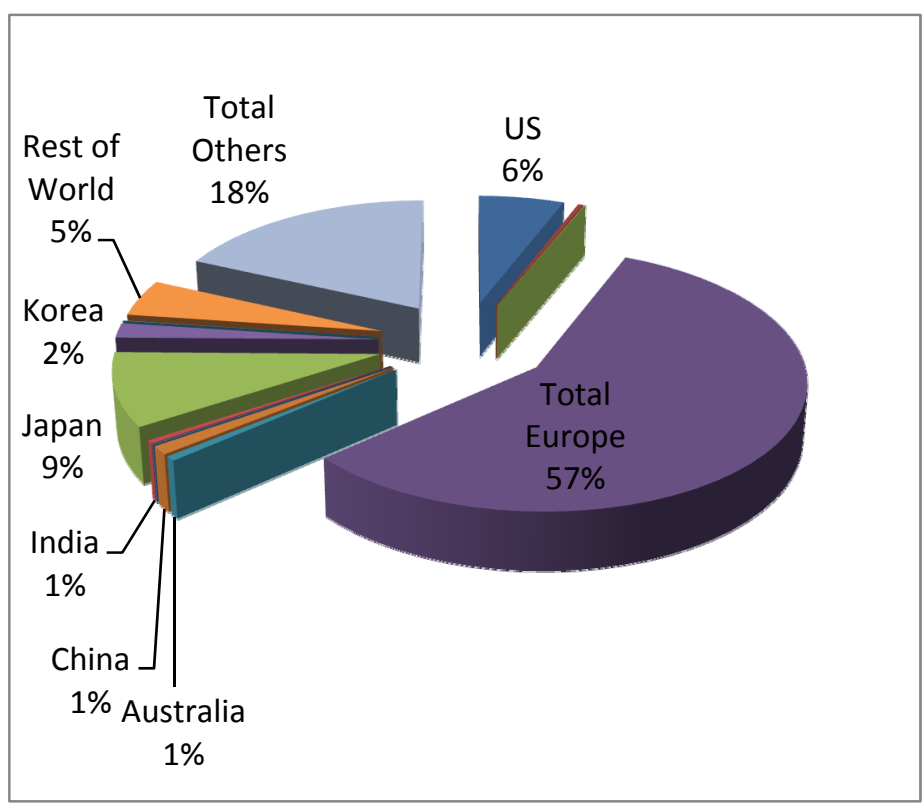

Figure 4.7 World Solar installed photovoltaic (PV) power in 2009
\& night cycle, weather (like clouds opposing the Sun light to reach earth), Earth's atmospheric gases, etc. In order to store this form of energy solar cells (photovoltaic cells) are used and hence naming it Solar photovoltaic power. Most of the Solar Photovoltaic power is installed in Europe because of the geographical conditional and hence contribution for a major $57 \%$ in the world's installation. 


\subsubsection{Wind/ Cumulative installed wind turbine capacity}

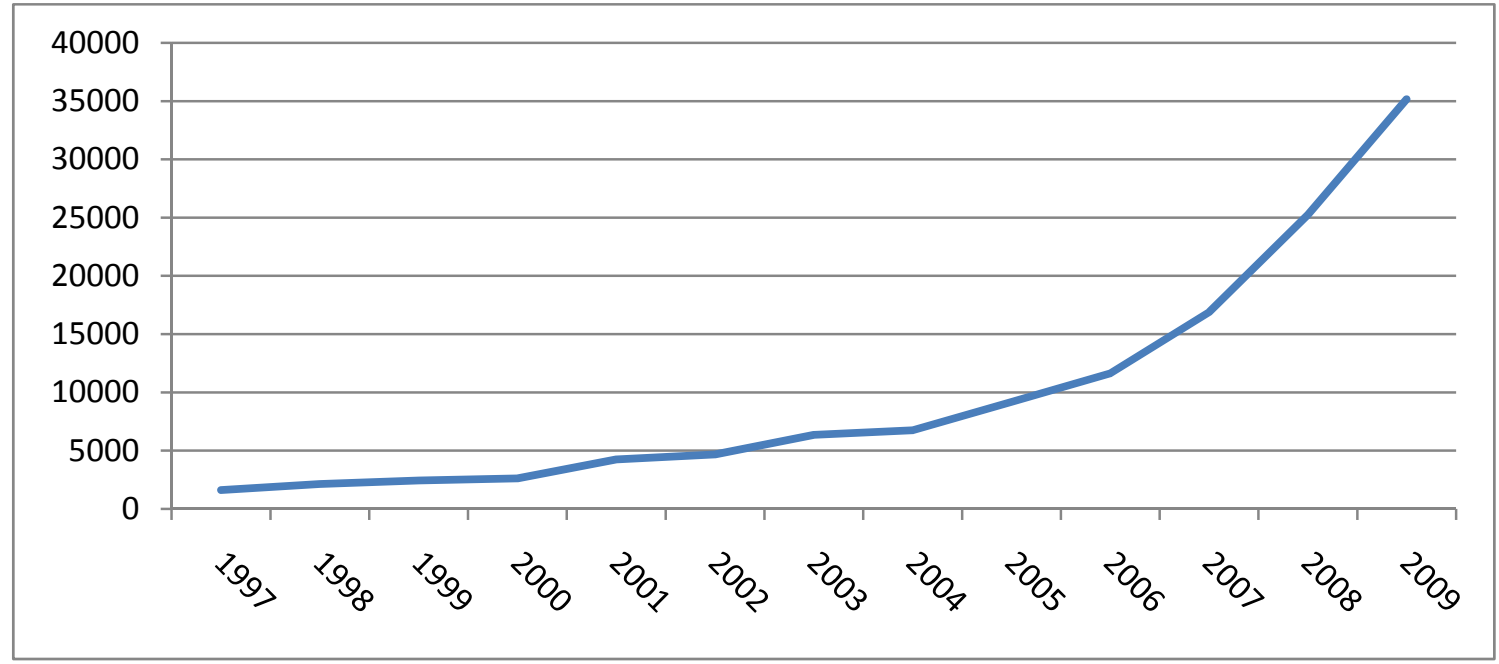

Figure 4.8 US installed Wind turbine power (in Megawatts)

Wind energy is converted to electricity using wind turbines. As shown in figure 4.8 over the past decade US increased the installation capacity from $2 \mathrm{GW}$ to $40 \mathrm{GW}$. Wind energy in the US is more installed in the mountain region as shown in chapter 2. In figure 4.9 the world statistics of installed wind turbine power in 2009. As shown in figure 4.9, Europe and the US contribute for major contribution of Wind power in the World according to the EIA statistics 2009.

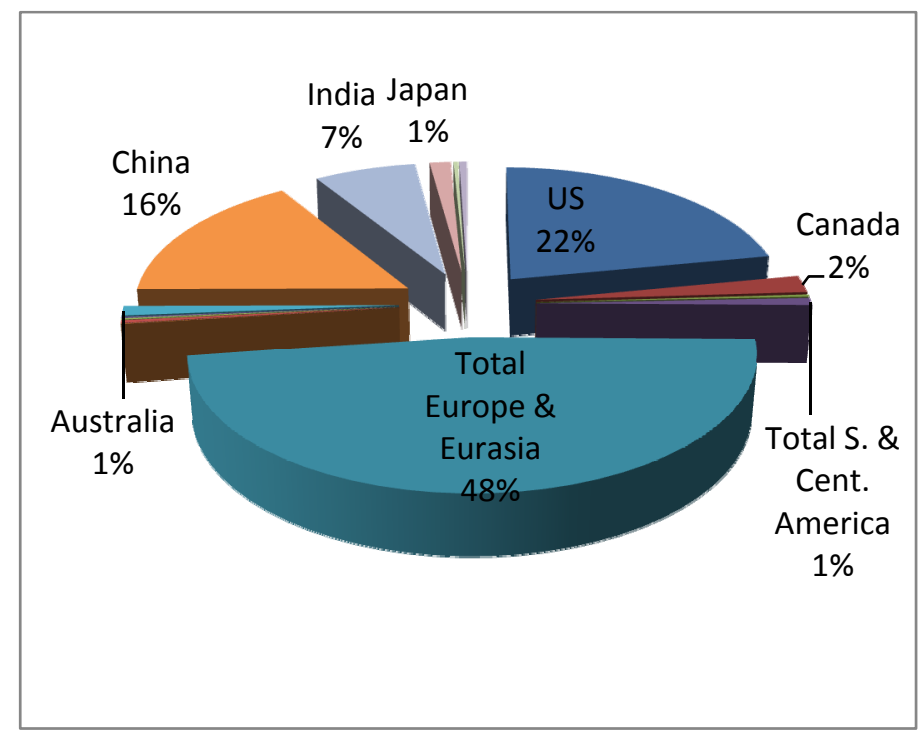

The major problem with the wind turbines is the maintain cost. Also the geographical location when wind energy is available in abundance.

Figure 4.9 World installed Wind turbine power in 2009 


\subsubsection{Non -Renewable Energy Resources}

All fossil fuels, Nuclear energy resources come under this classification. These resources are no replenished. Examples are Oil, Gas, Nuclear, Hydroelectricity etc. A brief description of statistics about the production and consumption of these various energies are discussed in the following sections.

Oil production

\subsubsection{Coal Consumption \& Production}

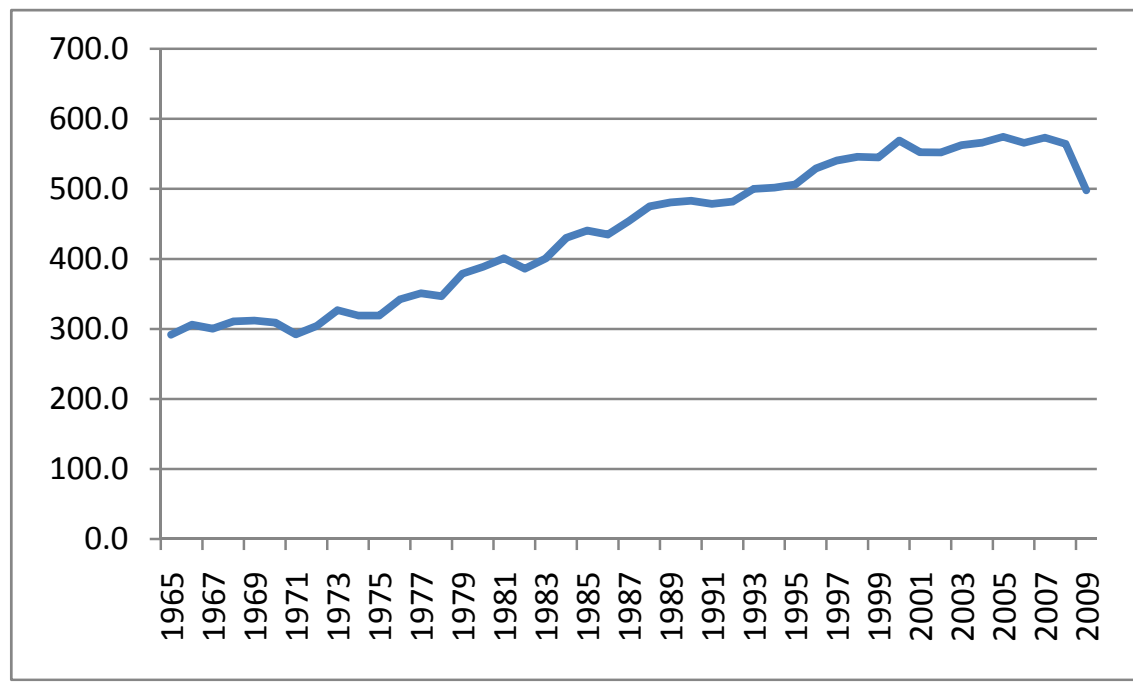

Figure 4.10 US Coal Consumption in 2009 (in Million tones oil equivalent)

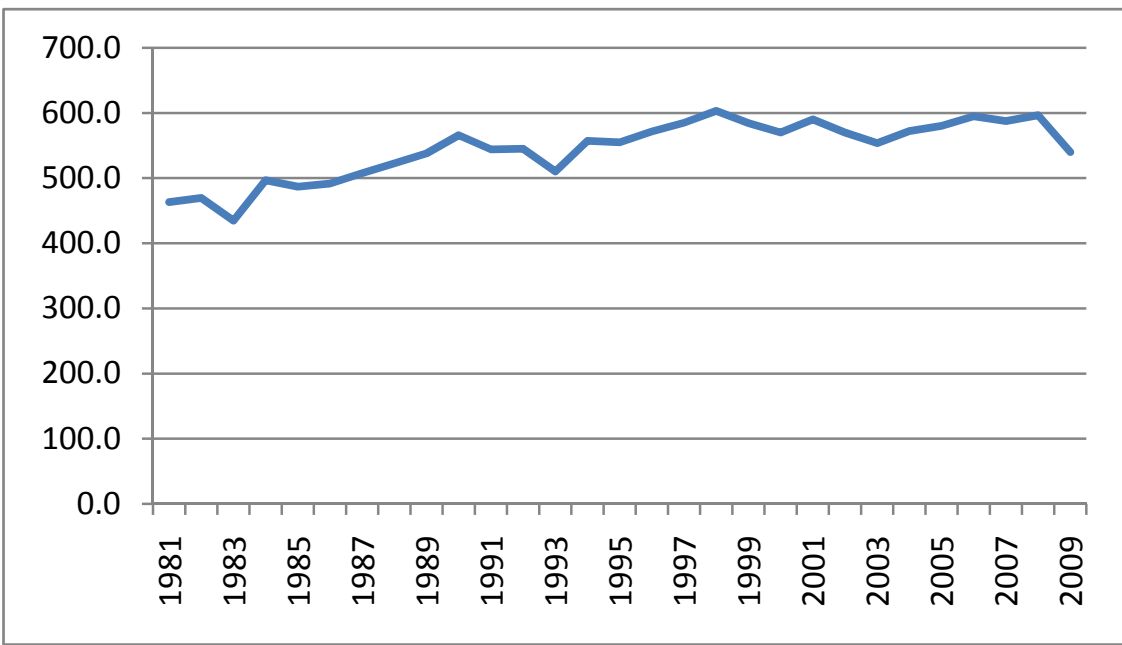

Figure 4.11 US Coal Production in 2009 (in Million tones oil equivalent)
Coal is one of the most prominently used non renewable resources throughout the world. Instead of the discovery of various kinds of power generation methods, power from coal has been the most widely used source because of its reliability, affordability and the easy power generation method. More than $23 \%$ of the US total energy is from coal. Figure 4.10 and 4.11 represent the consumption and production of coal in the US over the past decades. 


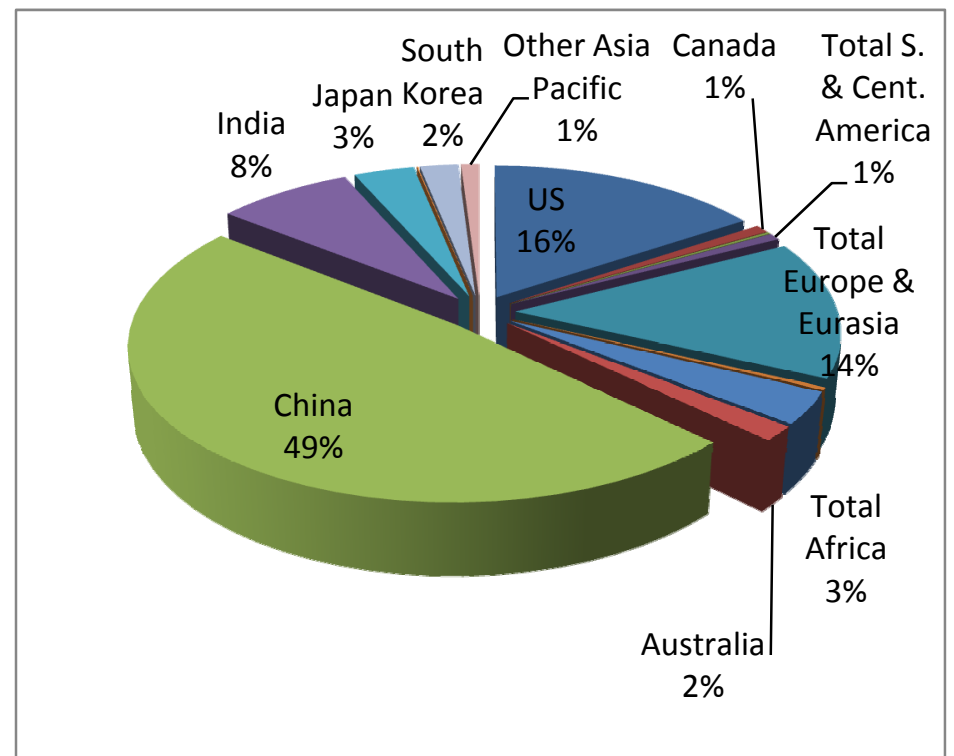

In figure 4.12 and 4.13 the coal consumption increases constantly from 1965 till 2009 from 300 million tons of oil equivalent to 500 million tons of oil equivalent. But the production on average is 500 million tons of oil equivalents. China is all time largest producer and consumer according to EIA world statistics in 2009.

Figure 4.12 World's Coal Consumption in 2009

On an average the demand for coal is high and the availability of these resources is limited. Hence an alternative fuel which is reliable, clean and abundant is required.

The two other nonrenewable resources which are widely used are oil and natural gas. These are discussed in detailed in the following sections. IN US alone more than $95 \%$ of the power is from the non-renewable resources like coal, oil, natural gas, nuclear, etc.

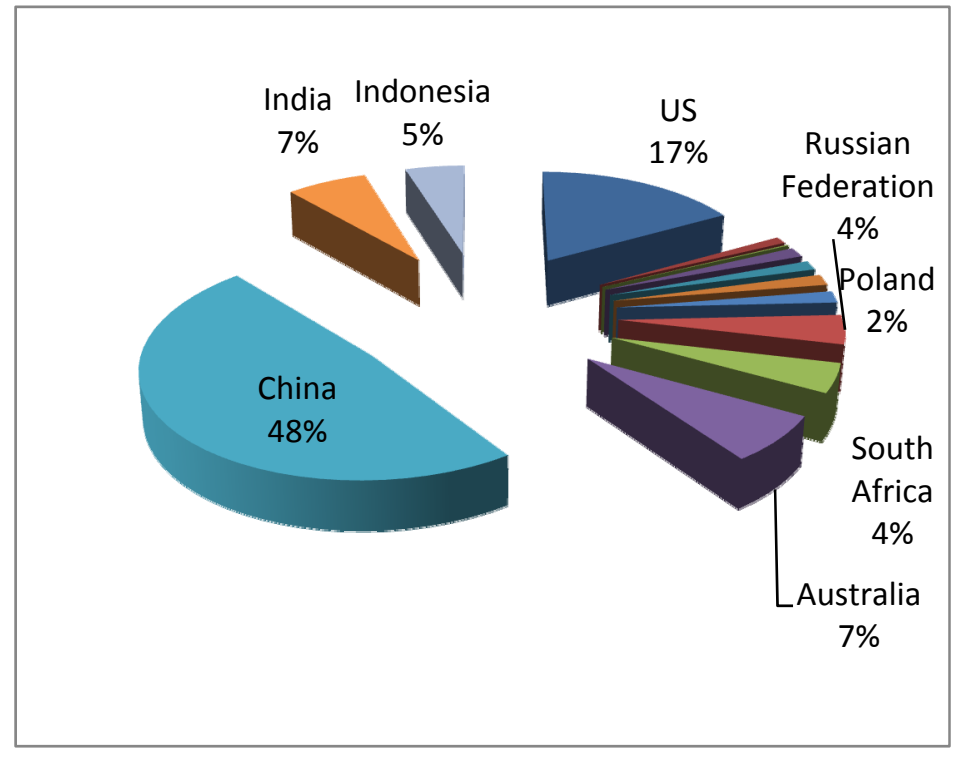

Figure 4.13 World's Coal Production in 2009 


\subsubsection{Natural Gas Consumption \& Production}

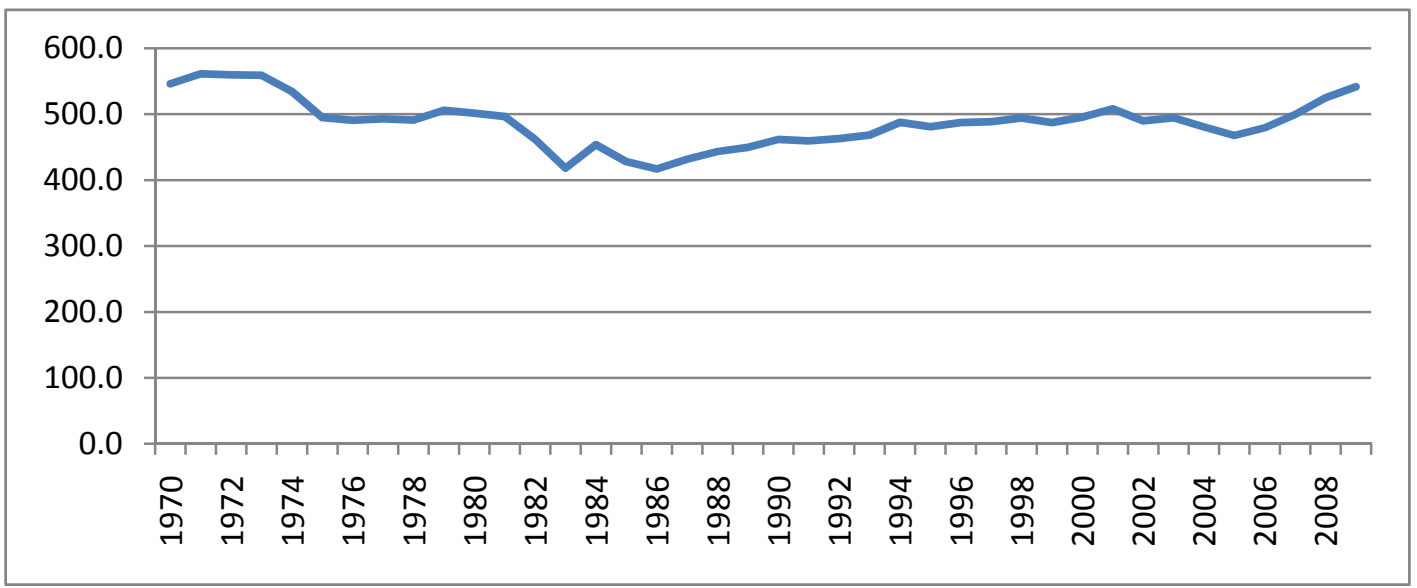

Figure 4.14 US Natural Gas Production (in Million tons oil equivalent)

Natural gas is the next best alternative fossil fuel widely used. Natural gas more abundantly used after the invention of automobiles and residential needs like cooking, heating, etc.

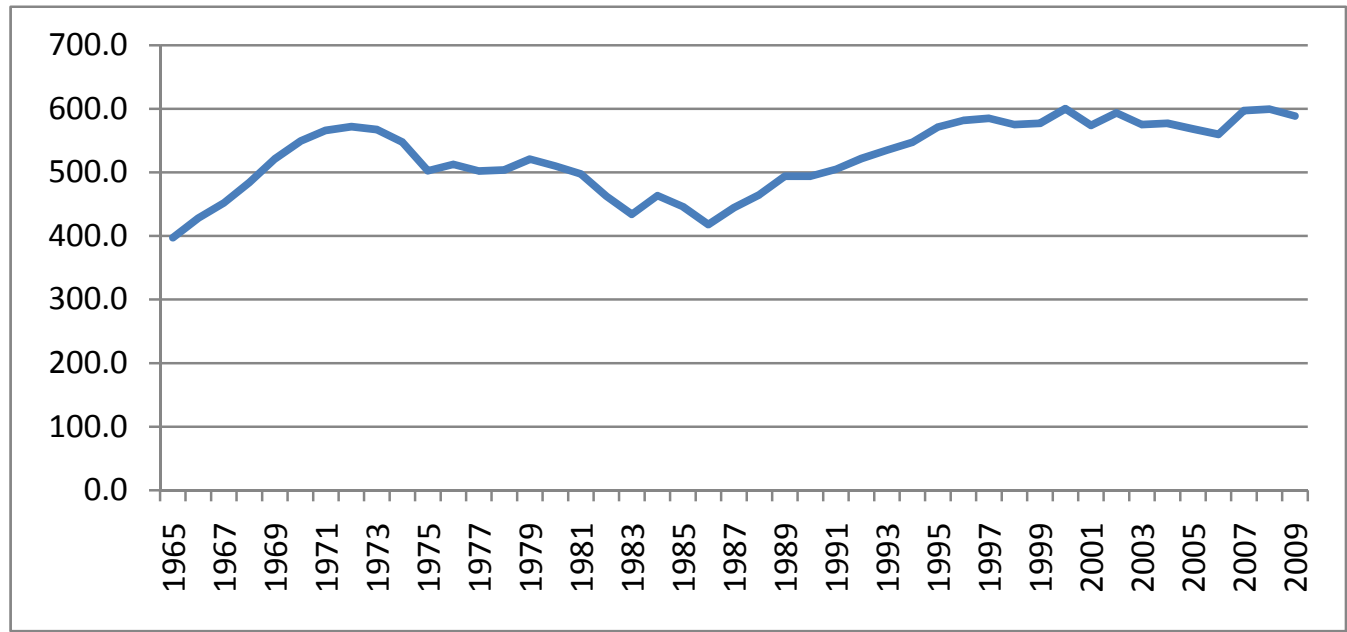

Figure 4.15 US Natural Gas Consumption (in Million tones oil equivalent)

Both figure 4.14 and figure 4.15 represent the production and consumption of natural gas in the US over the past few decades. Natural gas contributes for over $27 \%$ of US total energy according to statistics in 2009. 


\subsubsection{Oil Consumption}

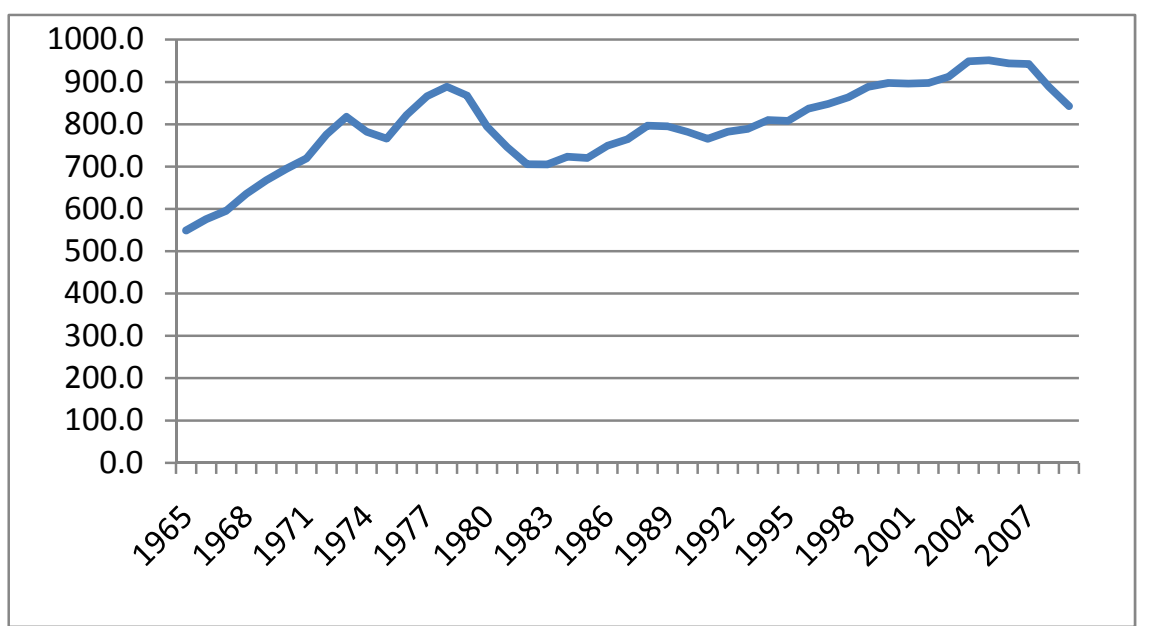

Crude oil is one of the major fossil fuels used in our daily life. Diesel, petroleum, kerosene, etc are extracted from this energy resource.

Figure 4.16 US Oil Consumption (in Million tones oil equivalent)

These resources are mostly available in the Middle East, parts of Africa and the US. Crude oil is extracted mostly on the sea beds. As shown in the figure US consumes more than 700 million tons of oil equivalents in 2009 and the demands are estimated to reach 1000 million tons oil equivalent in 2020. In the US alone oil contributed for $38 \%$ of the total fuel consumption. The largest oil consumers in the world as shown in figure 4.17 are Europe, US, China, Middle East, etc, respectively.

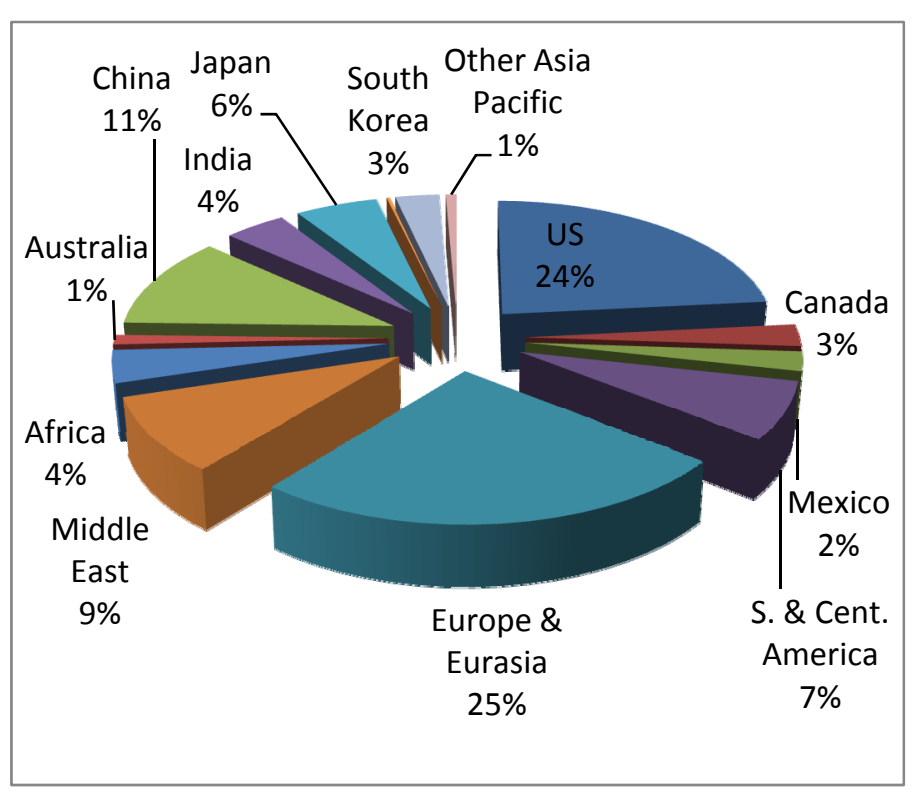

Figure 4.17 World's Oil Consumption in 2009 


\subsubsection{Nuclear Consumption}

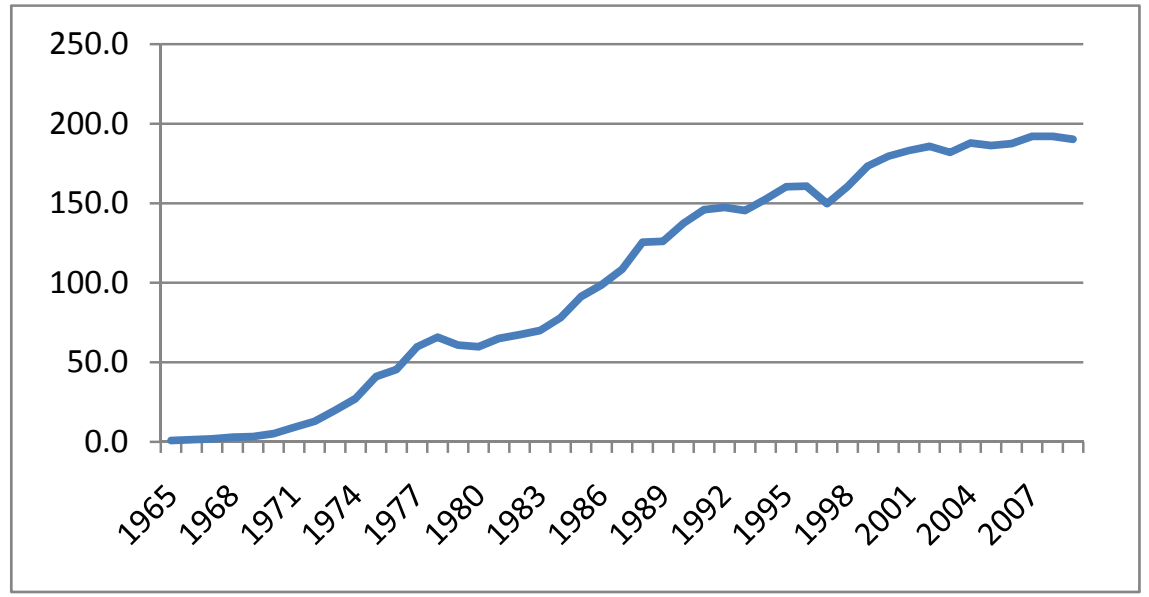

Figure 4.18 US Nuclear Consumption (in Million tones oil equivalent)
Nuclear

Power is one of the most prominent energy resources in the united stated for the past few decades. More than $17 \%$ of the total energy is from nuclear resources. The main resources used for power generation is $\mathrm{U}_{238}$ and $\mathrm{U}_{235}$.

In 2009 more than 180 million tones oil equivalent of nuclear is consumed as shown in figure 4.18. But due to the decreasing nuclear resources, these resources are slowly decreasing its popularity over other resources. Also due to the threats in recent years these are becoming non friendly.

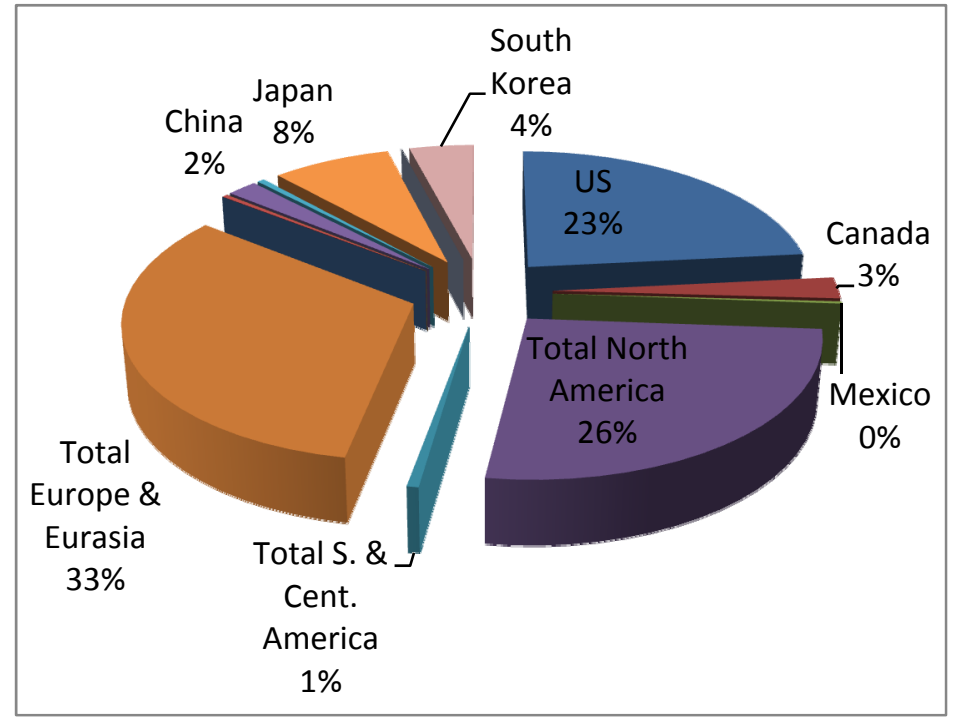

Figure 4.19 World Nuclear Consumption in 2009 (in Million tones oil equivalent)
North America is one of the largest consumers of nuclear power followed by Europe and Japan. As shown in fig. 4.19, one-third of the world's consumption is by Europe making it the world's leading nuclear Energy consuming countries. 


\subsubsection{Ethanol Production}

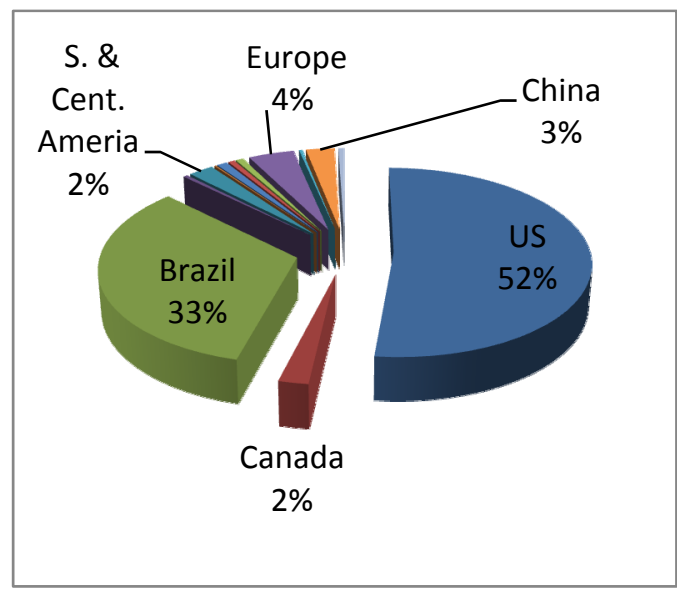

Figure 4.20 World Ethanol Production in 2009 (in thousand tons of oil equivalents)

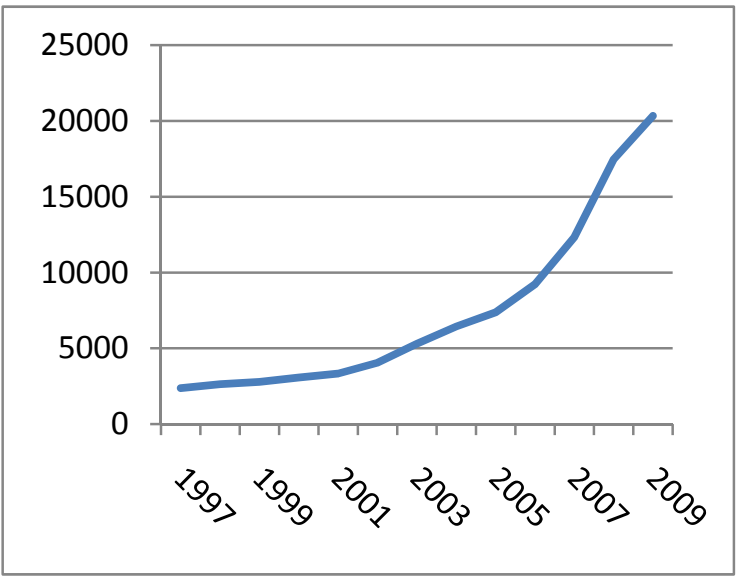

Figure 4.21 US Ethanol Production (in thousand tons of oil equivalents)

Due to the increase in awareness of the harmful effects of $\mathrm{CO}_{2}$ ethanol being a bio fuel gained its popularity. United stated is one of the World's largest ethanol producers following Brazil. Ethanol is a bio fuel generally used in automobiles as a substitute for gasoline, petrol or diesel. Figure 4.21 is a representation of the increase in ethanol production over the last 15 years. Ethanol is generally produced from sugar cane, potato, corn, etc. As shown in figure 4.20 US is the largest producer following Brazil. More than $85 \%$ of the ethanol is produced in the two countries.

\subsection{Benefits of SBS Power over Other Fuels}

All the above section stated the various energy resources production. This is very important for the current thesis because the need for SBSP (Space Based Solar power) is clearly understood after stating all the above data. At present the power demand by the world is $8000 \mathrm{GWe}$. This number is supposed to be increased in the coming 10 years by twice the amount and by 2050 it almost 4 times the demand as of now. But with the present available resources including all the above stated resources, we could only meet $25 \%$ of the needs. This is a serious problem to be considered and the Best way to produce will be a clean, efficient, reliable, abundant power. Which leaves us no option else the sun. As the power produced by sun is stated earlier in chapter 1 , we could meet the demands for at least 4 million years from now if we could used the solar power. But the photovoltaic power is not reliable because of weather condition, day\& night, etc. Hence the plan for SBSP would long for years and will be a mile stone for mankind leading into a powerful new source of energy. 


\subsection{Power Calculations}

\subsubsection{Introduction}

Section 4.1 describes in detail the energy resources, their consumption and production statistics. It is estimated that by 2050 world requires $8000 \mathrm{GW}$ of power which means the energy demand increases by $60 \%$ and with the present available resources, it can only meet $40 \%$ of the total demand.

Due to the increase in the energy demand and a shortage in the available energy resources, scientists have been always searching for a source of energy which can be clean, green and abundant. One such great exploration leads to the invention of Space Solar Power. Dr. Peter Glaser first introduced the concept of transmitting the solar power from space to the earth in the form of microwave beams in early 1965. The proposed system had a huge space craft at the geo-synchronizing orbit transmitting power to earth via microwave beams.

Later there were a huge number of proposals targeting a large power transmission from space to sun using radio waves, microwaves and laser technologies. The huge success of the GPS added undying interesting in the Space Solar power. Over the years there have been huge discussions, proposals and conferences on this topic. The challenging aspect of this system has been the Engineering problem which has been resolved due to the tremendous technological growth over years.

The pentagon's national security office (NSSO) has presented a report on the use of space solar power and has approved for a demo. The NSSO air force collaboration leads to a new policy release on the space solar power. As mentioned in chapter 1 , the project is said to be in existence by 2025 and it can be fully used by 2050 . This report stated that in order to maintain a friendly relationship with Iran, Iraq after the war for the oil resources this project will be helpful. Hence this is a project done by the DOE (Department of Energy) and NSSO together.

\subsubsection{Power calculations for the designed space craft}

This section describes about the power calculations of the space craft design discussed in chapter 2. The transmission losses, atmospheric losses, eclipse losses are all included in the calculation of the power downloading capacity of the space craft.

In figure 4.22, a schematic representation of the space craft is shown downloading power collected at the SOPHU (Solar Power Harvesting Unit) transmitted to LEO ( Low Earth Orbit) satellite via a TLS ( transmission Line System) to the PCBS (Power Collector Base Station) on the Earth surface. 


\subsubsection{Power collected by the SOPHU}

The maximum power capacity of solar cells at this moment is $1400 \mathrm{~W} / \mathrm{m}^{2}$. The dimension of each SOPHU grid as mentioned in figure 21 is $100 \mathrm{~m} * 100 \mathrm{~m}$ i.e., a 10,000 square meters. Assuming a collector efficiency of $100 \%$, the power collected at each SOPHU grid is as follows.

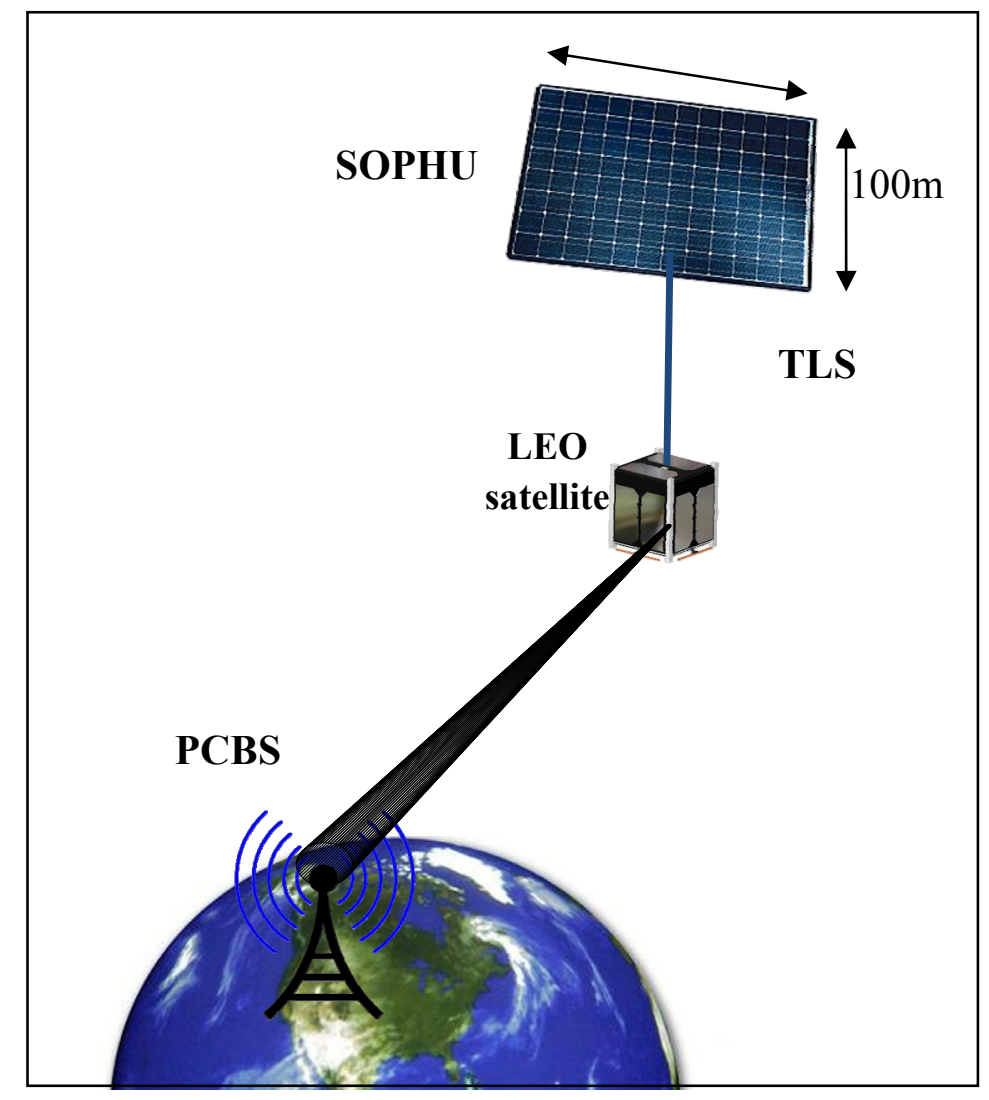

Power collected $=$ collector area* efficiency* solar cell harvest capacity Power collected $=100 \mathrm{~m} * 100 \mathrm{~m} * 100 \% * 1400 \mathrm{~W} / \mathrm{m}^{2}$ Hence, Power Collected $=1.4 * 10^{7} \mathrm{~W}$

\subsubsection{Converting Watts $(\mathrm{W})$ to decibels $(\mathrm{dB})$}

$$
10^{\mathrm{P}(\mathrm{dB}) / 10}=\mathrm{P}(\mathrm{W})
$$

The above is a formula used o convert $\mathrm{dB}$ to $\mathrm{W}$ and vice versa.

Here, $\mathrm{P}(\mathrm{dB})$ represents power in $\mathrm{dB}$ and $\mathrm{P}(\mathrm{W})$ represents power in watts $(\mathrm{W})$

$$
\text { Hence, } 10^{\mathrm{P}(\mathrm{dB}) / 10}=1.4 * 10^{7} \mathrm{~W}
$$

$\mathrm{P}_{(\mathrm{dB})}=71.46228$, is the power collected at SOPHU in decibels $(\mathrm{dB})$ 


\subsubsection{Calculating the losses during the entire transmission}

The major losses to be considered while calculating power for space bases solar power grid are as follows

(1) Losses due to TLS

(2) Losses due to eclipse

(3) Losses due to ionosphere

(4) Losses due to atmosphere

A few assumptions are made in the calculation as follows

1. A microwave beam with a frequency of $5000 \mathrm{MHz}$ is considered for calculation to transmit the collected power at the SOPHU to PCBS.

2. The SOPHU's altitude is considered $1000 \mathrm{kms}$ and the LEO satellite's altitude $200 \mathrm{kms}$.

3. Losses due to the TLS is $0.1 \mathrm{~dB} / \mathrm{km}$

4. The sum of atmospheric and ionosphere losses are considered to be $1 \mathrm{~dB}$

The formula to calculate the total losses is given as follows.

$$
\begin{array}{rl}
L_{S B S P G}=L_{T L S} & * \frac{\left(d_{k m, M E O}-d_{k m, L E O}\right)}{100}+32.45+20 * \log \left(d_{k m, L E O}\right)+20 * \log \left(f_{M H Z}\right) \\
& +L_{I O N}^{\prime}+L_{A t m}+L_{E C L}
\end{array}
$$

Where

$L_{S B S P G}=$ Total losses in The Space Based Solar Power Grid in $\mathrm{dB}$

$L_{T L S}=$ losses due to TLS in $\mathrm{dB}$

$d_{k m, M E O}=$ altitude of the SOPHU at MEO in kilometers $(\mathrm{kms})$

$d_{k m, L E O}=$ altitude of the LEO satellite in kilometers $(\mathrm{kms})$

$f_{M H z}=$ frequency of the transmitting waves in Mega Hetrz $(\mathrm{MHz})$

$L_{I O N}^{\prime}=$ Losses due to Ionosphere

$L_{A t m}=$ Losses due to Atmosphere

$L_{E C L}=$ Losses during Eclipse

$R_{E}=$ Polar Radius of earth in kilometers $(\mathrm{kms})$ 


$$
\begin{aligned}
& \therefore L_{S B S P G}=0.1 * \frac{(1000-200)}{100}+32.45+20 * \log (200)+20 * \log (5000)+1+L_{E C L} \\
& \text { but, } \quad L_{E C L}=10 * \log \left(\frac{\pi}{\sin ^{-1}\left(\frac{R_{E}}{d_{k m}+R_{E}}\right)}\right) \\
& \therefore \quad L_{E C L}=10 * \log \left(\frac{\pi}{\sin ^{-1}\left(\frac{6371}{1000+6371}\right)}\right)=10 * \log \left(\frac{\pi}{75.9^{0}}\right) d B \\
& \text { Hence, } \quad L_{S B S P G} \\
& =0.1 * \frac{(1000-200)}{100}+32.45+20 * \log (200)+20 * \log (5000)+1 \\
& +10 * \log \left(\frac{\pi}{75.9^{0}}\right) \\
& \text { Hence, } \quad L_{S B S P G}=157.8699 \mathrm{~dB}
\end{aligned}
$$

\subsubsection{Calculating the Power transmitted in $\mathrm{dB}$}

After calculating the net losses during the transmission, Power transmitted is calculated by using the following formula.

$$
P_{t, d B}+G_{t, d B}+G_{r, d B}=L_{S B S P G, d B}+P_{r, d B}
$$

Where,

$P_{t, d B}=$ Power transmitted by SOPHU in $\mathrm{dB}$

$G_{t, d B}=$ Gain transmitted in $\mathrm{dB}$

$G_{r, d B}=$ Gain received in $\mathrm{dB}$

$L_{S B S P G, d B}=$ Total Losses of the Space Based Solar Power Grid in $\mathrm{dB}$

$P_{r, d B}=$ Power received in $\mathrm{dB}$

$P_{t, d B}$ is calculated to be $71.46228 \mathrm{~dB}$ in the previous section, $G_{t, d B}$ is assumed to be $94 \mathrm{~dB}, G_{r, d B}$ is $82 \mathrm{~dB}$

$$
\begin{gathered}
\therefore 71.46228+94+82=157.8699+P_{r, d B} \\
\text { Hence } P_{r, d B}=89.5913 d B
\end{gathered}
$$




\subsubsection{Calculating the Power transmitted in Watts $(W)$}

$$
\begin{gathered}
10^{\left(\frac{P_{(d B)}}{10}\right)}=P_{(W)} \\
10^{\left(\frac{89.5913}{10}\right)}=P_{(W)}
\end{gathered}
$$

Hence Power Received at the PCBS in watts $P_{(W)}=0.95 \mathrm{GW} \approx 1 \mathrm{GW}$

Thus, Each Power grid is capable of transmitting 1GW to the PCBS

\subsection{Power transmission vs. Altitude}

Power according to the formulae's depends majorly on the altitude. Table 4.1 shows the variation of the power received in Watts (W)

Table 4.1

\begin{tabular}{|c|c|c|}
\hline ALTITUDE (kms) & $\begin{array}{c}\text { INCLINATION } \\
\text { (degrees) }\end{array}$ & POWER in (Watts) \\
\hline 500 & 96.1229 & $1.71 \mathrm{E}+09$ \\
\hline 1000 & 96.5704 & $1.53 \mathrm{E}+09$ \\
\hline 1500 & 97.0182 & $1.55 \mathrm{E}+08$ \\
\hline 2000 & 97.4665 & $5.13 \mathrm{E}+07$ \\
\hline 2500 & 97.9153 & $2.43 \mathrm{E}+07$ \\
\hline 3000 & 98.3645 & $1.38 \mathrm{E}+07$ \\
\hline 3500 & 98.8143 & $8.67 \mathrm{E}+06$ \\
\hline 4000 & 99.2646 & $5.87 \mathrm{E}+06$ \\
\hline 4500 & 99.7155 & $4.18 \mathrm{E}+06$ \\
\hline 5000 & 100.167 & $3.09 \mathrm{E}+06$ \\
\hline 5500 & 100.6191 & $2.36 \mathrm{E}+06$ \\
\hline 6000 & 101.0719 & $1.85 \mathrm{E}+06$ \\
\hline 6500 & 101.5254 & $1.48 \mathrm{E}+06$ \\
\hline 7000 & 101.9796 & $1.20 \mathrm{E}+06$ \\
\hline 7500 & 102.4347 & $9.90 \mathrm{E}+05$ \\
\hline 8000 & 102.8905 & $8.26 \mathrm{E}+05$ \\
\hline 8500 & 103.3471 & $6.97 \mathrm{E}+05$ \\
\hline 9000 & 103.8046 & $5.95 \mathrm{E}+05$ \\
\hline 9500 & 104.263 & $5.11 \mathrm{E}+05$ \\
\hline 10000 & 104.7223 & $4.43 \mathrm{E}+05$ \\
\hline
\end{tabular}

Power Transmission vs. Altitude 


\section{RESULTS}

\subsection{Best Suitable Orbit Elements calculations}

In order to find a right orbit for our application it is clear from all the above chapters that we need a sun synchronizing orbit as the satellite needs to be in the Sun's orientation always. Hence one of the orbit constrain can be found by using the formulae's stated in chapter 1 . The second important condition is that a ground station always needs to receive power. Hence it is better to have a repeated ground track. Hence the conclusion is we need a Sun-Synchronizing Repeating ground track for our application.

As discussed we need to find the right orbit elements satisfying all the conditions. Recalling again from chapter 1, the orbital elements are:

(1) The orbit plane Inclination (i)

(2) Right Ascension of Ascending node RAAN $(\Omega)$

(3) Argument of perigee $(\omega)$

(4) The orbit eccentricity (e)

(5) Semi major axis of the Orbit (a)

(6) Position of the spacecraft on orbit (true anomaly, $\theta$ ).

$\Omega, \omega$ are assumed to be zero for initial calculations. Eccentricity (e) of the orbit is also assumed to be zero to have a circular orbit so that coverage is evenly distributed. True anomaly, $\theta$ varies with the space craft position hence it's a variable which is time dependent. Hence from the above we need to determine

(1) The orbit plane Inclination (i)

(2) Semi major axis of the Orbit (a)

(3) Repeating period for the ground track (Tf)

In order to determine the above three values a series of simulations are performed which are discussed in this section.

Starting with the calculation of a set of inclination, time period and semi-major axis from an excel sheet as stated below. This excel sheet was based on the formulae's for sun synchronizing repeated ground track. 
Table 5.1 is an example of the data sheet used. Column 1 and 2 are the User Requirements Sw (Swath Width in $\mathrm{Km}$ ) and Repeating time (Rt). In this example the Rt is 5 days. By varying the value of the Swath Width[34] various initial values and intermediately values are created as shown in columns 3-8.Column 3 and 4 are the Swath[35] Width at the equator in $\mathrm{km}$ and in radians. Column 5 is the drift angle per day in radians $(\Delta \phi)$. Column 6 is an initial value for the altitude $(\mathrm{H})$ created to calculate the right orbital elements are shown in table 5.2.

Table 5.1

User Requirements for the Sun Synchronous Repeated Ground Track Data Sheet

\begin{tabular}{|c|c|c|c|c|c|c|c|}
\hline \multicolumn{2}{|c|}{ User requirements } & \multicolumn{6}{|c|}{ 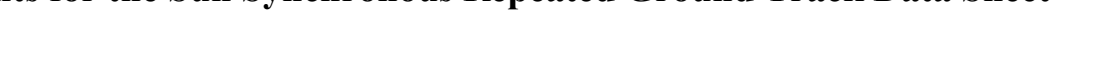 } \\
\hline $\mathrm{Sw}(\mathrm{km})$ & Rt & $\begin{array}{c}\text { Sw on } \\
\text { equator } \\
(\mathrm{km})\end{array}$ & $\begin{array}{l}\text { Sw on } \\
\text { equator } \\
(\mathrm{rad})\end{array}$ & $\Delta \phi(\mathrm{rad})$ & $\begin{array}{c}\mathrm{H} \\
(\mathrm{Kms})\end{array}$ & & \\
\hline 448 & 5 & 517.3058 & 0.081106 & 0.40553 & 418.550 & 77.4692 & 0.46925 \\
\hline 454 & 5 & 524.234 & 0.082192 & 0.41096 & 479.100 & 76.4454 & 0.445431 \\
\hline 460 & 5 & 531.1622 & 0.083279 & 0.41639 & 539.384 & 75.4483 & 0.448317 \\
\hline 466 & 5 & 538.0905 & 0.084365 & 0.42182 & 599.407 & 74.4768 & 0.476879 \\
\hline 473 & 5 & 546.1734 & 0.085632 & 0.42816 & 669.108 & 73.3746 & 0.374684 \\
\hline 479 & 5 & 553.1016 & 0.086718 & 0.43359 & 728.579 & 72.4555 & 0.455586 \\
\hline 486 & 5 & 561.1845 & 0.087986 & 0.43992 & 797.649 & 71.4119 & 0.411987 \\
\hline
\end{tabular}

Table 5.2 shows results for the User requirement's data for 5 days to repeat the orbit.

$\begin{array}{lll}\mathrm{n} & \rightarrow & \text { number of orbits to repeat } \\ \mathrm{H} & \rightarrow & \text { altitude for sun-synchronous repeated ground track in } \mathrm{km} \\ \text { Period } & \rightarrow & \text { Orbital period for one orbit in minutes } \\ \mathrm{I} & \rightarrow & \text { inclination of the orbit in degrees } \\ \Delta \phi & \rightarrow & \text { drift angle in radians } \\ \mathrm{n} / \mathrm{m} & \rightarrow & \text { number of orbits completed per day } \\ \mathrm{j} & \rightarrow & \text { non-decimal part of } \mathrm{n} / \mathrm{m} \text { which is the condition for the repeated ground } \\ \text { trace orbit }\end{array}$

Table 5.2

Results for the Sun synchronous repeated ground track data sheet

\begin{tabular}{|c|c|c|c|c|c|c|c|c|c|}
\hline RESULTS & & & & & & & & & \\
\hline $\mathrm{n}$ & $\mathrm{H}$ & Period(min) & $\mathrm{I}$ & $\Delta \phi$ & $\mathrm{n} / \mathrm{m}$ & $\mathrm{j}$ & $\mathrm{k} / \mathrm{m}$ & $\mathrm{k}$ & $\mathrm{Sw}(\mathrm{km})$ \\
\hline 77 & 446.136 & 93.50709 & 97.1990 & 0.40800 & 15.4 & 15 & 0.4 & 2 & 450.730 \\
76 & 505.867 & 94.73745 & 97.4232 & 0.41337 & 15.2 & 15 & 0.2 & 1 & 456.660 \\
75 & 566.923 & 96.00062 & 97.6576 & 0.41888 & 15 & 15 & 0 & 0 & 2313.74 \\
74 & 629.352 & 97.29792 & 97.9028 & 0.42454 & 14.8 & 14 & 0.8 & 4 & 469.003 \\
73 & 693.202 & 98.63077 & 98.1594 & 0.43035 & 14.6 & 14 & 0.6 & 3 & 475.427 \\
72 & 758.526 & 100.0006 & 98.4282 & 0.43633 & 14.4 & 14 & 0.4 & 2 & 482.030 \\
71 & 825.381 & 101.4091 & 98.7099 & 0.44248 & 14.2 & 14 & 0.2 & 1 & 488.820 \\
\hline
\end{tabular}


Hence, Inclination and altitude can be determined as stated above, by using the sun-synchronous repeating ground trace condition. This procedure is repeated for 5-20 days for a set of altitude ranging from $500-5000 \mathrm{kms}$. The entire data is simulated and a ground trace is plotted as shown in figure 5.1.

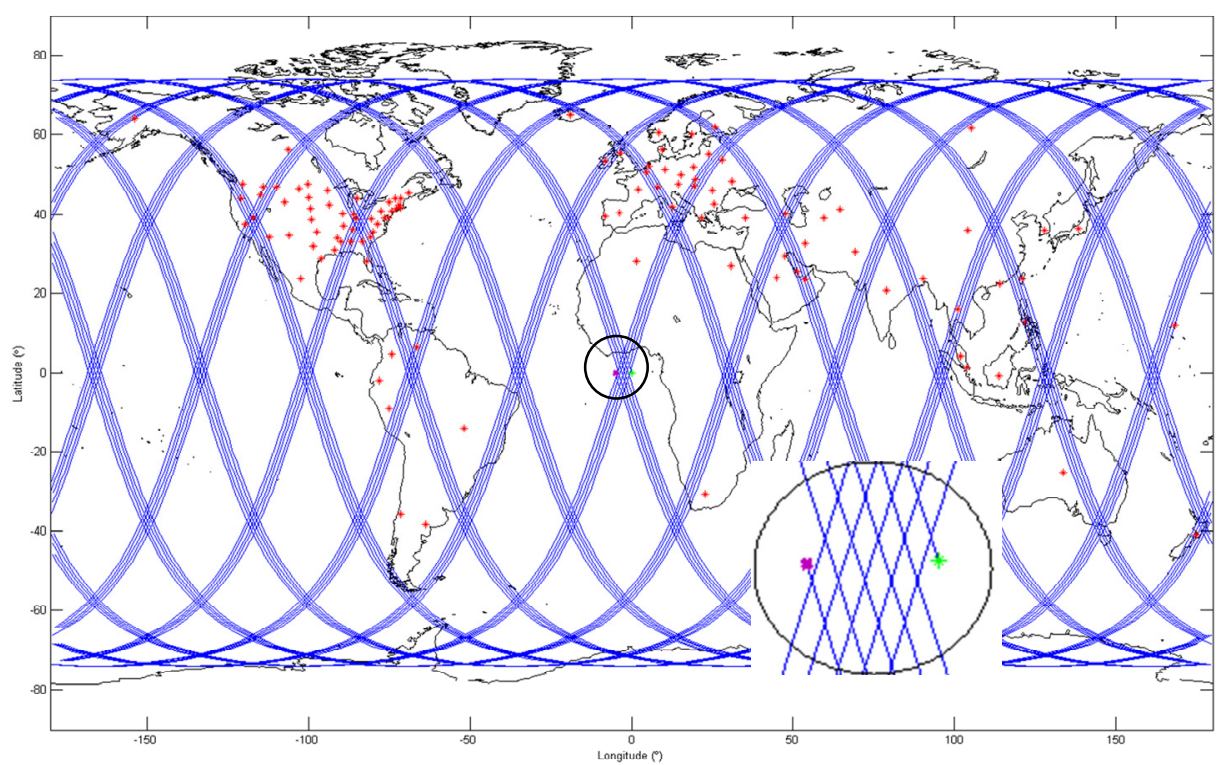

Figure 5.1 Ground trace for 5 days sun synchronous repeating orbit

The above figure 5.1 represents the ground trace on earth map the red dots are the ground stations selected based on the data mentioned in chapter 4. On close observation I found error in the plot as shown within the circle in figure 5.1. As the plot is according to repeated ground trace the trace is expected to come back to the same initial position.

In the circle the green dot is the starting and the red dot is the ending point of the trace. Then After a series of checking my data and the code, I asked Dr.Ossama my advisor and he stated that this is because of perturbations. Hence I tried to correct it by using the perturbation formulae's stated in chapter 2. Once the corrections were done the track was looking better but still had an error of tolerance 0.0001 degrees. The corrected plot is shown in figure 5.2

The same plot is shown but which includes the perturbation calculations. The circle is zoomed to the side for clarity. The green dot and the red dot are almost coinciding indicating that the track is now a repeated track for a period of 5 days. Hence finally after figuring this formulae's out in 45 days, I further carried on with the simulations. The initial several days though I knew that there was a problem with perturbations I would not get the answers because of typo mistake in the reference where I took the formulae's from. After my repeating effort of another few days, I could finally succeed with the calculations of repeated sun-synchronizing orbit. 


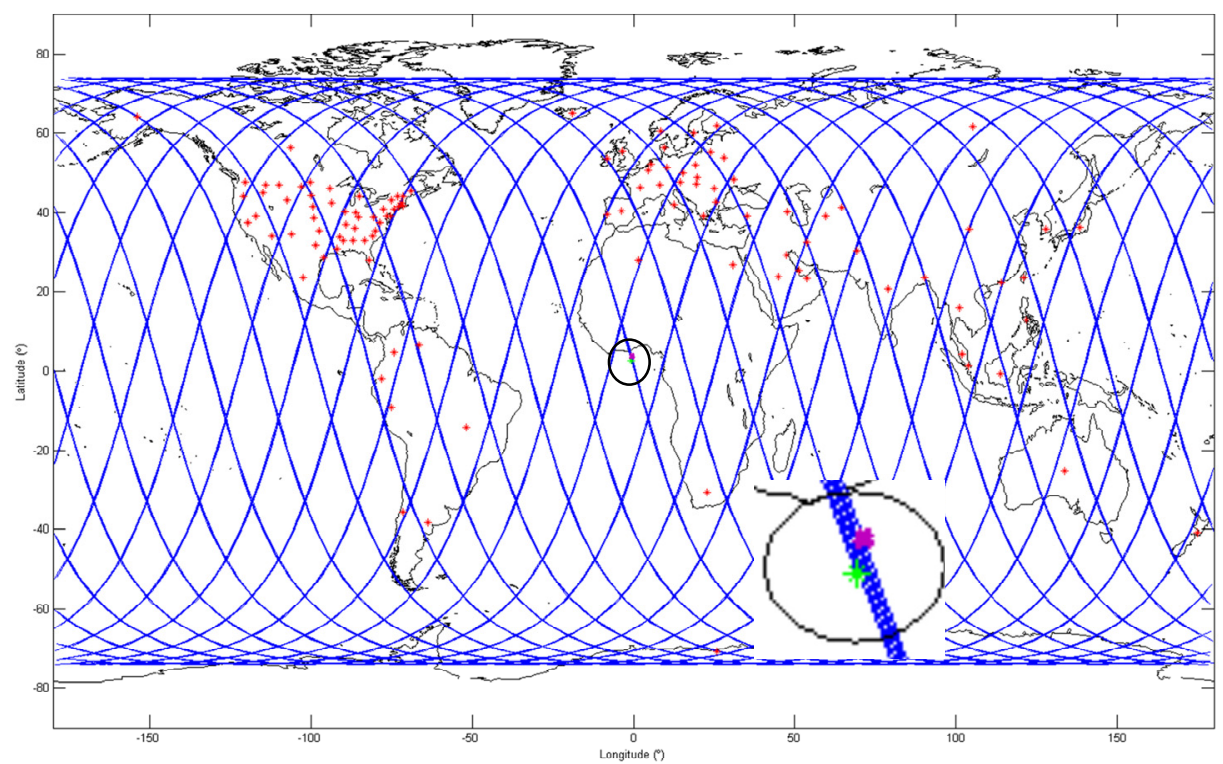

Figure 5.2 Ground trace for 5 days sun synchronous repeating orbit with perturbations

After correcting the perturbation[26] values, I continued with the simulations for each set orbit elements. There were more than 15,000 sets to simulate, as considered 5-20 days repeating period with a permutation of $500 \mathrm{~km}-5000 \mathrm{~km}$ of altitude of the orbit. This took me about 9 days to simulate. After all the simulations are done I tried to calculate the ground track which is closest to the all the 112 ground stations considered. Each ground station is given a number. Here is the list of all the numberings given to the ground stations for the simulations.

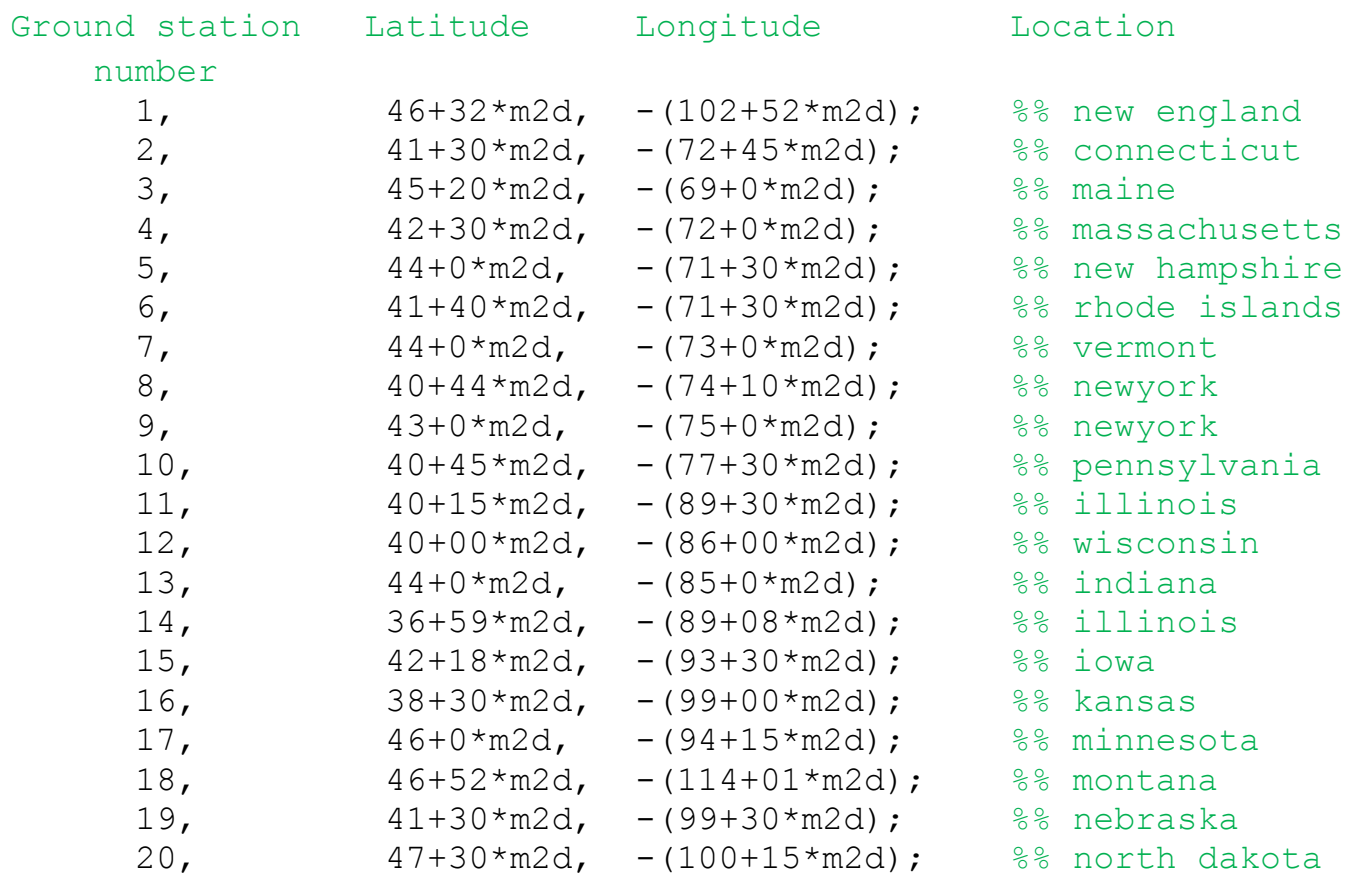




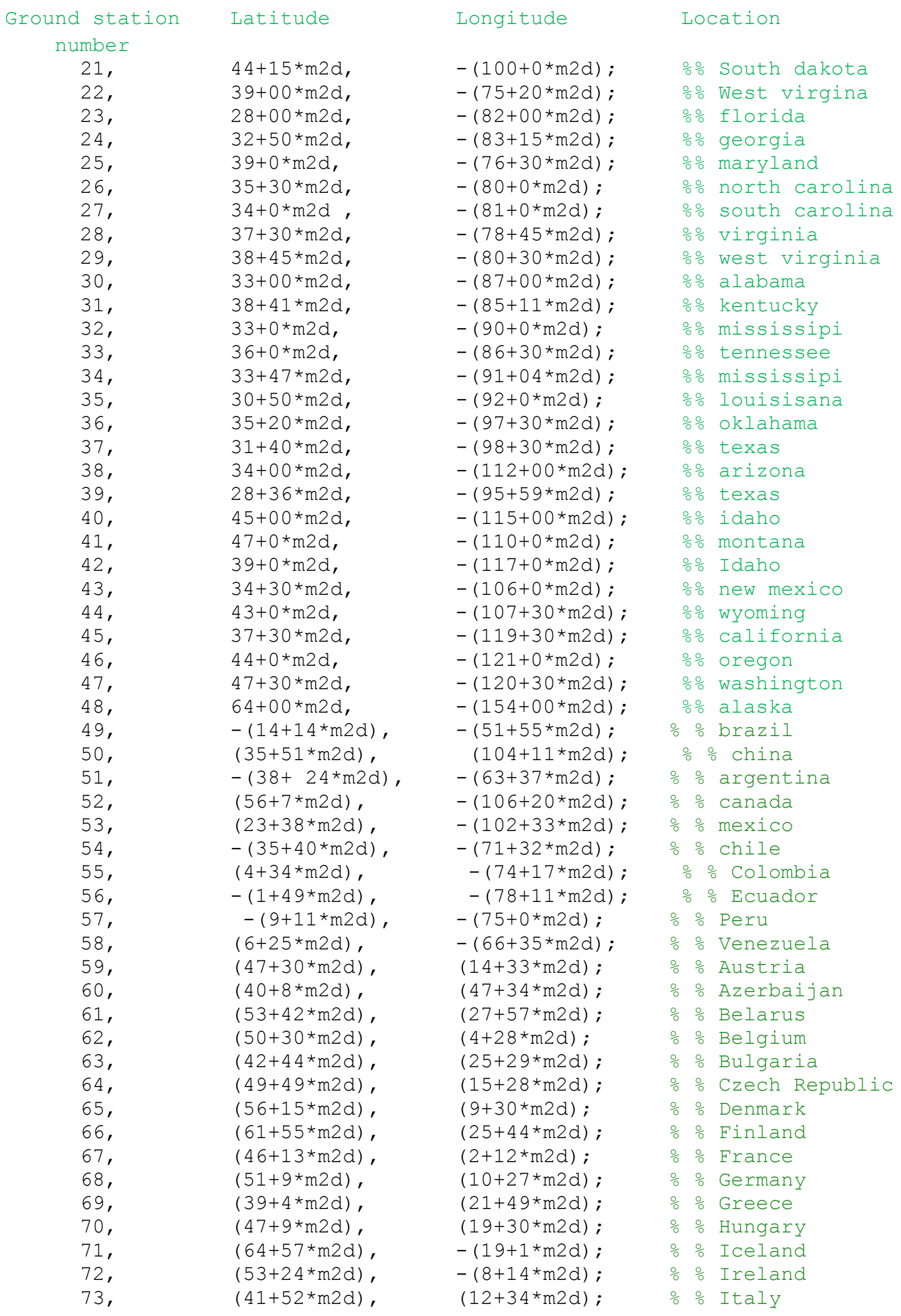




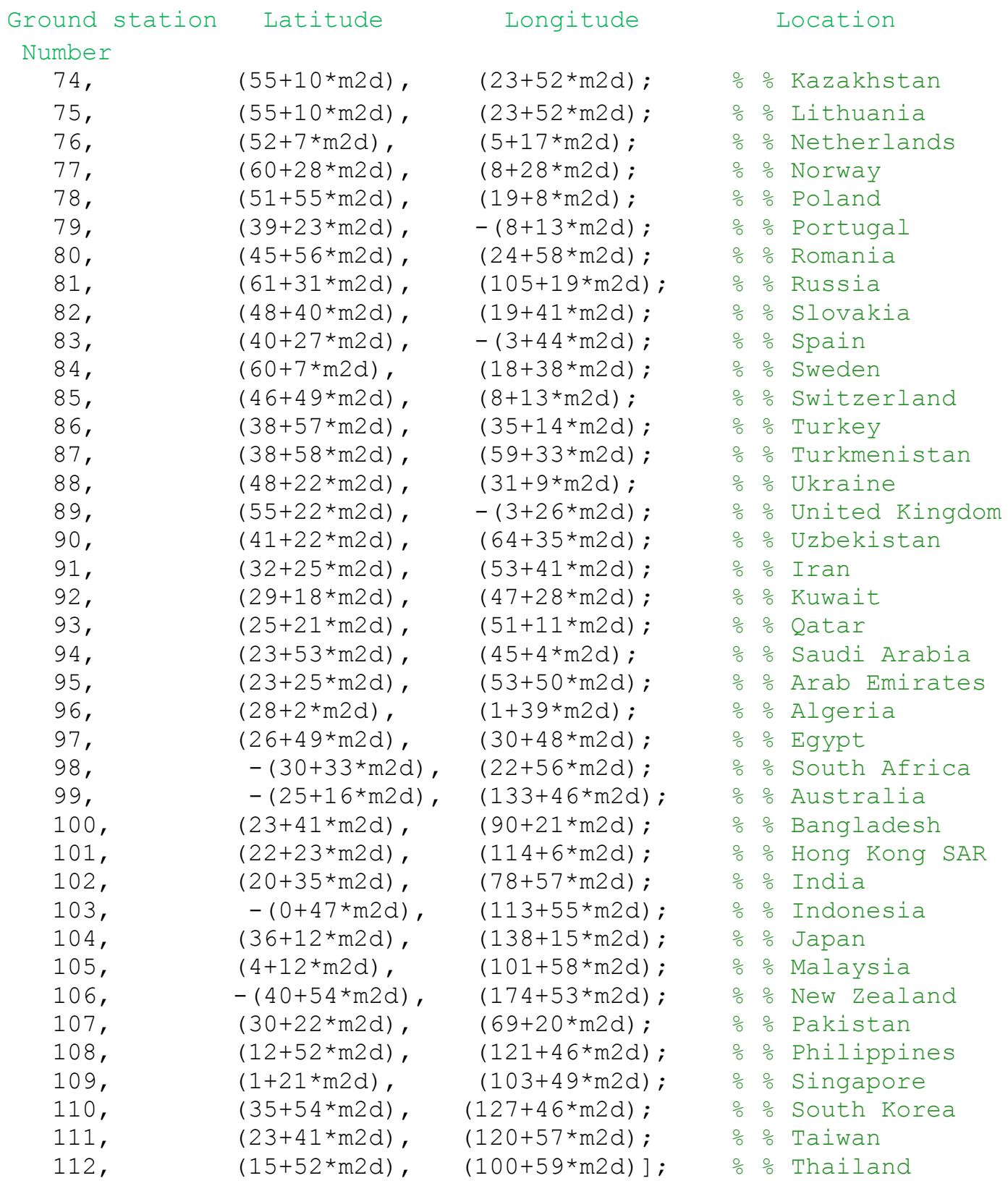

The best way was to assume a range of $50 \mathrm{~km}$ or $100 \mathrm{kms}$ field of view from the trace to the ground station and find the best set, i.e., the ground trace which sees the maximum number of ground stations within the $200 \mathrm{~km}$ range.

\section{Algorithm1}

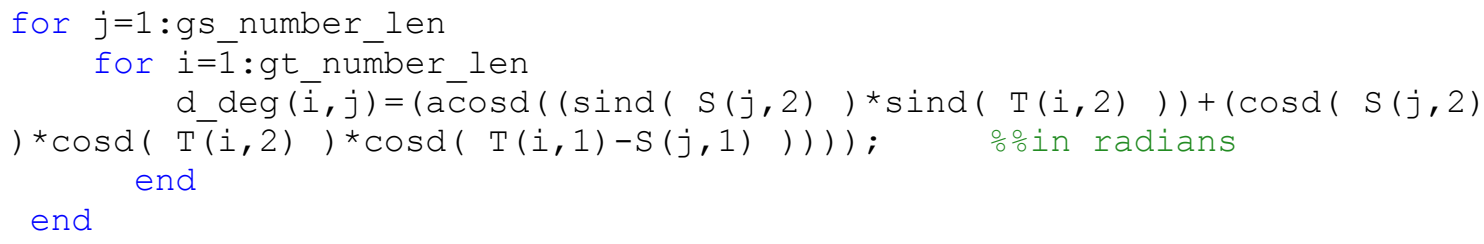


The distance is calculating by using the above algorithm 1 in spherical coordinate system. After simulating all the results for the 15,000 sets of data it was really difficult to select from the huge data. Hence I went to seek Dr. Osama's advice. He asked me to find a way where I can minimize the data. I stopped writing further code and started documenting part of the thesis. One day I was writing the power chapter and then me across a table which stated the power calculations Vs. The altitude previously calculated. Then I realized that as the altitude increases the power downloading capacity decreases. I referred to a paper Dr.Ossama wrote about energy and power along with Dr.Sayed Zekavat a professor at Michigan Technological University in Electrical Engineering department. I previously contacted him because I had a difficulty in calculating the power as stated in the paper. He helped me figure out the table at the end of chapter 4 which stated the variation of power with the altitude of the space craft. Hence I went back to my advisor Dr.Ossama, and discussed the results in the table. Because the space craft's are required to download a $1 \mathrm{GW}$ of power at each ground station is a very important requirement. The altitude was supposed to be around $1000 \mathrm{kms}$. In order to recall the tabular column I am stating the column here again.

Table 5.3

Power downloaded at different Sun synchronous altitudes

\begin{tabular}{|c|c|c|}
\hline $\begin{array}{c}\text { ALTITUDE } \\
\text { (Kms) }\end{array}$ & $\begin{array}{c}\text { INCLINATION } \\
\text { (degrees) }\end{array}$ & POWER in (Watts) \\
\hline 500 & 96.1229 & $1.71 \mathrm{E}+09$ \\
\hline 1000 & 96.5704 & $1.53 \mathrm{E}+09$ \\
\hline 1500 & 97.0182 & $1.55 \mathrm{E}+08$ \\
\hline 2000 & 97.4665 & $5.13 \mathrm{E}+07$ \\
\hline 2500 & 97.9153 & $2.43 \mathrm{E}+07$ \\
\hline 3000 & 98.3645 & $1.38 \mathrm{E}+07$ \\
\hline 3500 & 98.8143 & $8.67 \mathrm{E}+06$ \\
\hline 4000 & 99.2646 & $5.87 \mathrm{E}+06$ \\
\hline 4500 & 99.7155 & $4.18 \mathrm{E}+06$ \\
\hline 5000 & 100.167 & $3.09 \mathrm{E}+06$ \\
\hline 5500 & 100.6191 & $2.36 \mathrm{E}+06$ \\
\hline 6000 & 101.0719 & $1.85 \mathrm{E}+06$ \\
\hline 6500 & 101.5254 & $1.48 \mathrm{E}+06$ \\
\hline 7000 & 101.9796 & $1.20 \mathrm{E}+06$ \\
\hline 7500 & 102.4347 & $9.90 \mathrm{E}+05$ \\
\hline 8000 & 102.8905 & $8.26 \mathrm{E}+05$ \\
\hline 8500 & 103.3471 & $6.97 \mathrm{E}+05$ \\
\hline 9000 & 103.8046 & $5.95 \mathrm{E}+05$ \\
\hline 9500 & 104.263 & $5.11 \mathrm{E}+05$ \\
\hline 10000 & 104.7223 & $4.43 \mathrm{E}+05$ \\
\hline
\end{tabular}

In the table 5.3 the most prominent altitude and power are highlighted. Hence it is better to have an altitude range of $900 \mathrm{kms}-1500 \mathrm{kms}$. Hence I went back to my previous 
excel data sheet and collected data for 5-20 days but with an altitude ranging $800 \mathrm{kms}-$ $1500 \mathrm{kms}$.

I took this data and simulated the values in Matlab. The file gives the values of

(1) number of orbits to be repeated in the repeated time frame

(2) the altitude in $\mathrm{km}$

(3) Orbit period for one revolution \&

(4) Orbit inclination

An example of the data selected for simulation performed in Matlab for 15 days repeated period is shown as follows. This data is selected from the excel sheet discussed in table 5.1 and table 5.2. The data is arranged in a matrix form to make it easy for further calculations in Matlab.

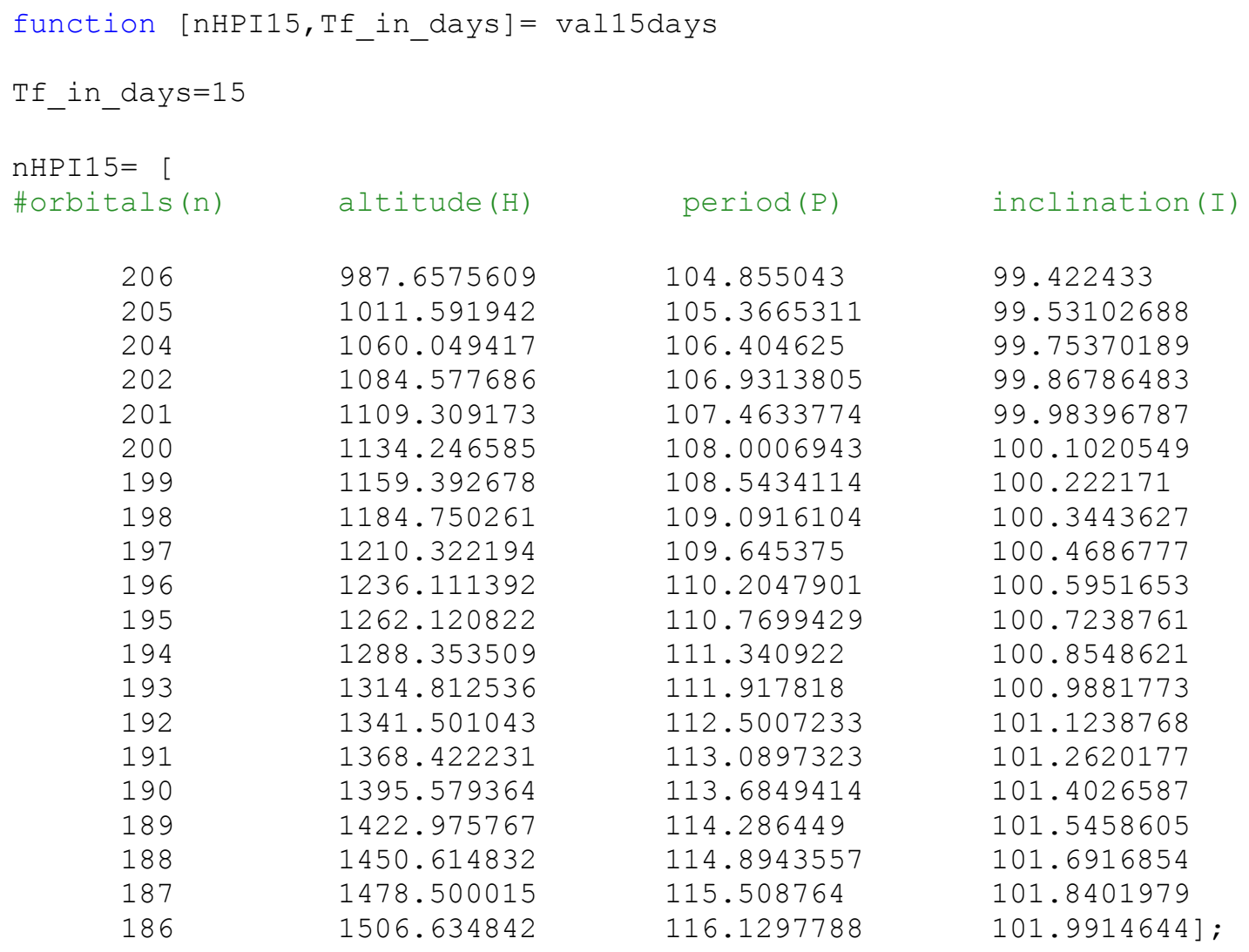

After the collection of all such data within a range of 5-20 repetition days and $500-1500 \mathrm{kms}$ altitude the distances between the track and the ground stations are recalculated by using the following formulae with the algorithm 1.

\section{Distance in degrees:}

$$
\begin{aligned}
& \text { disance (degress) } \\
& \qquad \begin{array}{l}
\quad=\cos ^{-1}\left(\sin \left(\text { Long }_{g s}\right) * \sin \left(\text { Long }_{g t}\right)\right. \\
\left.\quad+\cos \left(\text { Long }_{g s}\right) * \cos \left(\text { Long }_{g t}\right) * \cos \left(\text { Lat }_{g t}-\text { Lat }_{g t}\right)\right)
\end{array}
\end{aligned}
$$




\section{Distance in Kilometers:}

$$
\text { disance }(\text { Kilometers })=6378.14 * \text { disance }(\text { degress })
$$

Once all the distances are calculated the nearest distances range is fixed and then simulations are performed to find the maximum number of ground stations each ground track visits during the entire period of simulation (i.e., repeated period) within the specified range.

Here is an example of the nearest distances calculated for each ground station with the range of $200 \mathrm{kms}$ from the ground track.

$\begin{array}{lcc}\begin{array}{l}\text { nearest_distance_matrix }= \\ \text { \#distance }(\mathrm{kms})\end{array} & \begin{array}{c}\text { Ground station } \\ \text { numbers }\end{array} & \text { distance(radians) } \\ {[1.135277 \mathrm{e}+002} & 1 & 0.345183 \\ 1.135277 \mathrm{e}+002 & 2 & 0.494852 \\ 1.135277 \mathrm{e}+002 & 4 & 0.187048 \\ 1.135277 \mathrm{e}+002 & 4 & 0.081050 \\ 1.135277 \mathrm{e}+002 & 6 & 0.300408 \\ 1.135277 \mathrm{e}+002 & 7 & 0.272820 \\ 1.135277 \mathrm{e}+002 & 7 & 0.363268 \\ 1.135277 \mathrm{e}+002 & 7 & 0.379540 \\ 1.135277 \mathrm{e}+002 & 8 & 0.285095 \\ 1.135277 \mathrm{e}+002 & 8 & 0.316694 \\ 1.135277 \mathrm{e}+002 & 107 & 0.274645 \\ 1.135277 \mathrm{e}+002 & 108 & 0.403612 \\ 1.135277 \mathrm{e}+002 & 109 & 0.441192 \\ 1.135277 \mathrm{e}+002 & 109 & 0.304971 \\ 1.135277 \mathrm{e}+002 & 112 & 0.318963 \\ 1.135277 \mathrm{e}+002 & 112 & 0.198604]\end{array}$

All the ground stations which are visited by the ground track are tabulated as shown in above example. In this example we can observe that a ground station is visited more than once.

Hence, in order to count the number of ground stations visited during the period we use the following model.

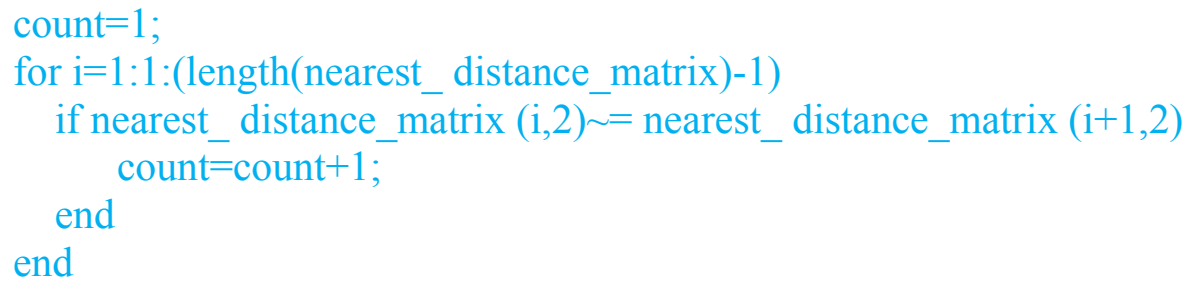

So this will give the total number of ground stations visited without repetition. 
Once all the results are plotted a data sheet is prepared to find the maximum visits in each set as shown in table 5.4

Table 5.4

Results for the complete set of ground tracks

\begin{tabular}{|c|c|c|c|c|c|c|c|c|c|c|c|c|c|c|c|c|c|}
\hline \multicolumn{18}{|c|}{ Number Of Days For The Orbit To Repeat } \\
\hline \multirow{10}{*}{ 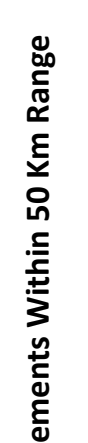 } & & 5 & 6 & 7 & 8 & 9 & 10 & 11 & 12 & 13 & 14 & 15 & 16 & 17 & 18 & 19 & 20 \\
\hline & 1 & 36 & 41 & 45 & 34 & 53 & 48 & 44 & 44 & 65 & 67 & 67 & 49 & 52 & 65 & 68 & 53 \\
\hline & 2 & 38 & 33 & 38 & 41 & 43 & 49 & 59 & 59 & 51 & 59 & 58 & 70 & 72 & 68 & 55 & 70 \\
\hline & 3 & 39 & 22 & 47 & 25 & 47 & 52 & 55 & 55 & 53 & 52 & 60 & 55 & 58 & 60 & 71 & 75 \\
\hline & 4 & 32 & 38 & 51 & 45 & 42 & 26 & 59 & 59 & 58 & 61 & 68 & 69 & 70 & 53 & 54 & 73 \\
\hline & 5 & 25 & 40 & 43 & 32 & 50 & 53 & 51 & 51 & 64 & 54 & 51 & 30 & 33 & 36 & 67 & 53 \\
\hline & 6 & 29 & 26 & 45 & 46 & 59 & 50 & 56 & 56 & 57 & 66 & 67 & 66 & 67 & 58 & 70 & 37 \\
\hline & 7 & 37 & 42 & 28 & 28 & 48 & 48 & 54 & 54 & 62 & 28 & 62 & 69 & 69 & 69 & 69 & 65 \\
\hline & 8 & 32 & 39 & 42 & 48 & 29 & 46 & 51 & 51 & 49 & 68 & 57 & 63 & 66 & 67 & 64 & 70 \\
\hline & 9 & & & 42 & 48 & 29 & 46 & 51 & 51 & 49 & 68 & 57 & 63 & 66 & 67 & 1 & 70 \\
\hline$\frac{10}{5}$ & 10 & & & 42 & 48 & 29 & 46 & 51 & 51 & 49 & 68 & 57 & 63 & 66 & 67 & 64 & 70 \\
\hline 훙 & 11 & & & 43 & 34 & 47 & 44 & 49 & 49 & 32 & 45 & 63 & 65 & 65 & 69 & 74 & 54 \\
\hline c & 12 & & & 48 & 42 & 52 & 49 & 56 & 56 & 51 & 61 & 36 & 72 & 72 & 56 & 77 & 71 \\
\hline 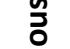 & 13 & & & & & 48 & 50 & 52 & 52 & 61 & 68 & 43 & 37 & 39 & 72 & 80 & 75 \\
\hline 赔 & 14 & & & & & 46 & 38 & 54 & 54 & 57 & 33 & 63 & 69 & 71 & 40 & 75 & 63 \\
\hline 工 & 15 & & & & & & 50 & 54 & 54 & 49 & 60 & 54 & 69 & 73 & 72 & 41 & 75 \\
\hline 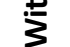 & 16 & & & & & & & 52 & 52 & 73 & 61 & 72 & 57 & 60 & 73 & 67 & 44 \\
\hline $\bar{c}$ & 17 & & & & & & & 56 & 56 & 59 & 56 & 62 & 50 & 51 & 78 & 79 & 79 \\
\hline o & 18 & & & & & & & & & 56 & 54 & 60 & 65 & 65 & 55 & 67 & 67 \\
\hline$\frac{\pi}{5}$ & 19 & & & & & & & & & 56 & 50 & 61 & 67 & 71 & 64 & 72 & 76 \\
\hline$\frac{E}{n}$ & 20 & & & & & & & & & & 56 & 57 & 71 & 75 & 68 & 55 & 62 \\
\hline$\stackrel{\nu}{ }$ & 21 & & & & & & & & & & 40 & 63 & 44 & 46 & 66 & 81 & 57 \\
\hline 7 & 22 & & & & & & & & & & & & 63 & 66 & 77 & 67 & 66 \\
\hline 운 & 23 & & & & & & & & & & & & 66 & 69 & 48 & 70 & 65 \\
\hline ฆ & 24 & & & & & & & & & & & & & & 63 & 71 & 69 \\
\hline$\xi$ & 25 & & & & & & & & & & & & & & 67 & 80 & 73 \\
\hline - & 26 & & & & & & & & & & & & & & & 72 & 53 \\
\hline \% & 27 & & & & & & & & & & & & & & & 61 & 71 \\
\hline & 28 & & & & & & & & & & & & & & & & 71 \\
\hline
\end{tabular}

Table 5.4 shows the maximum number of ground stations visited in corresponding repeating period of time. The best results are marked with red in the table. These values are listed separately in a different table along with the orbital values instead of the trial number from the matrix.

From the table 5.5 the best match is highlighted with green and the worst match with red. The best result says that for 19 days repeating period the ground trace sees a maximum number of 81 ground stations. Hence the best result calculated so far is shown as follows. Also Figure 5.3 is the plot for the best orbital elements.

$$
\{\mathbf{a}, \mathbf{e}, \mathbf{i}, \omega, \Omega, \boldsymbol{\theta}\}=\left\{\mathbf{R}_{\mathrm{E}}+1388.4,0,113.5^{0}, 0^{0}, 0^{0}, 0^{0} \text { to } 360^{0}\right\}
$$


Table 5.5

Data sheet for orbital elements selection

\begin{tabular}{|c|c|c|c|c|c|}
\hline $\begin{array}{c}\text { Repeating } \\
\text { Period } \\
\text { (days) }\end{array}$ & $\begin{array}{c}\text { Maximum } \\
\text { number Of } \\
\text { Ground Stations } \\
\text { Visited }\end{array}$ & $\begin{array}{c}\text { Total Number Of } \\
\text { Orbits During The } \\
\text { Repeated Period Of } \\
\text { Time }\end{array}$ & $\begin{array}{c}\text { Altitude } \\
(\mathrm{Km})\end{array}$ & $\begin{array}{c}\text { Inclination } \\
\text { (Degrees) }\end{array}$ & $\begin{array}{c}\text { Orbital } \\
\text { Period } \\
\text { (Minutes) }\end{array}$ \\
\hline 20 & 79 & 259 & 1281.8 & 111.2 & 100.8 \\
\hline $\mathbf{1 9}$ & $\mathbf{8 1}$ & $\mathbf{2 4 1}$ & $\mathbf{1 3 8 8 . 4}$ & $\mathbf{1 1 3 . 5}$ & $\mathbf{1 0 1 . 4}$ \\
\hline 18 & 78 & 231 & 1328.1 & 112.2 & 101.1 \\
\hline 17 & 75 & 201 & 1438.5 & 114.6 & 101.6 \\
\hline 16 & 72 & 195 & 1262.1 & 110.8 & 100.7 \\
\hline 15 & 72 & 191 & 1368.4 & 113.1 & 101.3 \\
\hline 14 & 68 & 188 & 1098.7 & 107.2 & 99.9 \\
\hline 13 & 73 & 164 & 1416.6 & 114.1 & 101.5 \\
\hline 12 & 59 & 162 & 1072.3 & 106.7 & 99.8 \\
\hline 12 & 59 & 164 & 1011.6 & 105.4 & 99.5 \\
\hline 11 & 59 & 151 & 989.82 & 104.901 & 99.4322 \\
\hline 11 & 59 & 149 & 1055.6 & 106.3 & 99.7 \\
\hline 10 & 53 & 134 & 1109.3 & 107.5 & 100 \\
\hline 9 & 59 & 119 & 1176.3 & 108.9 & 100.3 \\
\hline 8 & 48 & 103 & 1311.5 & 111.8 & 101 \\
\hline 7 & 51 & 94 & 1098.7 & 107.2 & 99.9 \\
\hline 6 & 42 & 77 & 1328.1 & 112.2 & 101.1 \\
\hline $\mathbf{5}$ & $\mathbf{3 9}$ & $\mathbf{6 7}$ & $\mathbf{1 1 0 9 . 3}$ & $\mathbf{1 0 7 . 5}$ & $\mathbf{1 0 0}$ \\
\hline
\end{tabular}

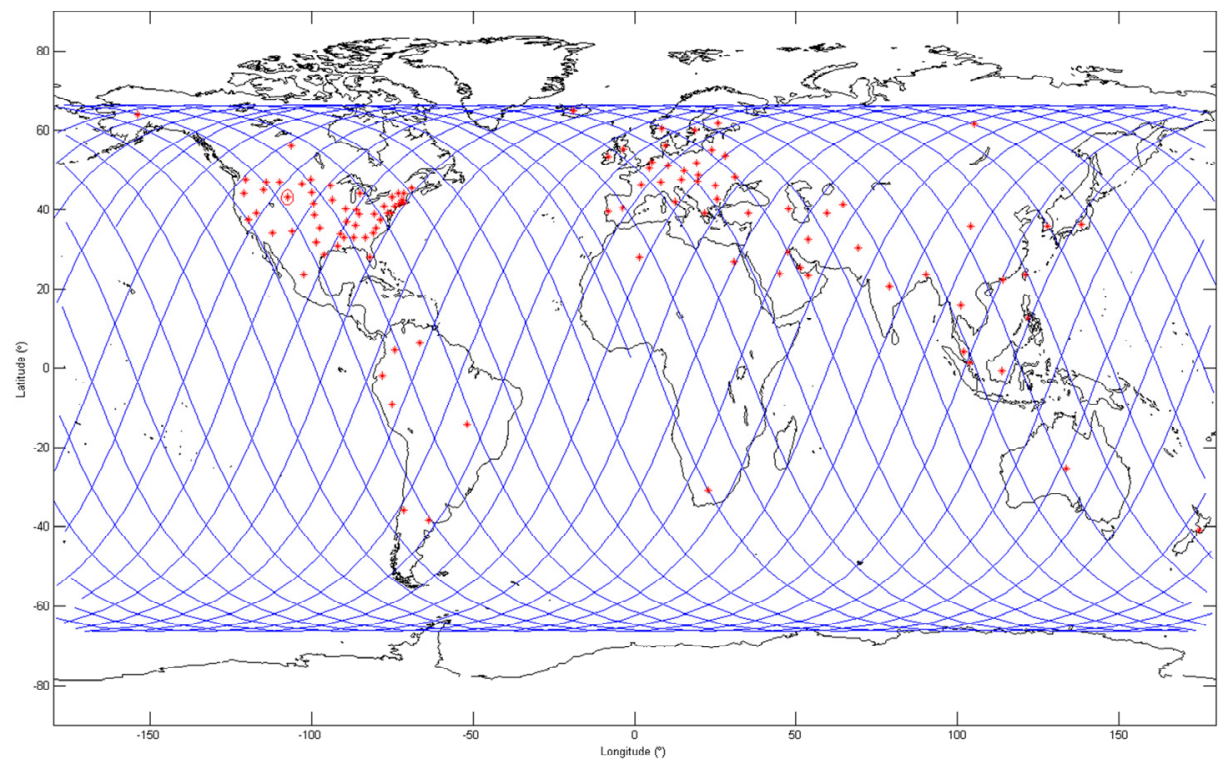

Figure 5.3 Ground trace for 19 days visiting maximum number of Ground stations 


\subsection{Selection of the second orbit}

To calculate the values, the orbit 2 should see all those ground stations which are unvisited by ground track 1 . Hence all such ground stations data is collected which are not visited during the orbit 1 and then the best orbit solution is determined. Here is a list of all the ground stations which are not visited during the Orbit 1.

\begin{tabular}{|c|c|c|c|c|}
\hline $\begin{array}{c}\text { Ground station } \\
\text { number }\end{array}$ & Latitude & Longitude & & Location \\
\hline 44, & $39+0 * m 2 d$ & $-(117+0 * m 2 d)$ & $\circ$ & ․ Wyoming, USA \\
\hline 47, & $43+0 * \mathrm{~m} 2 \mathrm{~d}$ & $-(107+30 * \mathrm{~m} 2 \mathrm{~d})$ & $\%$ & \% NewMexico, USA \\
\hline 56, & $(23+38 * m 2 d)$ & $-(102+33 * \mathrm{~m} 2 \mathrm{~d}) ;$ & $\%$ & \% Mexico \\
\hline 61, & $(6+25 * m 2 d)$ & $-(66+35 * \mathrm{~m} 2 \mathrm{~d}) ;$ & 응 & Venezuela \\
\hline 62, & $(47+30 * \mathrm{~m} 2 \mathrm{~d})$ & $(14+33 * \mathrm{~m} 2 \mathrm{~d})$ & $\frac{\circ}{0}$ & ㅇ Austria \\
\hline 63, & $(40+8 * m 2 d)$ & $(47+34 * m 2 d) ;$ & 응 & ㅇ Azerbaijan \\
\hline 65, & $(50+30 * \mathrm{~m} 2 \mathrm{~d})$ & $(4+28 * m 2 d) ;$ & 응 & \% Belgium \\
\hline 66, & $(42+44 * m 2 d)$ & $(25+29 * m 2 d) ;$ & $\circ$ & Bulgaria \\
\hline 67, & $(49+49 * m 2 d)$ & $(15+28 * m 2 d) ;$ & $\frac{\circ}{0}$ & \% Czech Republic \\
\hline 69, & $(61+55 * m 2 d)$ & $(25+44 * m 2 d) ;$ & 응 & ․ Finland \\
\hline 70 & $(46+13 * m 2 d)$ & $(2+12 * m 2 d) ;$ & 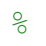 & ․ France \\
\hline 71, & $(51+9 * m 2 d)$ & $(10+27 * \mathrm{~m} 2 \mathrm{~d})$ & $\%$ & \% Germany \\
\hline 72, & $(39+4 * m 2 d)$ & $(21+49 * m 2 d) ;$ & $\%$ & \% Greece \\
\hline 73, & $(47+9 * m 2 d)$ & $(19+30 \star \mathrm{m} 2 \mathrm{~d}) ;$ & $\%$ & \% Hungary \\
\hline 74, & $(64+57 * m 2 d)$ & $-(19+1 \star m 2 d) ;$ & 응 & ㅇ Iceland \\
\hline 75, & $(53+24 * m 2 d)$ & $-(8+14 * m 2 d)$ & $\%$ & \%Ireland \\
\hline 76, & $(41+52 * m 2 d)$ & $(12+34 * m 2 d) ;$ & $\frac{\circ}{0}$ & 응 Italy \\
\hline 79, & $(52+7 * m 2 d)$ & $(5+17 \star m 2 d) ;$ & $\%$ & \% Netherlands \\
\hline 80 & $(60+28 * m 2 d)$ & $(8+28 * m 2 d) ;$ & $\frac{\circ}{0}$ & 응 Norway \\
\hline 82, & $(39+23 * \mathrm{~m} 2 \mathrm{~d})$ & $-(8+13 * m 2 d)$ & $\%$ & \% Portugal \\
\hline 83, & $(45+56 * \mathrm{~m} 2 \mathrm{~d})$ & $(24+58 * \mathrm{~m} 2 \mathrm{~d})$ & 응 & o Romania \\
\hline 88, & $(46+49 * m 2 d)$ & $(8+13 \star m 2 d) ;$ & $\%$ & \% Switzerland \\
\hline 89, & $(38+57 * \mathrm{~m} 2 \mathrm{~d})$ & $\left(35+14{ }^{\star} \mathrm{m} 2 \mathrm{~d}\right) ;$ & $\%$ & 응 Turky \\
\hline 93, & $(41+22 * m 2 d)$ & $(64+35 * \mathrm{~m} 2 \mathrm{~d}) ;$ & $\%$ & Uzbekistan \\
\hline 95, & $(29+18 * m 2 d)$ & $(47+28 * m 2 d) ;$ & 응 & 응 Kuwait \\
\hline 98, & $(23+25 * m 2 d)$ & $(53+50 * \mathrm{~m} 2 \mathrm{~d}) ;$ & $\%$ & \% Arab Emirates \\
\hline 99, & $(28+2 * m 2 d)$ & $(1+39 * m 2 d) ;$ & $\%$ & \% Algeria \\
\hline 101, & $-(30+33 * \mathrm{~m} 2 \mathrm{~d})$ & $(22+56 \star \mathrm{m} 2 \mathrm{~d}) ;$ & $\%$ & \% South Africa \\
\hline 105, & $(20+35 * \mathrm{~m} 2 \mathrm{~d})$ & $(78+57 \star \mathrm{m} 2 \mathrm{~d}) ;$ & $\%$ & \% India \\
\hline 108, & $(4+12 \star m 2 d)$ & $(101+58 * \mathrm{~m} 2 \mathrm{~d})]$; & $\%$ & \% Malaysia \\
\hline
\end{tabular}

Hence are are 31 ground stations which are not visited by the orbit1. So a second orbit is designed such that it sees maximum number of these 31 unseen ground stations.

The orbital elements for the first orbit selected are:

$$
\{\mathbf{a}, \mathbf{e}, \mathbf{i}, \omega, \Omega, \boldsymbol{\theta}\}=\left\{\mathbf{R}_{\mathrm{E}}+1388.4,0,113.5^{0}, 0^{0}, 0^{0}, 0^{0} \text { to } 360^{0}\right\}
$$

All the orbital elements for the second orbit remain same except the RAAN $(\Omega)$. For the initial orbit $\Omega$ was $0^{0}$. To calculate the RAAN $(\Omega)$, for the second orbit the following simulations are performed, by considering the parameter RAAN of covering maximum 
number of ground stations. So approximately the new orbital elements for the second orbit may look like the following:

$$
\{\mathbf{a}, \mathbf{e}, \mathbf{i}, \omega, \Omega, \boldsymbol{\theta}\}=\left\{\mathbf{R}_{\mathbf{E}}+1388.4,0,113.5^{0}, 0^{0}, ?, 0^{0} \text { to } 360^{0}\right\}
$$

To find out the value of $\Omega$, a set of $\Omega$ values are considered

$\Omega=\left\{30^{\circ}, 60^{\circ}, 90^{\circ}, 120^{\circ}, 150^{\circ}, 180^{\circ}, 210^{\circ}, 240^{\circ}, 270^{\circ}, 300^{\circ}, 330^{\circ}, 360^{\circ}\right\}$

For all these values the set of ground stations visited is calculated. Here is an example.

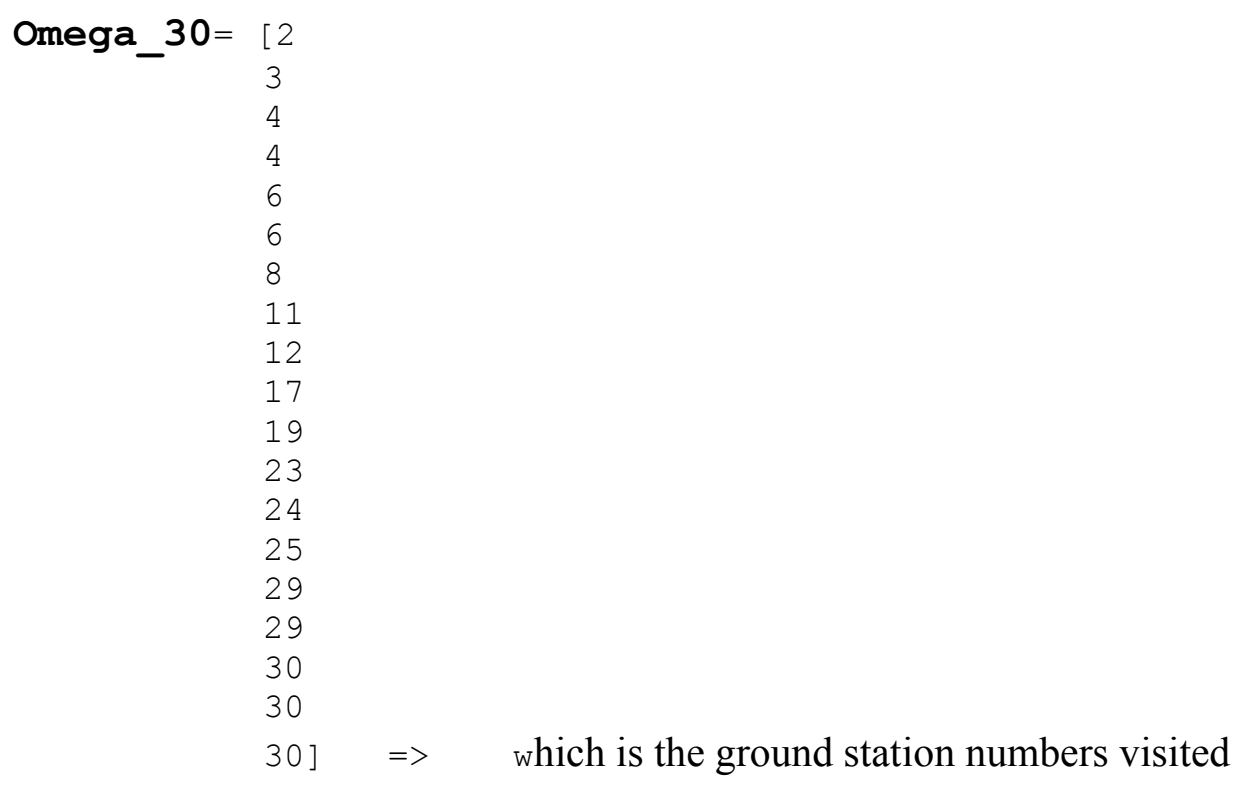

Once all the set of ground stations visited are calculated, then the number of nonrepeating ground station are calculated by using a simple algorithm 2 as follows.

In the above example the total numbers of ground stations visited are 19. Example ground station \#6 and \# 29 has been visited for 2 times but the ground station \# 30, rest of all the stations are visited once. But the total number of non repetition numbers is 14 . Hence we need an algorithm to help count the total number of ground stations visited without repetition. Here is an algorithm 2 which helps count the unrepeated.

\section{$\underline{\text { Algorithm2 }}$}

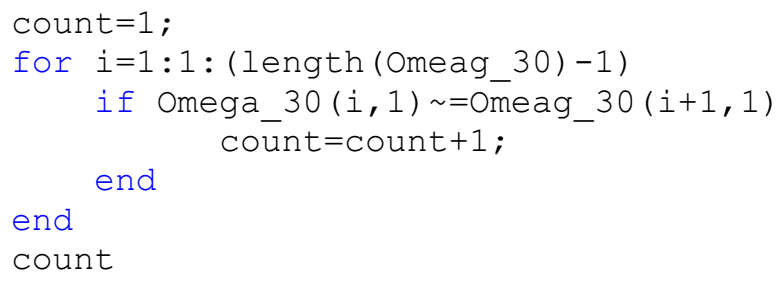


Therefore 14 different ground stations can be visited by the orbit with $\Omega=30^{\circ}$. Similarly for all the $\Omega$ `s the number of ground stations visited without repetition are calculated and tabulated as following.

Table 5.6

Maximum Number of Ground Stations Visited

\begin{tabular}{|c|c|}
\hline RAAN (degrees) & $\begin{array}{c}\text { Max. Number of Ground } \\
\text { Stations visited }\end{array}$ \\
\hline 30 & 14 \\
\hline 60 & 16 \\
\hline 90 & 16 \\
\hline 120 & 12 \\
\hline 150 & 12 \\
\hline 180 & 14 \\
\hline 210 & 12 \\
\hline 240 & 14 \\
\hline 270 & 14 \\
\hline 300 & $\mathbf{1 7}$ \\
\hline 330 & 12 \\
\hline 360 & 14 \\
\hline
\end{tabular}

From the above table, it can be inferred that the maximum number of ground stations visited are 17 by the orbit with $\Omega=300^{\circ}$ which is highlighted.

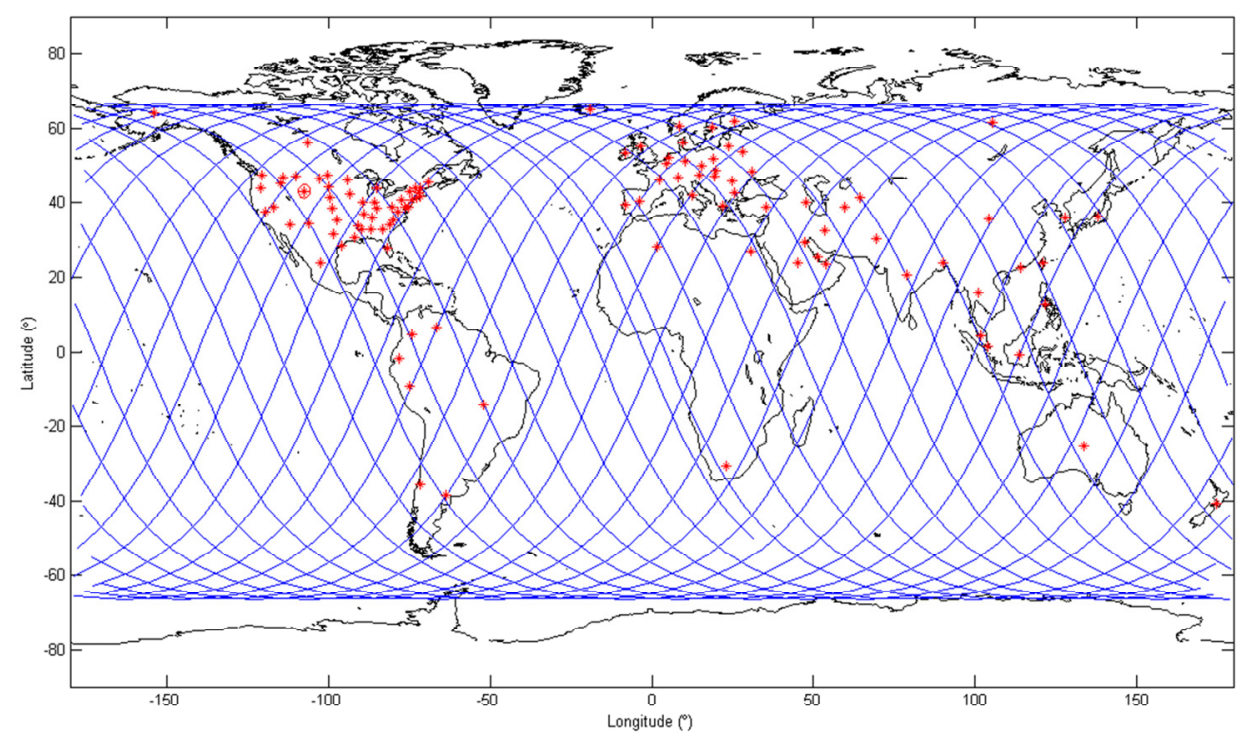

Figure 5.4 Maximum Number of Ground Stations visited 
Figure 5.4 is a ground trace plot of the orbital elements selected

$$
\left\{\mathbf{R}_{\mathrm{E}}+1388.4,0,113.5^{0}, 0^{0}, 300^{0}, 0^{0} \text { to } 360^{0}\right\}
$$

Therefore, the maximum numbers of ground stations visited during the second orbit are from this set of ground stations listed above.

Hence from table 6 and table 4 the final results are:

Table 5.7

Maximum Number of Ground Stations Visited

\begin{tabular}{|c|c|c|}
\hline Orbit \# & $\begin{array}{l}\text { Orbital Elements } \\
\{a, e, i, \omega, \Omega, \theta\}\end{array}$ & $\begin{array}{l}\text { Maximum number of } \\
\text { ground stations visited }\end{array}$ \\
\hline 1 & $\left\{\mathbf{R}_{\mathrm{E}}+\mathbf{1 3 8 8 . 4}, \underset{360^{0}}{\mathbf{0},} \mathbf{1 1 3 . 5}^{0}, 0^{0}, 0^{0}, 0^{0}\right.$ to & 81 \\
\hline 2 & $\begin{array}{l}\left\{\mathbf{R}_{\mathbf{E}}+1388.4,0,113.5^{0}, 0^{0}, 300^{0}, 0^{0} \text { to }\right. \\
\left.360^{0}\right\}\end{array}$ & 75 \\
\hline \multicolumn{2}{|c|}{$\begin{array}{l}\text { Number of common ground stations } \\
\text { covered by both orbit } 1 \& 2\end{array}$} & 58 \\
\hline \multicolumn{2}{|c|}{$\begin{array}{l}\text { Total Number of ground stations covered } \\
\text { by both orbit } 1 \& 2\end{array}$} & 98 \\
\hline
\end{tabular}

Hence out of the 112 ground stations chosen, both the orbit 1 and 2 can visit at least 98 ground stations during the repetition period.

The following sections discusses more about the coverage period of the spacecrafts during the repetition period of 19 days to know about the power downloading capacity at each ground station. 


\subsection{Time of Coverage calculations}

Once the right orbital elements are determined it is important to calculate the coverage time and gap time. The power downloaded per second at a ground station is $1 \mathrm{GW}$. Hence if the total coverage time is calculated this will give us a detailed idea of the total power downloaded at each ground station. It is also important to know when the power is downloaded and the period, for which the ground station cannot download any amount of power, so that the electricity generated in the space y our satellite structure can be saved using a battery and then transmitted it to the ground station. This procedure will make sure that none of the power generated is wasted without collection or downloading ${ }^{[36]}$.

The two orbits selected are:

$$
\begin{gathered}
\left\{R_{\mathrm{E}}+1388.4,0,113.5^{0}, 0^{0}, 0^{0}, 0^{0} \text { to } 360^{0}\right\} \\
\left\{\mathbf{R}_{\mathrm{E}}+1388.4,0,113.5^{0}, 0^{0}, 300^{0}, 0^{0} \text { to } 360^{0}\right\}
\end{gathered}
$$

A ground station is selected to illustrate the Coverage time calculated for the entire period of 19 days in the following sections. The ground station selected here is Illinois (Ground station \# 11).

To calculate the gap time and coverage time the following algorithms are used:

\section{$\underline{\text { Algorithm5 }}$}

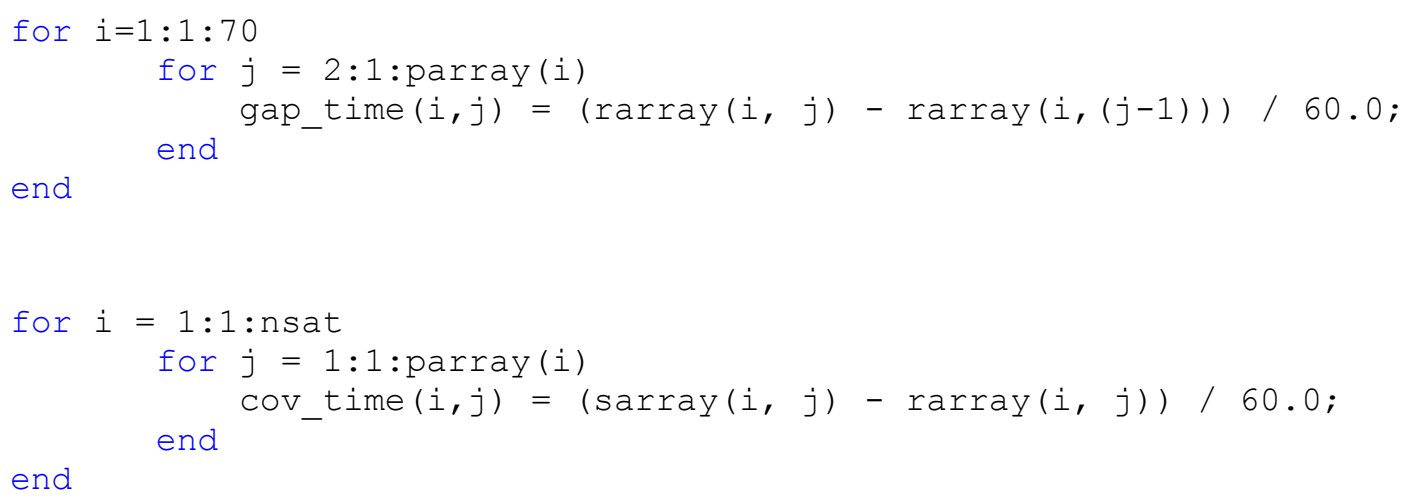

Where, sarray is the set time \&

rarray is the rise time of the spacecraft over a particular ground station

\section{Example:}

The marking represent the time of view of the spacecraft over the selected ground stations. Example here is Illinois. There are 70 spacecrafts in the selected orbit hence the figure 5.5 represents the time at which each spacecraft sees Illinois in minutes 
$\underline{\text { Day1 }}$

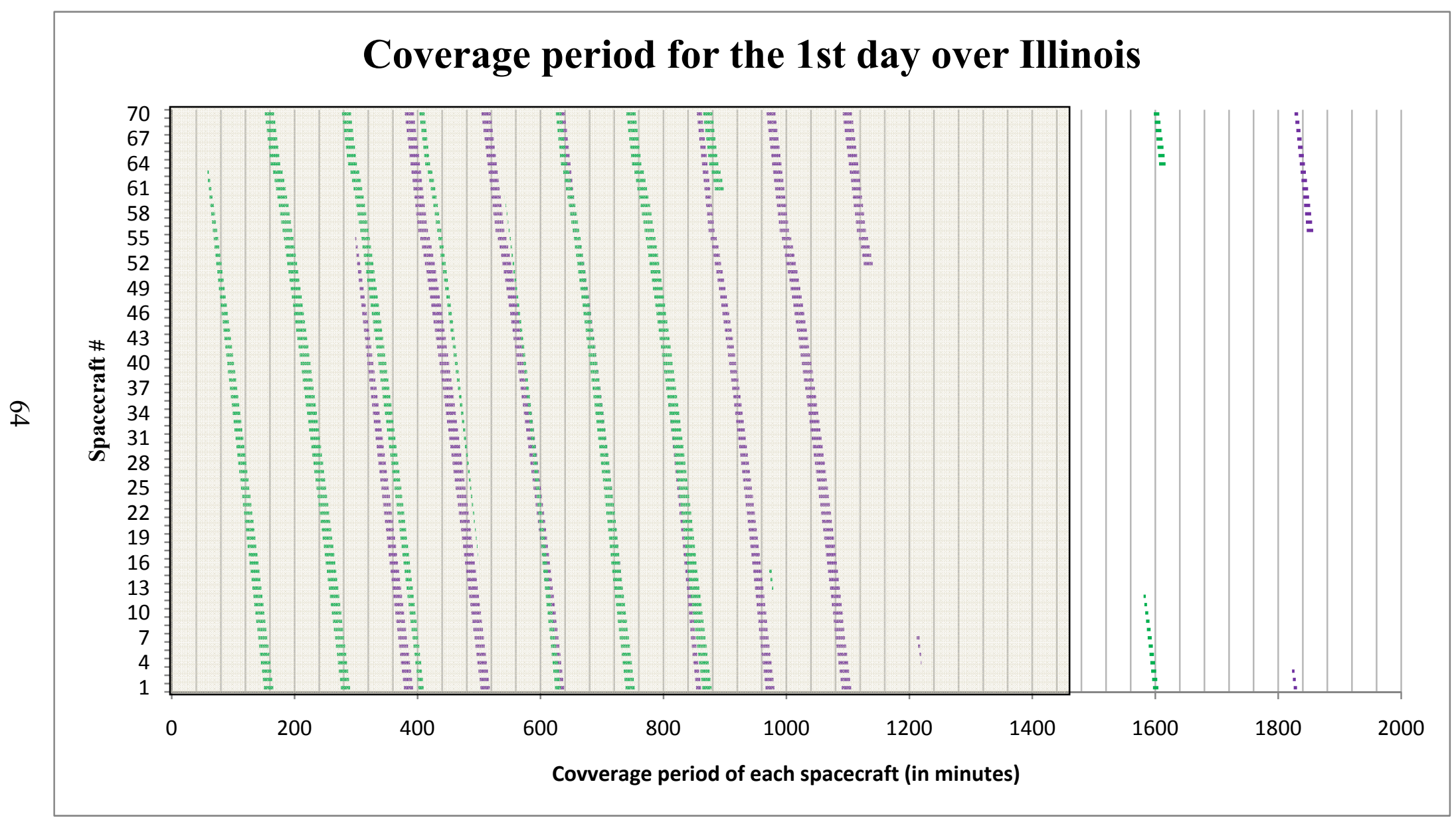

Figure 5.5 Coverage period for the $1^{\text {st }}$ day over Illinois 
Day2

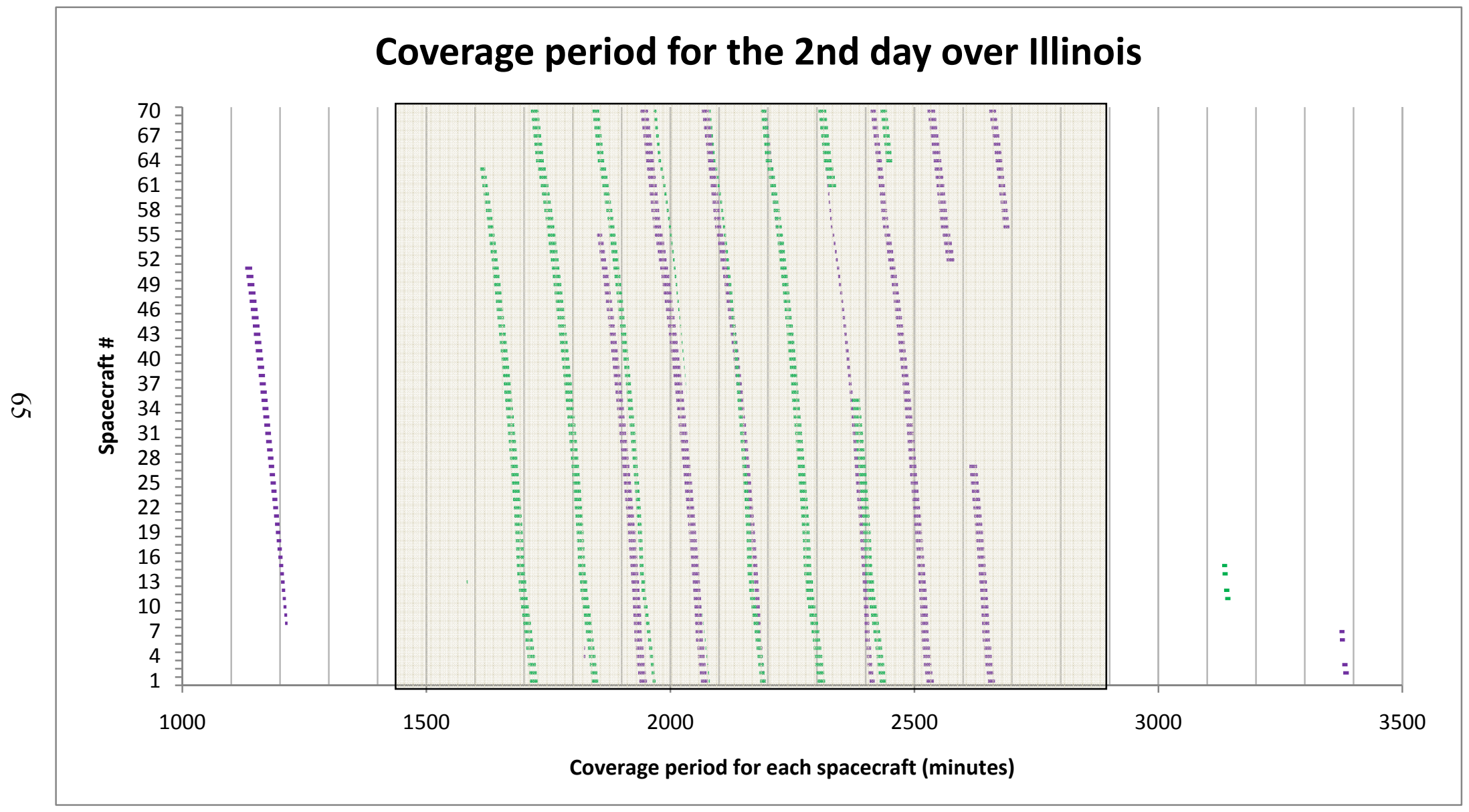

Figure 5.6 Coverage period for the $2^{\text {nd }}$ day over Illinois 
Day 3

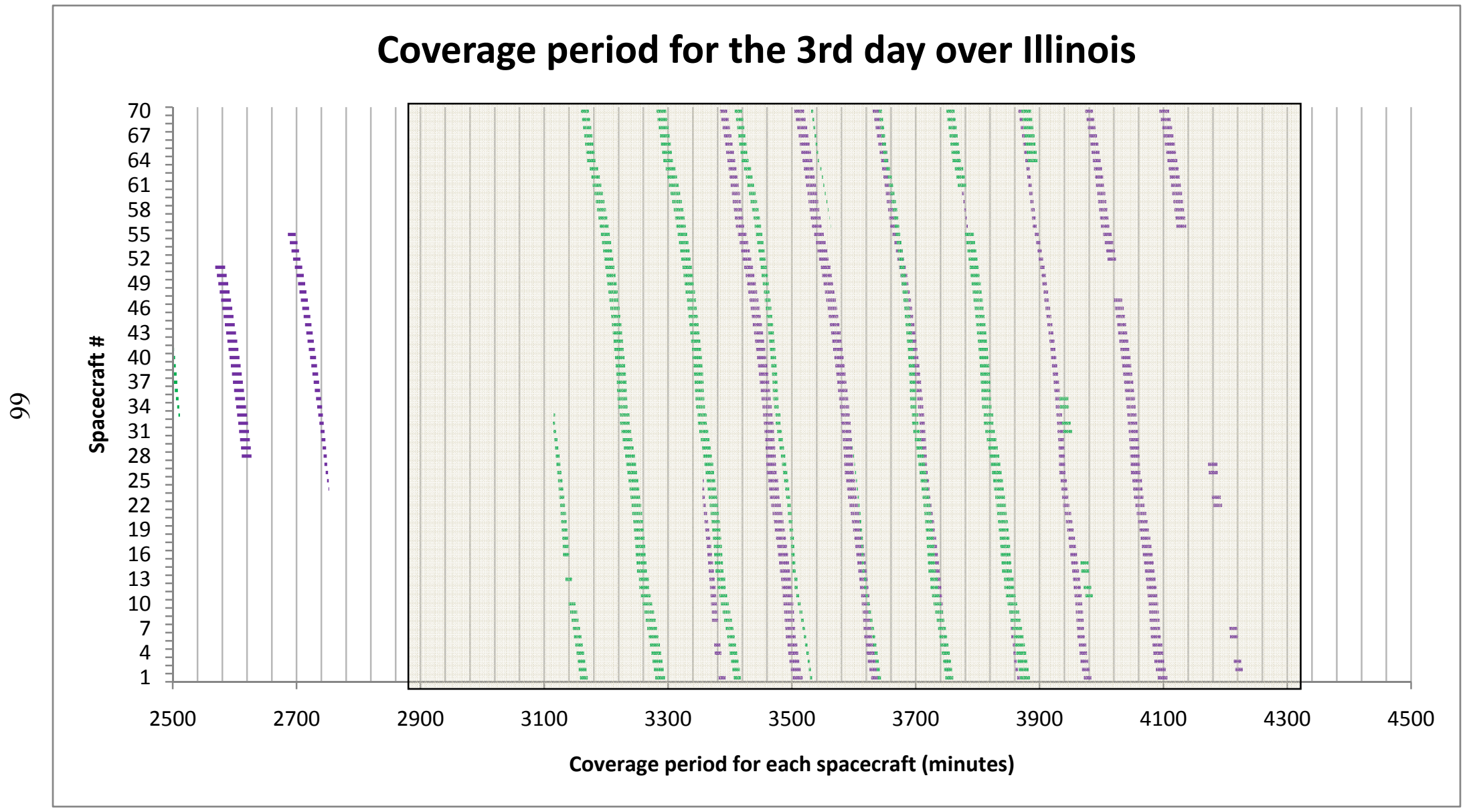

Figure 5.7 Coverage period for the $3^{\text {rd }}$ day over Illinois 
Day 4

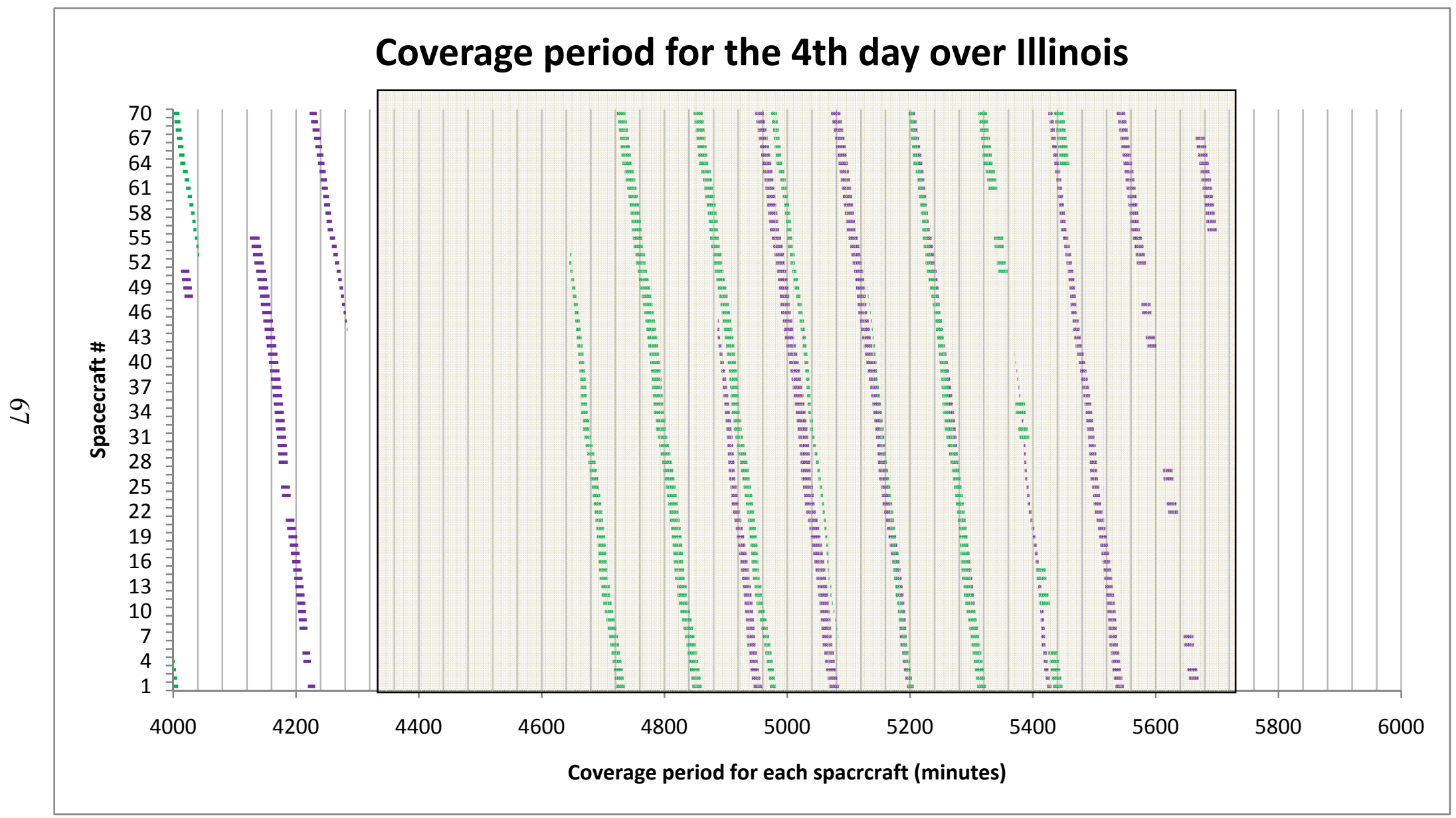

Figure 5.8 Coverage period for the $4^{\text {th }}$ day over Illinois 
Day 5

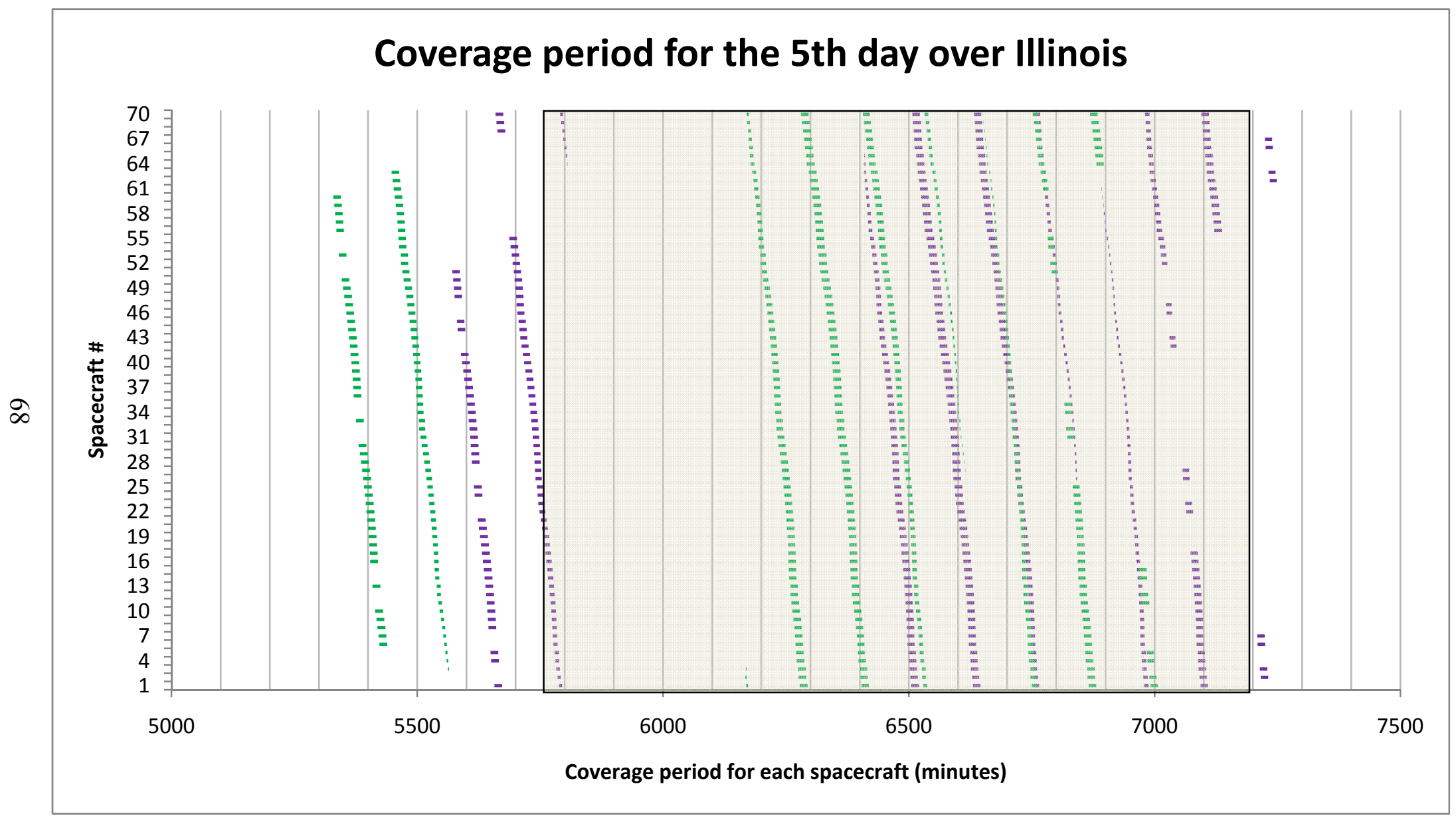

Figure 5.9 Coverage period for the $5^{\text {th }}$ day over Illinois 
Day 6

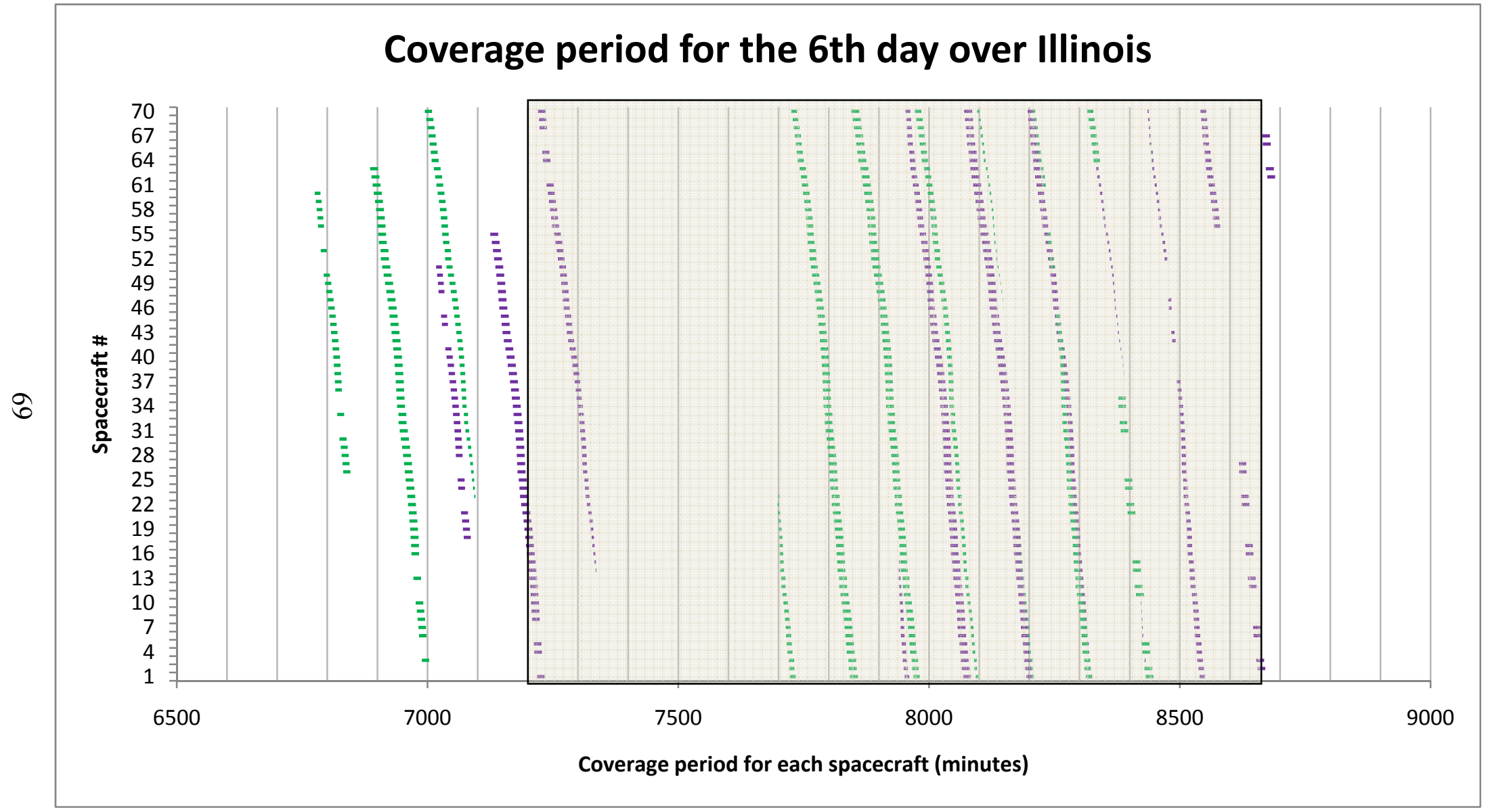

Figure 5.10 Coverage period for the $6^{\text {th }}$ day over Illinois 
$\underline{\text { Day } 7}$

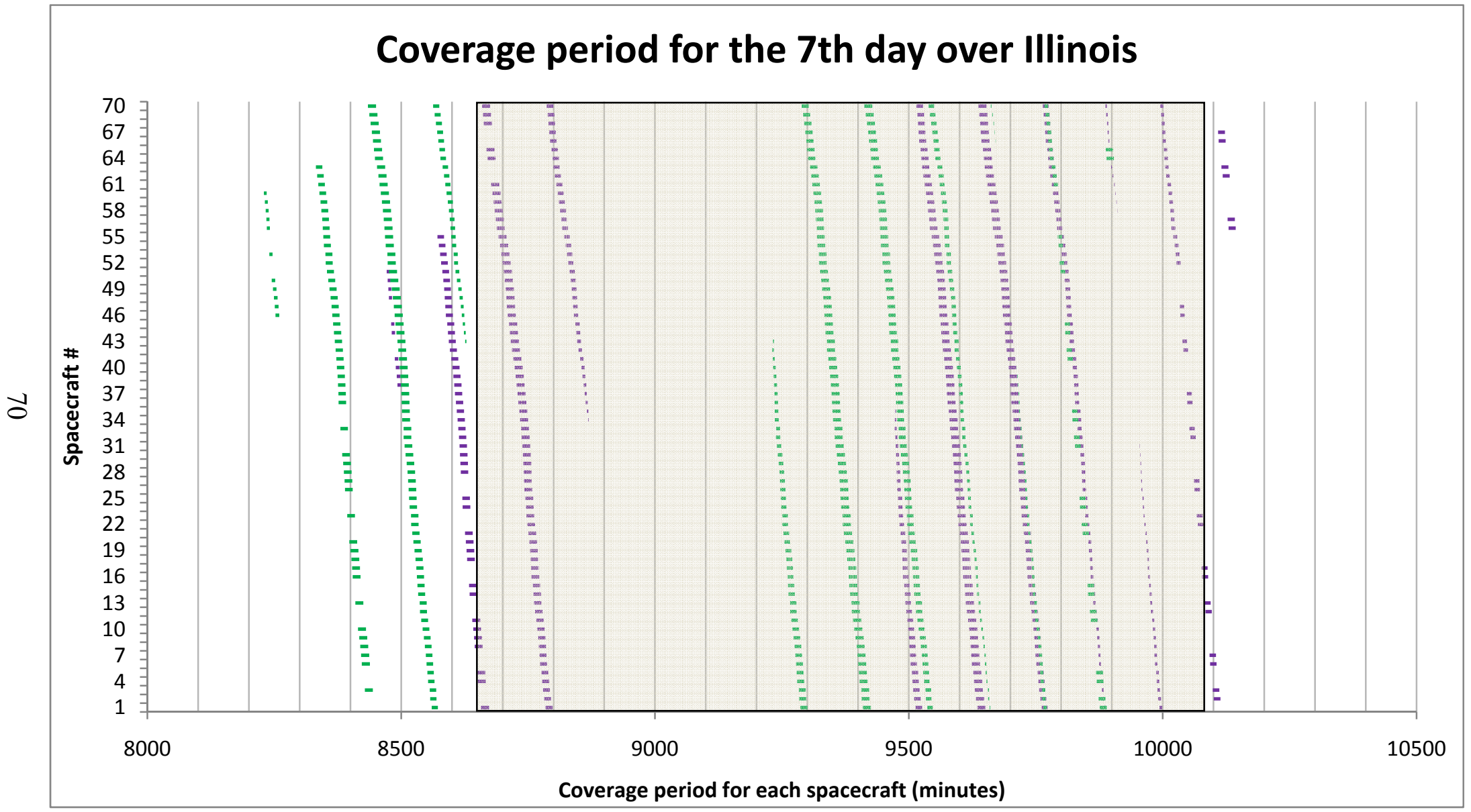

Figure 5.11 Coverage period for the $7^{\text {th }}$ day over Illinois 
$\underline{\text { Day } 8}$

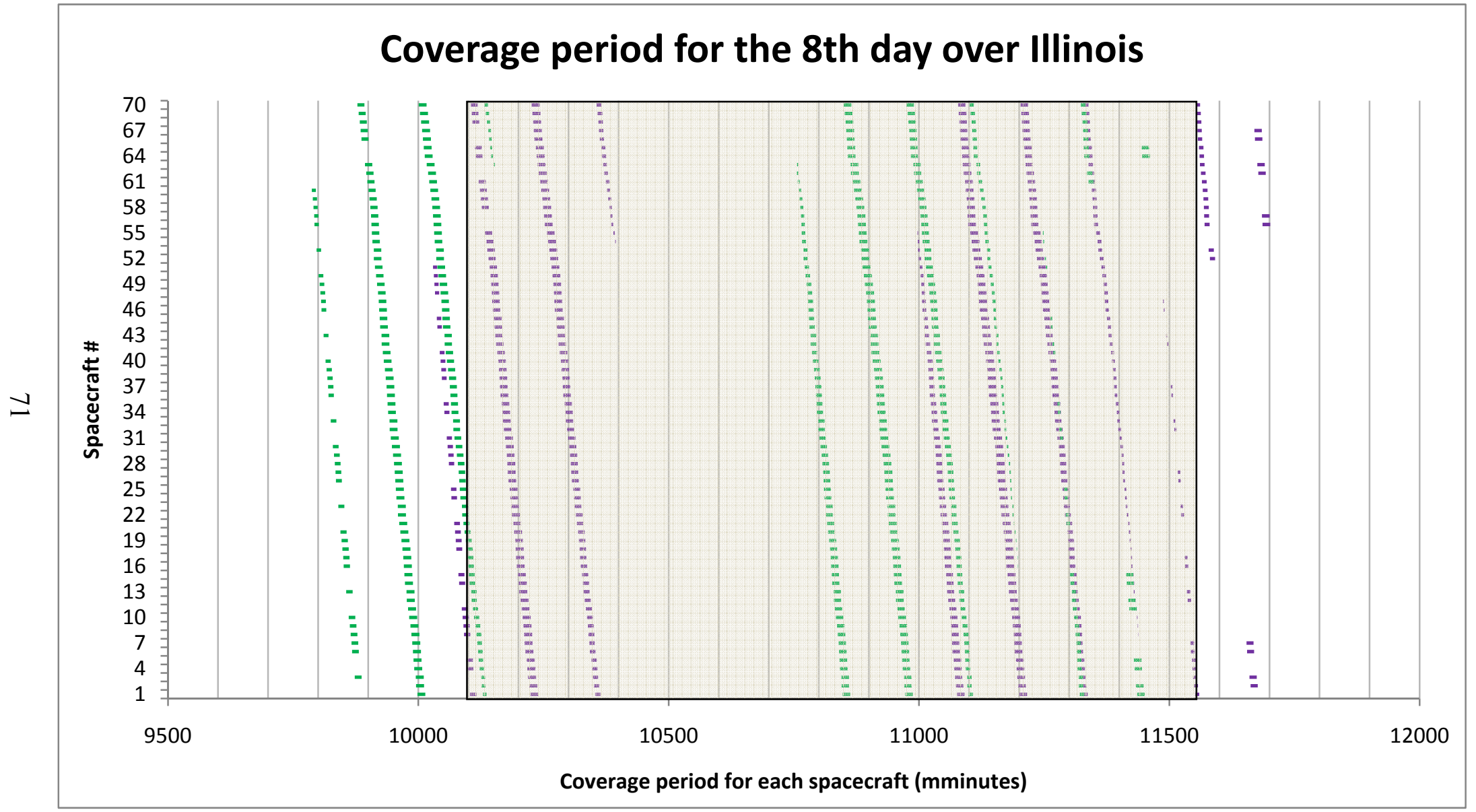

Figure 5.12 Coverage period for the $8^{\text {th }}$ day over Illinois 
Day 9

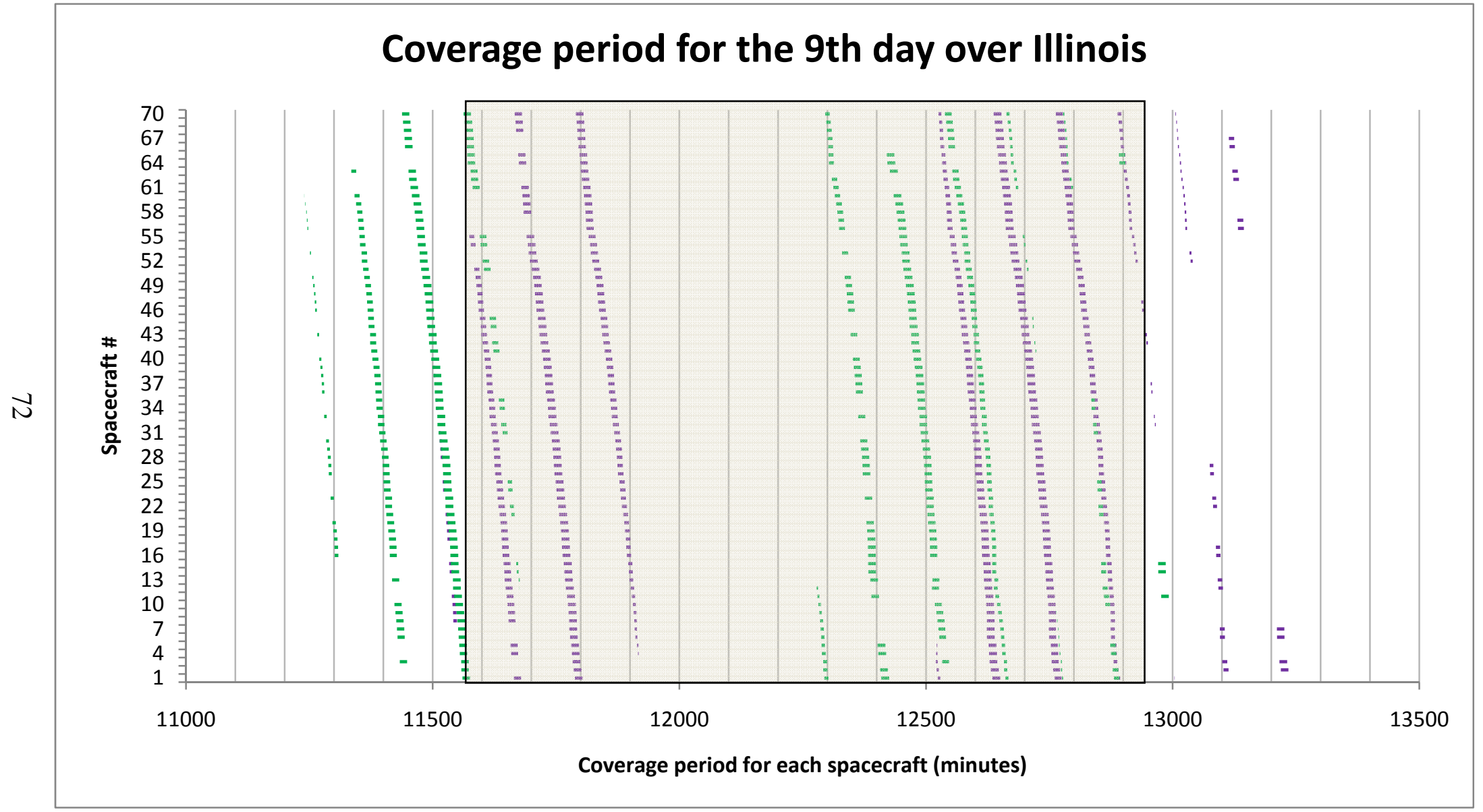

Figure 5.13 Coverage period for the $9^{\text {th }}$ day over Illinois 


\section{Day 10}

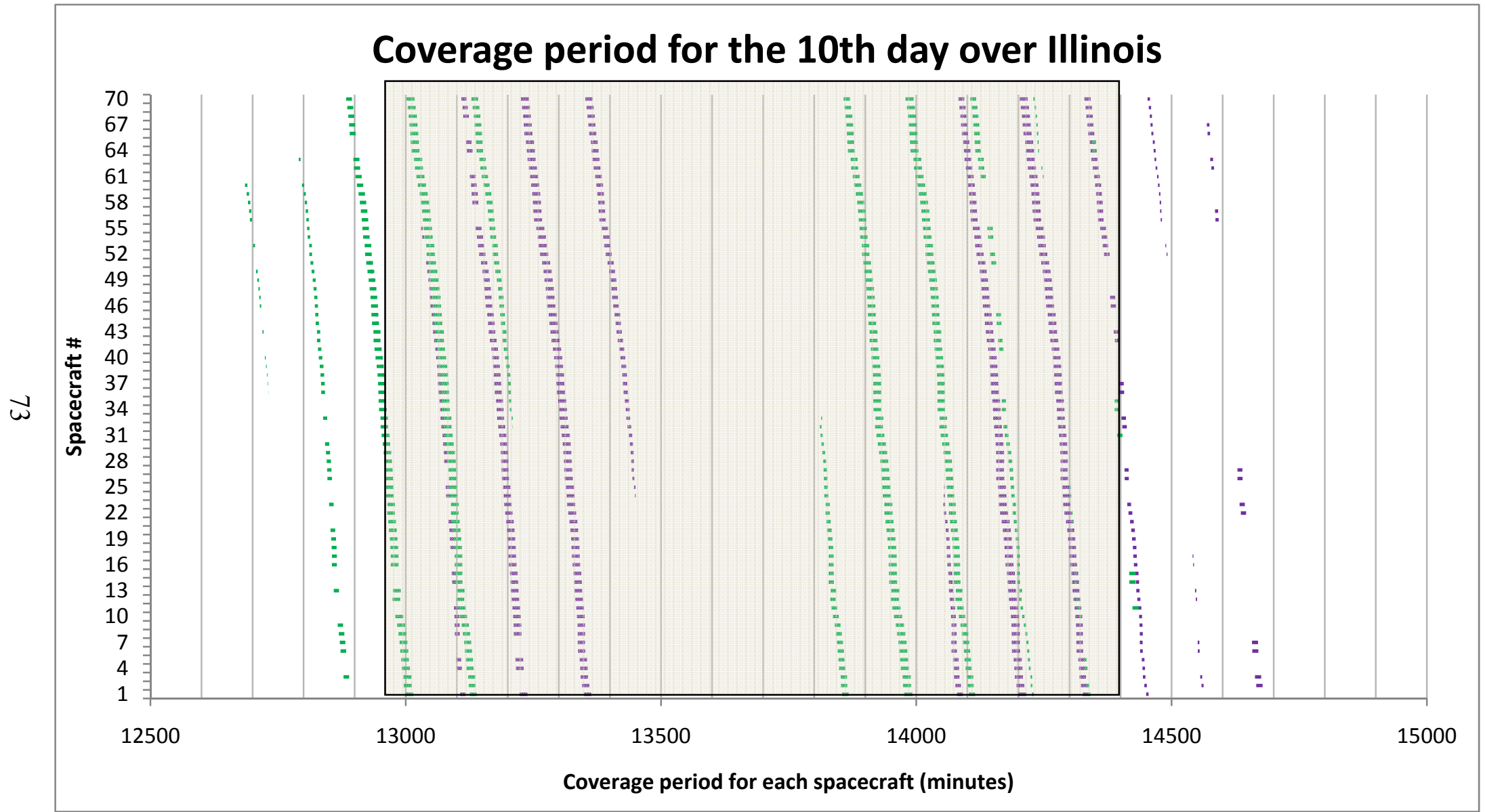

Figure 5.14 Coverage period for the $10^{\text {th }}$ day over Illinois 


\section{Day 11}

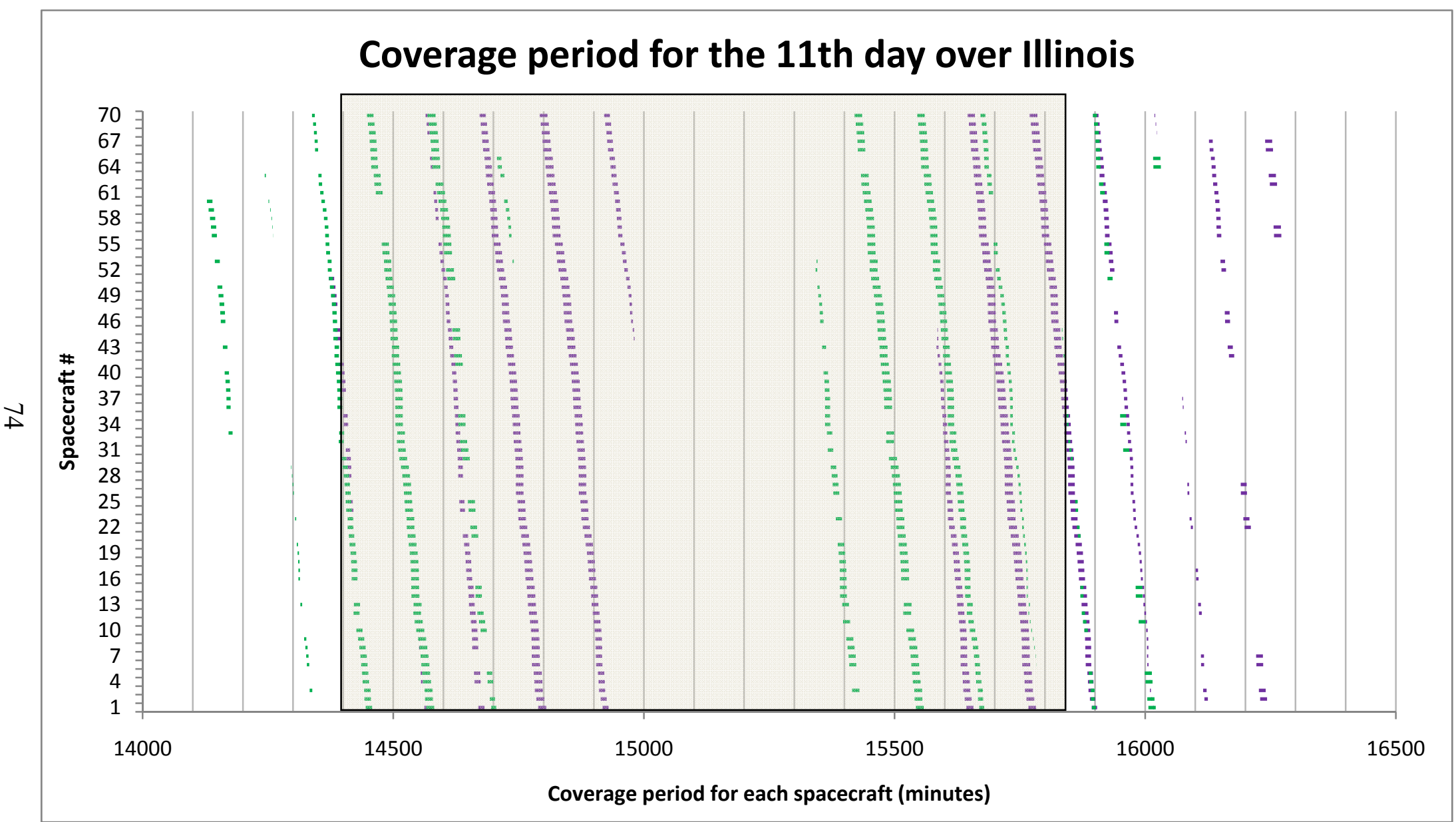

Figure 5.15 Coverage period for the $11^{\text {th }}$ day over Illinois 


\section{Day 12}

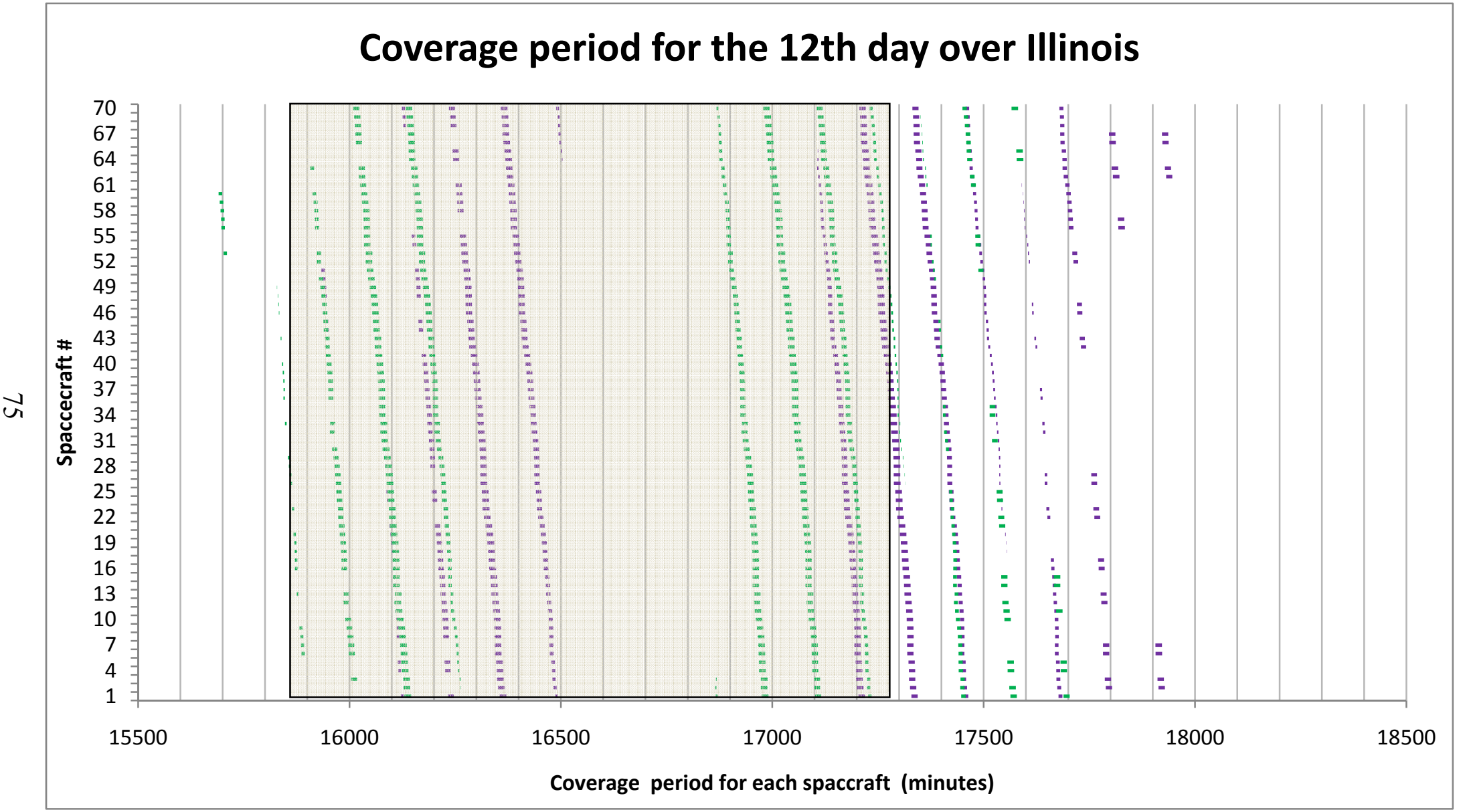

Figure 5.16 Coverage period for the $12^{\text {th }}$ day over Illinois 


\section{Day 13}

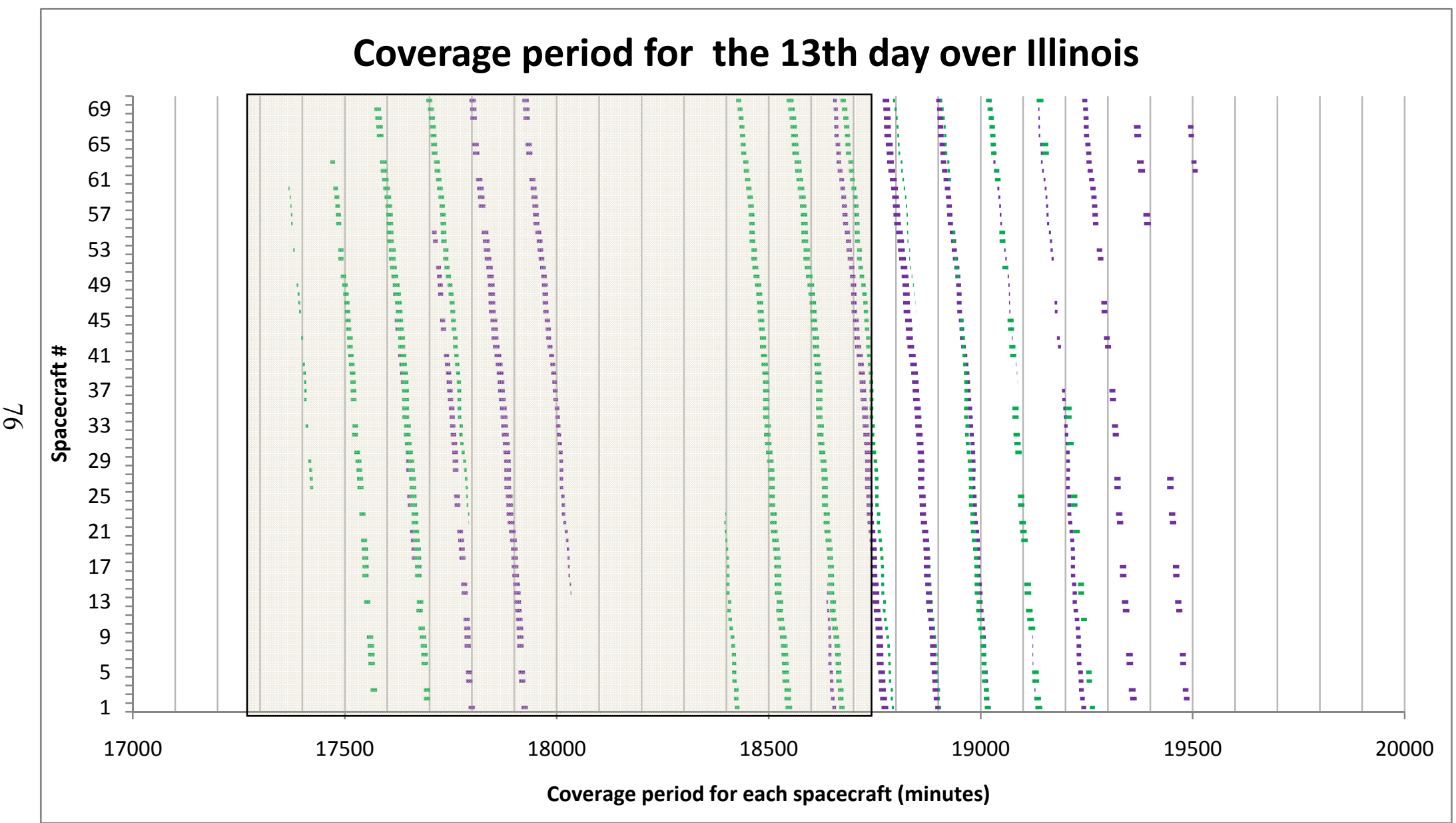

Figure 5.17 Coverage period for the $13^{\text {th }}$ day over Illinois 


\section{Day 14}

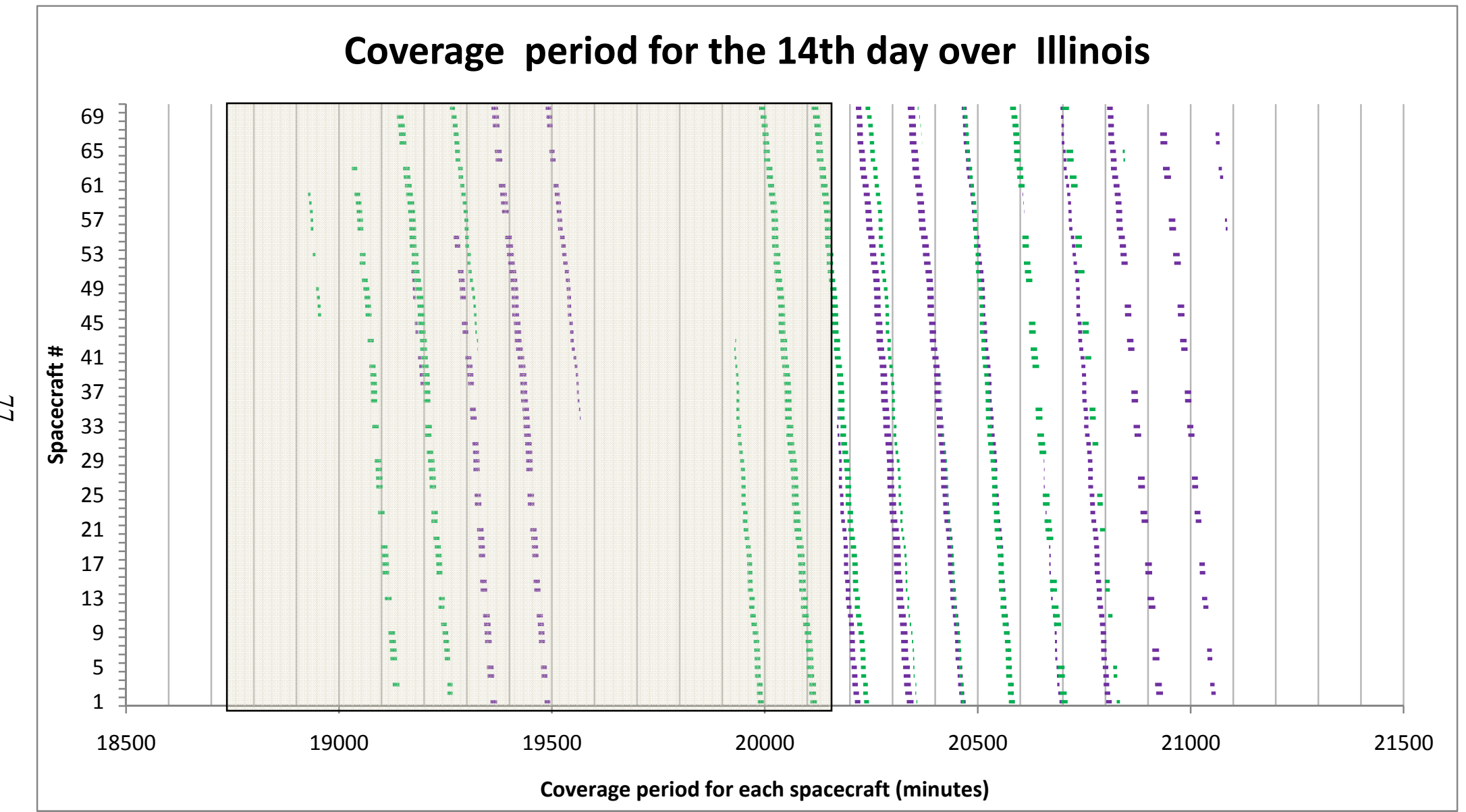

Figure 5.18 Coverage period for the $14^{\text {th }}$ day over Illinois 


\section{Day 15}

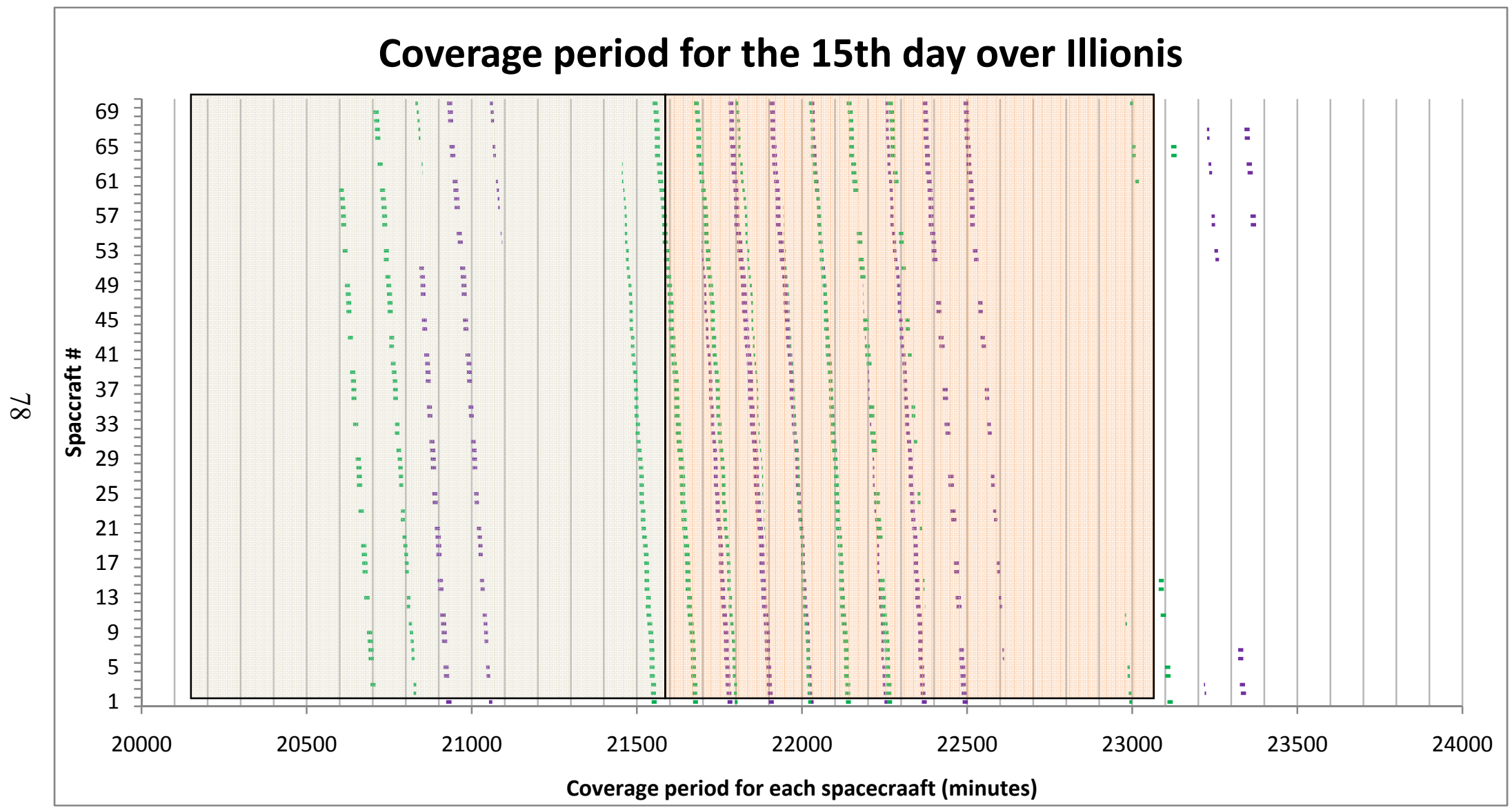

Figure 5.19 Coverage period for the $15^{\text {th }}$ day over Illinois 


\section{Day 16}

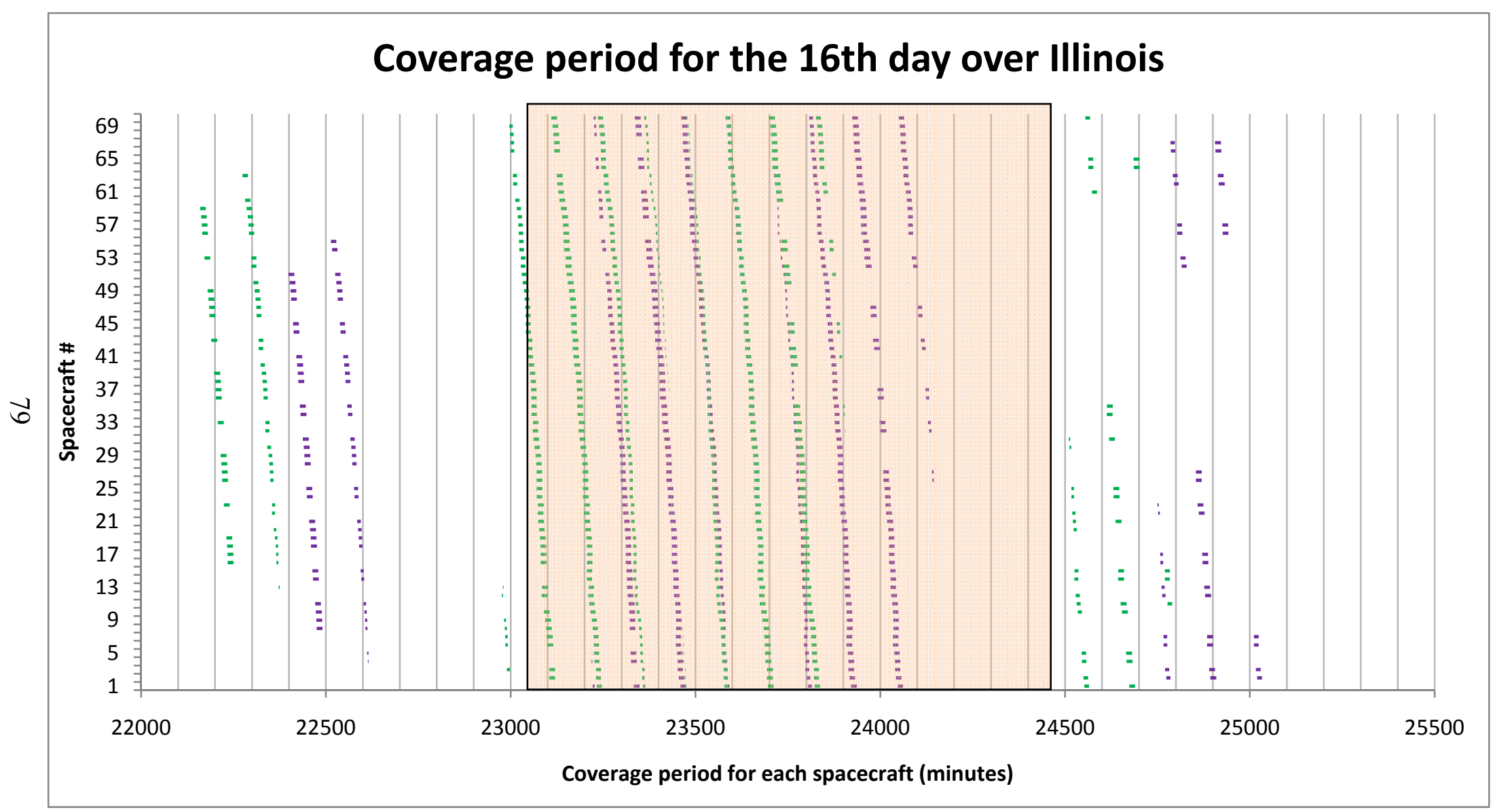

Figure 5.20 Coverage period for the $16^{\text {th }}$ day over Illinois 


\section{Day 17}

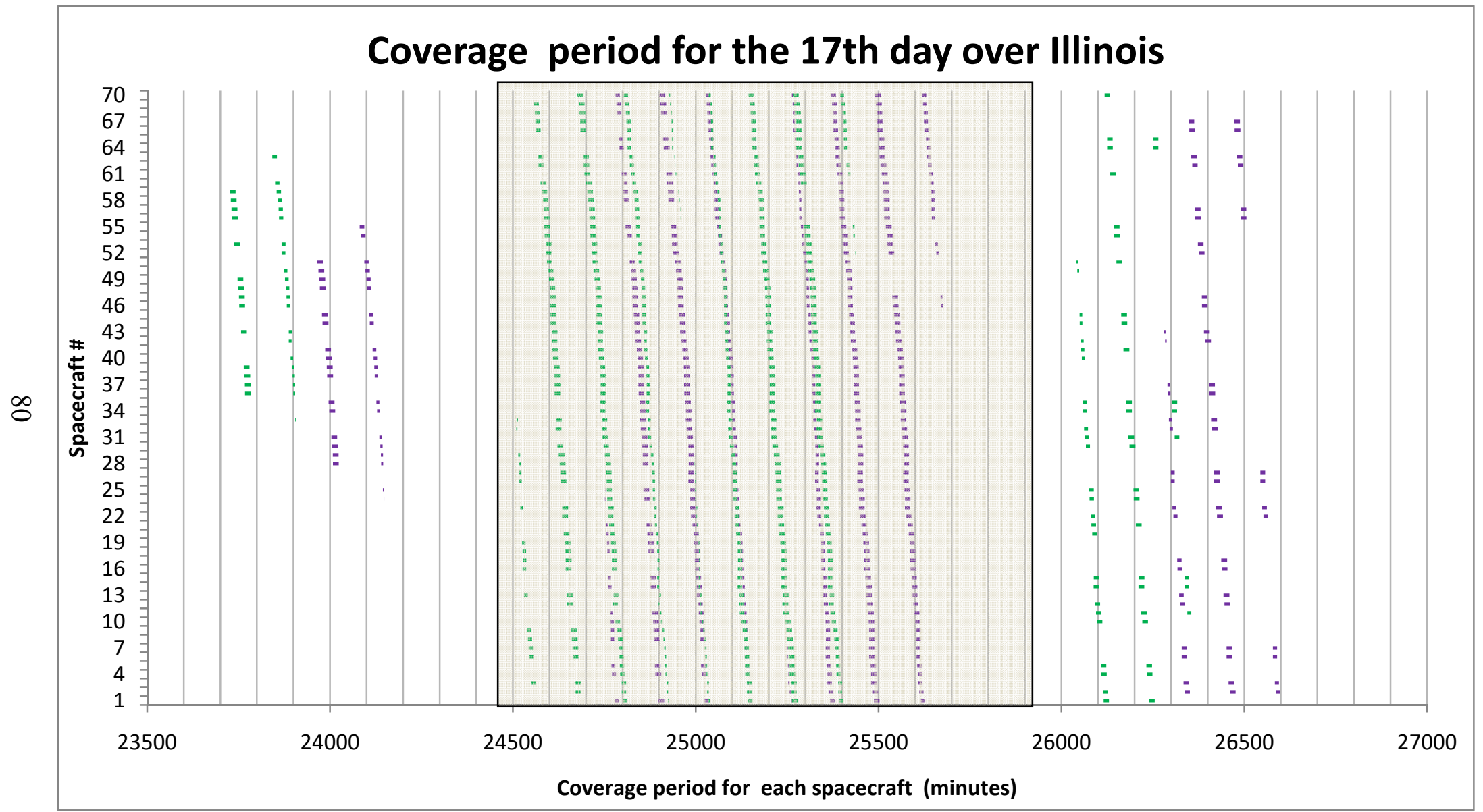

Figure 5.21 Coverage period for the $17^{\text {th }}$ day over Illinois 


\section{Day 18}

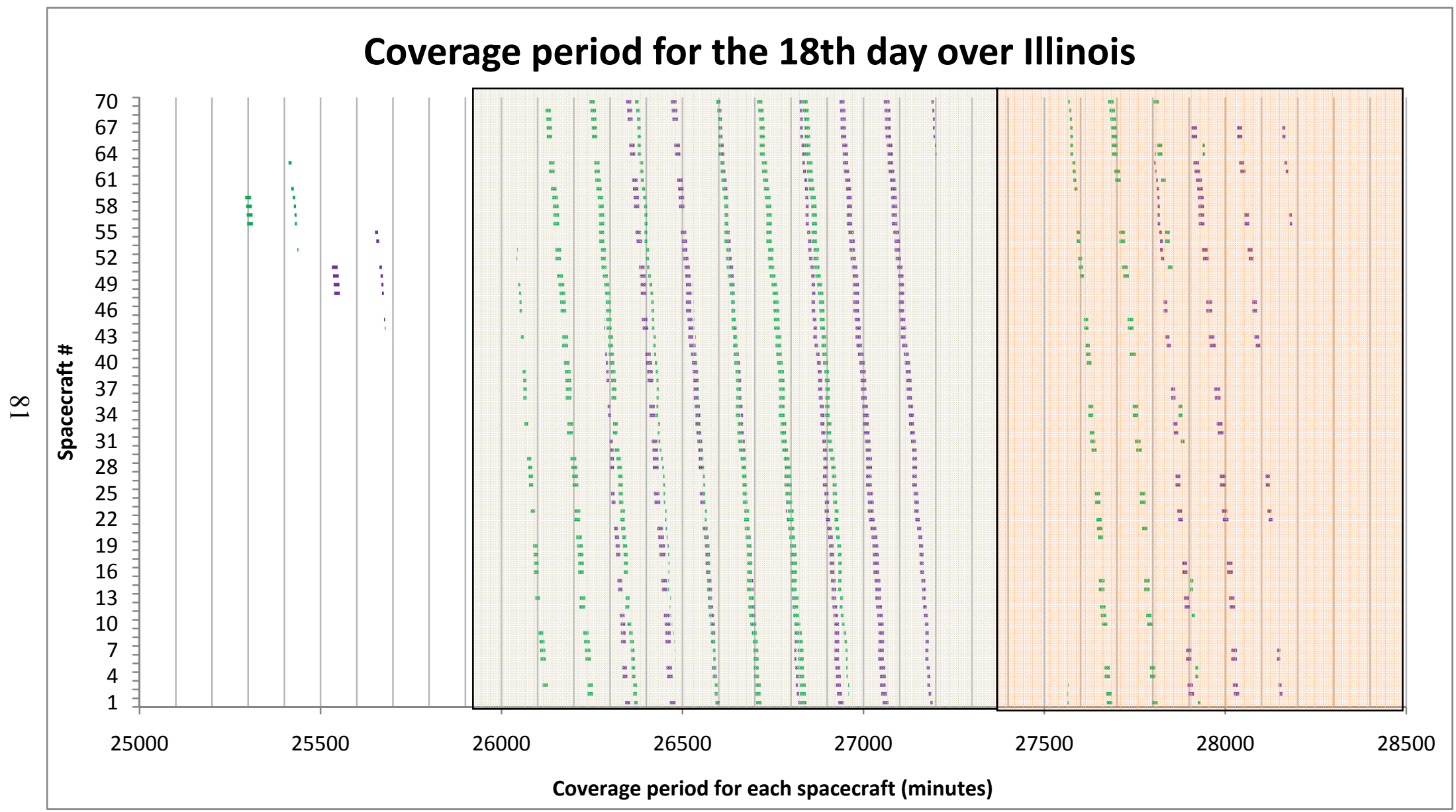

Figure 5.22 Coverage period for the $18^{\text {th }}$ day over Illinois 


\section{Day 19}

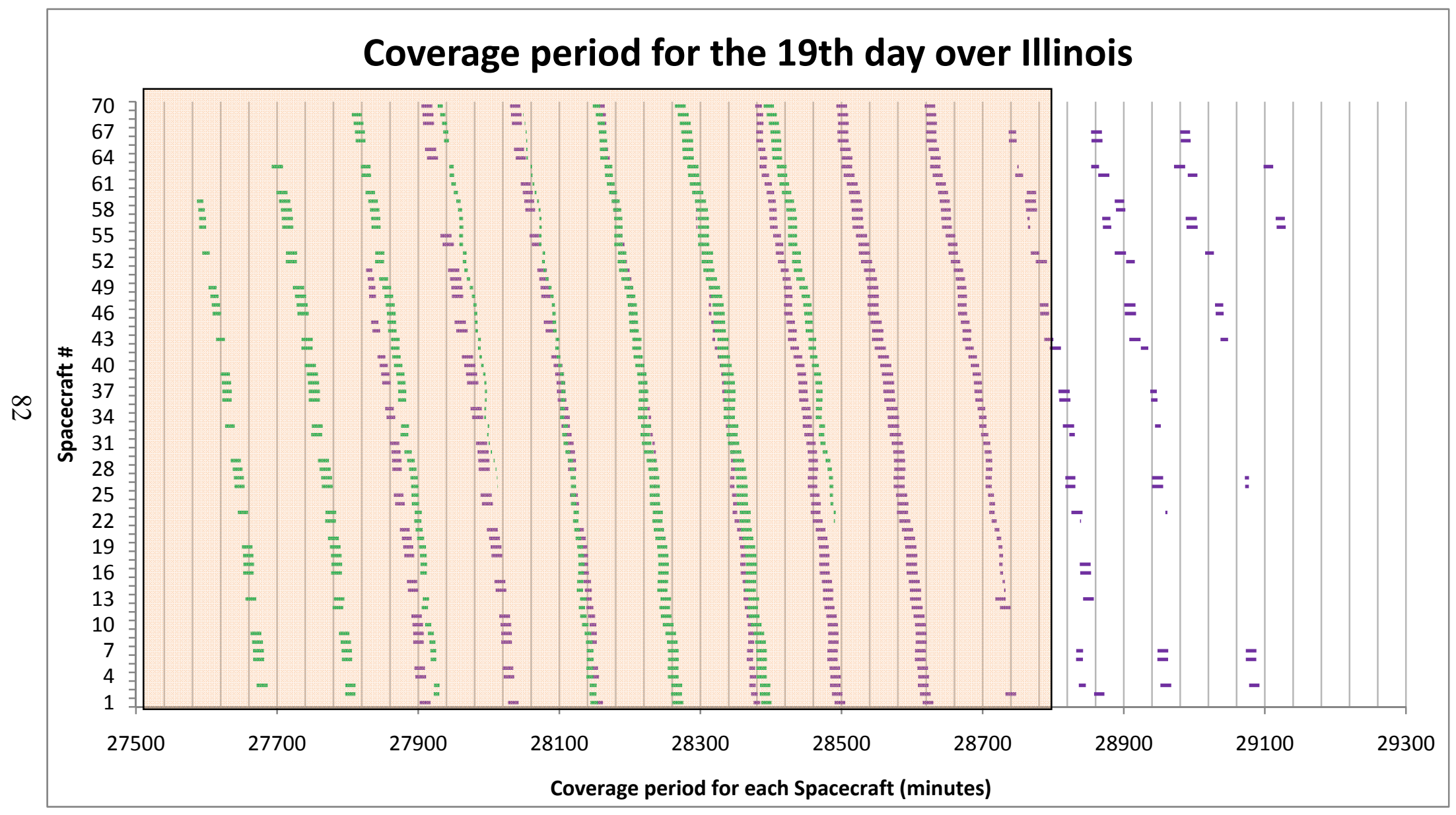

Figure 5.23 Coverage period for the $19^{\text {th }}$ day over Illinois 
All the above figures represent the coverage period of each spacecraft over the selected ground station Illinois. To understand the graphs presented here is a small illustration.

Figure 5.22 is a graph for 18 days repetition period

The $\mathrm{x}$-axis is from 25000 minutes to 28500 minutes. The $\mathrm{y}$-axis represents 1-70 spacecrafts which are represent in orbit 1 and 2 each. The red lines are used to represent orbit 1 spacecrafts and the green are to represent orbit 2 spacecrafts.

The highlighted part of the graph in yellow presents the $18^{\text {th }}$ day of the orbital period and the highlighted part in purple represent a part of $19^{\text {th }}$ day of the orbital period.

Ex: the yellow highlights are starts at 25920 minutes (18 days) and ends at 27360 minutes (19days) that means the yellow highlighted are talk about the $18^{\text {th }}$ day of the spacecraft. There are lines in every part of the highlighted area except a little part in the beginning and at the end. This shows that there is coverage throughout the period except that unmarked times.

Similarly the graphs for all the days are plotted so that we have a detailed understanding for all the days the ground track visits Illinois.

The 48 arbitrary ground tracks selected in the United States are as follows. A total coverage and gap period is represented for all the selected 48 ground stations are shown in fig.5.24.

\section{Arbitrary Selection of the Ground Stations in the US}

$\begin{array}{cl}\begin{array}{c}\text { Ground station } \\ \text { number }\end{array} & \text { Latitude } \\ 1, & 46+32 * \mathrm{~m} 2 \mathrm{~d}, \\ 2, & 41+30 * \mathrm{~m} 2 \mathrm{~d}, \\ 3, & 45+20 * \mathrm{~m} 2 \mathrm{~d}, \\ 4, & 42+30 * \mathrm{~m} 2 \mathrm{~d}, \\ 5, & 44+0 * \mathrm{~m} 2 \mathrm{~d}, \\ 6, & 41+40 * \mathrm{~m} 2 \mathrm{~d}, \\ 7, & 44+0 * \mathrm{~m} 2 \mathrm{~d}, \\ 8, & 40+44 * \mathrm{~m} 2 \mathrm{~d}, \\ 9, & 43+0 * \mathrm{~m} 2 \mathrm{~d}, \\ 10, & 40+45 * \mathrm{~m} 2 \mathrm{~d}, \\ 11, & 40+15 * \mathrm{~m} 2 \mathrm{~d}, \\ 12, & 40+00 * \mathrm{~m} 2 \mathrm{~d}, \\ 13, & 44+0 * \mathrm{~m} 2 \mathrm{~d}, \\ 14, & 36+59 * \mathrm{~m} 2 \mathrm{~d}, \\ 15, & 42+18 * \mathrm{~m} 2 \mathrm{~d}, \\ 16, & 38+30 * \mathrm{~m} 2 \mathrm{~d},\end{array}$

Longitude

Location

$-(102+52 * \mathrm{~m} 2 \mathrm{~d})$

$\% \%$ new england

$-(72+45 * \mathrm{~m} 2 \mathrm{~d})$

$\% \%$ connecticut

$-(69+0 * \mathrm{~m} 2 \mathrm{~d})$

$\% \%$ maine

$-(72+0 * \mathrm{~m} 2 \mathrm{~d})$

$\% \%$ massachusetts

$-(71+30 * \mathrm{~m} 2 \mathrm{~d})$;

$\% \%$ new hampshire

$-(71+30 * \mathrm{~m} 2 \mathrm{~d})$;

$\% \%$ rhode islands

$-(73+0 * \mathrm{~m} 2 \mathrm{~d})$;

$\% \%$ vermont

$-(74+10 * \mathrm{~m} 2 \mathrm{~d})$;

$\% \%$ newyork

$-(75+0 * \mathrm{~m} 2 \mathrm{~d})$;

$\% \%$ newyork

$-(77+30 * \mathrm{~m} 2 \mathrm{~d})$;

$-(89+30 * \mathrm{~m} 2 \mathrm{~d})$;

$\% \%$ pennsylvania

$-(86+00 * \mathrm{~m} 2 \mathrm{~d})$;

$\% \%$ illinois

$-(85+0 * \mathrm{~m} 2 \mathrm{~d})$;

$\% \%$ wisconsin

$-(89+08 * \mathrm{~m} 2 \mathrm{~d})$;

$\% \%$ indiana

$-(93+30 * \mathrm{~m} 2 \mathrm{~d})$;

$\% \%$ illinois

$-(99+00 * \mathrm{~m} 2 \mathrm{~d})$;

$\% \%$ iowa

$\% \%$ kansas 


\begin{tabular}{|c|c|c|c|}
\hline $\begin{array}{c}\text { Ground station } \\
\text { number }\end{array}$ & Latitude & Longitude & Location \\
\hline 17 & $46+0 * \mathrm{~m} 2 \mathrm{~d}$ & $-(94+15 * \mathrm{~m} 2 \mathrm{~d})$ & $\% \%$ minnesota \\
\hline 18 & $46+52 * \mathrm{~m} 2 \mathrm{~d}$ & $-\left(114+01 *^{m} 2 d\right)$ & $\% \%$ montana \\
\hline 19 & $41+30 * \mathrm{~m} 2 \mathrm{~d}$ & $-(99+30 * \mathrm{~m} 2 \mathrm{~d})$ & $\% \%$ nebraska \\
\hline 20 & $47+30 * \mathrm{~m} 2 \mathrm{~d}$ & $-\left(100+15^{*} \mathrm{~m} 2 \mathrm{~d}\right)$ & $\% \%$ north dakota \\
\hline 21 & $44+15 * \mathrm{~m} 2 \mathrm{~d}$ & $-(100+0 * \mathrm{~m} 2 \mathrm{~d})$ & $\% \%$ South dakota \\
\hline 22 & $39+00 * \mathrm{~m} 2 \mathrm{~d}$ & $-(75+20 * \mathrm{~m} 2 \mathrm{~d})$ & $\% \%$ West virgina \\
\hline 23 & $28+00 * \mathrm{~m} 2 \mathrm{~d}$ & $-(82+00 * \mathrm{~m} 2 \mathrm{~d})$ & $\% \%$ florida \\
\hline 24 & $32+50 * \mathrm{~m} 2 \mathrm{~d}$ & $-(83+15 * \mathrm{~m} 2 \mathrm{~d})$ & $\% \%$ georgia \\
\hline 25 & $39+0 * \mathrm{~m} 2 \mathrm{~d}$ & $-(76+30 * \mathrm{~m} 2 \mathrm{~d})$ & $\% \%$ maryland \\
\hline 26 & $35+30 * \mathrm{~m} 2 \mathrm{~d}$ & $-(80+0 * \mathrm{~m} 2 \mathrm{~d})$ & $\% \%$ north carolina \\
\hline 27 & $34+0 * \mathrm{~m} 2 \mathrm{~d}$ & $-(81+0 * m 2 d)$ & $\% \%$ south carolina \\
\hline 28 & $37+30 * \mathrm{~m} 2 \mathrm{~d}$ & $-\left(78+45^{*} \mathrm{~m} 2 \mathrm{~d}\right)$ & $\% \%$ virginia \\
\hline 29 & $38+45 * \mathrm{~m} 2 \mathrm{~d}$ & $-(80+30 * \mathrm{~m} 2 \mathrm{~d})$ & $\% \%$ west virginia \\
\hline 30 & $33+00 * \mathrm{~m} 2 \mathrm{~d}$ & $-(87+00 * \mathrm{~m} 2 \mathrm{~d})$ & $\% \%$ alabam \\
\hline 31 , & $38+41 * \mathrm{~m} 2 \mathrm{~d}$ & $-(85+11 * \mathrm{~m} 2 \mathrm{~d})$ & $\% \%$ kentucky \\
\hline 32 , & $33+0 * \mathrm{~m} 2 \mathrm{~d}$ & $-(90+0 * \mathrm{~m} 2 \mathrm{~d})$ & $\% \%$ mississipi \\
\hline 33 & $36+0 * \mathrm{~m} 2 \mathrm{~d}$ & $-(86+30 * \mathrm{~m} 2 \mathrm{~d})$ & $\% \%$ tennessee \\
\hline 34 & $33+47 * \mathrm{~m} 2 \mathrm{~d}$ & $-(91+04 * \mathrm{~m} 2 \mathrm{~d})$ & $\% \%$ mississipi \\
\hline 35 , & $30+50 * \mathrm{~m} 2 \mathrm{~d}$ & $-(92+0 * \mathrm{~m} 2 \mathrm{~d})$ & $\% \%$ louisisana \\
\hline 36 , & $35+20 * \mathrm{~m} 2 \mathrm{~d}$ & $-(97+30 * \mathrm{~m} 2 \mathrm{~d})$ & $\% \%$ oklahama \\
\hline 37 & $31+40 * \mathrm{~m} 2 \mathrm{~d}$ & $-(98+30 * m 2 d)$ & $\% \%$ texas \\
\hline 38 & $34+00 * \mathrm{~m} 2 \mathrm{~d}$ & $-(112+00 * \mathrm{~m} 2 \mathrm{~d})$ & $\% \%$ arizona \\
\hline 39 & $28+36 * \mathrm{~m} 2 \mathrm{~d}$ & $-(95+59 * \mathrm{~m} 2 \mathrm{~d})$ & $\% \%$ texas \\
\hline 40 & $45+00 * \mathrm{~m} 2 \mathrm{~d}$ & $-(115+00 * \mathrm{~m} 2 \mathrm{~d})$ & $\% \%$ idaho \\
\hline 41 , & $47+0 * \mathrm{~m} 2 \mathrm{~d}$, & $-(110+0 * \mathrm{~m} 2 \mathrm{~d})$ & $\% \%$ montana \\
\hline 42 , & $39+0 * \mathrm{~m} 2 \mathrm{~d}$ & $-(117+0 * \mathrm{~m} 2 \mathrm{~d})$ & $\% \%$ Idaho \\
\hline 43 & $34+30 * \mathrm{~m} 2 \mathrm{~d}$ & $-(106+0 * m 2 d)$ & $\% \%$ new mexico \\
\hline 44 & $43+0 * \mathrm{~m} 2 \mathrm{~d}$ & $-(107+30 * \mathrm{~m} 2 \mathrm{~d})$ & $\% \%$ wyoming \\
\hline 45 & $37+30 * \mathrm{~m} 2 \mathrm{~d}$ & $-(119+30 * \mathrm{~m} 2 \mathrm{~d})$ & $\% \%$ california \\
\hline 46 & $44+0 * \mathrm{~m} 2 \mathrm{~d}$ & $-(121+0 * \mathrm{~m} 2 \mathrm{~d})$ & $\% \%$ oregon \\
\hline 47 & $47+30 * \mathrm{~m} 2 \mathrm{~d}$ & $-(120+30 * \mathrm{~m} 2 \mathrm{~d})$ & $\% \%$ washington \\
\hline 48 & $64+00 * \mathrm{~m} 2 \mathrm{~d}$ & $-(154+00 * \mathrm{~m} 2 \mathrm{~d})$ & $\% \%$ alaska \\
\hline
\end{tabular}

The above columns represent the ground station number, Latitude, Longitude and the location name respectively. Once the ground stations are selected a series of simulations are performed to calculate the gap time and coverage time for each ground station and the results are in the graph below by using the algorithm 2 . The example mentioned in the previous section just plots the results for a single ground station (Ex: Illinois). Here all the coverage and gap time for all the sets of 48 ground stations mentioned above are plotted. 


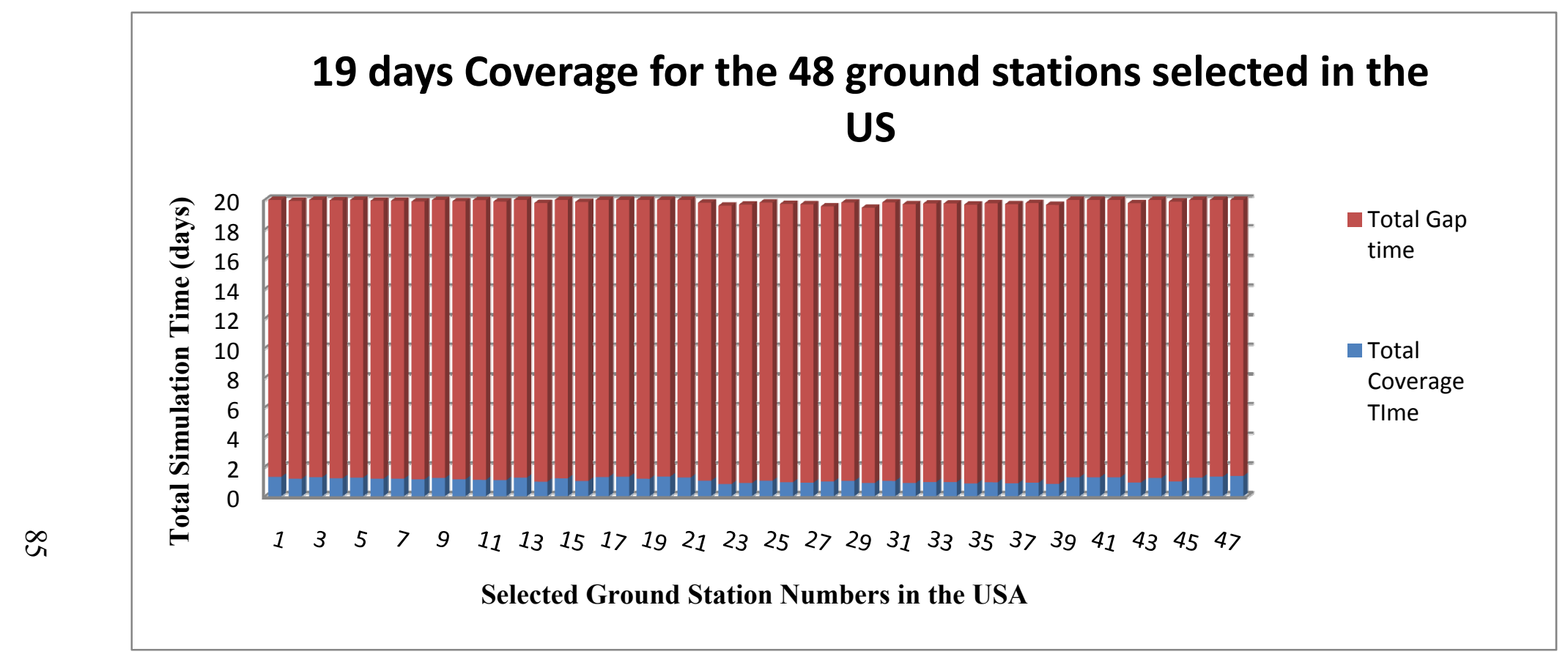

Figure 5.24 Coverage for the 48 ground stations selected in the US

From the above observations we can infer that, out of 19 days of coverage period at least 1 day is covered for each ground station 


\section{References}

[1] U. E. I. Administration, "Independent statisctics and analysis," U. D. o. Energy, Ed., ed. Washington (DC).

[2] B. E. Shapiro, "GTARG - The TOPEX/POSEIDON Ground Track Maintenance Maneuver Targeting Program - User's Reference Manual," California Institute of Technology, Pasadena, CA June 11993.

[3] P. V. Boudewijn Ambrosius, "Introduction to Orbital Mechanics. Part of lecture series ae1-801," ed. Delft Institute for Earth-Oriented Space Research: Space Engineering \& Technology I.

[4] P. W. Fortescue, et al., Spacecraft systems engineering, 3rd ed. Chichester, England ; Hoboken, NJ: J. Wiley, 2003.

[5] N. Pie, "Mission Design Concepts for Repeat Ground track Orbits and Application to the ICESat Mission," Doctor of Philosophy, University of Texas at Austin, Austin, 2008.

[6] R. J. Boain, "A-B-Cs of Sun-synchronous orbit mission design " in Spaceflight Mechanics San Diego, Calif 2004, pp. 85- 104.

[7] D. A. Vallado, Fundamentals of astrodynamics and applications, 3rd ed. New York: Springer, 2007.

[8] P. Glaser, "Method and Apparatus for Converting Solar Radiation to Electrical Power," US Patent, 1973.

Exploration.

Available: http://solarsystem.nasa.gov/planets/profile.cfm?Object=Sun

[10] R. D. a. J. Grey, "Lasers for Wireless Power Transmission," Jet Propulsion Laboratory Reportjanuary 1999.

[11] R. Gopalaswami, "An International Preliminary Feasibility Study On Space Based Solar Power Stations," Kalam-National Space Society Energy Technology Universal Initiative, IndiaAug. 162010.

[12] R. W. J. S. Gilmore, "Predicting low earth orbit satellite communications quality and visibility over time," presented at the Southern African Telecommunication Networks and Applications Conference (SATNAC), 2009.

[13] N. M. B. Komerath, N, "The Space Power Grid," presented at the 57th International Astronautical Federation Congress, Valencia, Spain, 2006.

[14] N. Komerath, "The Space Power Grid: Synergy between space, energy and security policies," in Science and Innovation Policy, 2009 Atlanta Conference on, 2009, pp. 1-7.

[15] N. OASIS, "Space Solar Power Satellites, The Once and Future Energy Solution," ed: Edward D. McCullough, 2010.

[16] Solar Power Satellites and Microwave Wireless Power Transmission Technology [Online]. Available: http://electricalandelectronics.org/wpcontent/uploads/2008/10/sps.pdf 
[17] "Space Based Solar Power as an Opportunity for Strategic Security. Phase 0 Architecture Feasibility Study," National Security Space Office10 Oct. 2007.

[18] "The Sun to the Earth - and Beyond: A Decadal Research Strategy in Solar and Space Physics," Solar and Space Physics Survey Committee, Washington, D.C.

[19] R. V. Chow Kim Paw, "Solar power profile prediction for low earth orbit satellites," Jornal Mekanikal., vol. 28, pp. 1 - 15, 2009.

[20] B. V. S. Ryan M. McLinko, "Space-based Solar Power Generation Using a Distributed Network of Satellites and Methods for Efficient Space Power Transmission," Massachusetts Institute of Technology, Cambridge (MA, USA).

[21] F. E. Little, "Solar Power Satellites: Recent Developments," Center for Space Power,Texas A\&M University College Station.

[22] O. A. Seyed A. (Reza) Zekavat, Shu T. Goh, Daniel R. Fuhrmann, "A Novel Space-Based Solar Power Collection via LEO Satellite Networks: Orbital Management via Wireless Local Positioning Systems," presented at the Aerospace Conference 2010.

[23] M. Kim Ramos. (2000, Solar power constellations implications for the united states air force. Thesis dissertation. USAF.

[24] R. H. Sekhar Angepat, "Ground Station Selection and Feasability Analysis," CARLETON UNIVERSITY2005.

[25] O. Abdelkhalik and A. Gad, "Optimization of space orbits design for Earth orbiting missions," Acta Astronautica, vol. 68, pp. 1307-1317.

[26] C. S. University, "Orbital Mechanics Data A Recipe for Orbit Propagation: Perturbed Keplerian Orbit," ed.

[27] L. S. Franco Ongaro, "Peter glaser lecture: space and a sustainable 21st century energy system," presented at the 57th International Astronautical Congress, 2006.

[28] J. R. Wertz, Mission Geometry: Orbit and Constellation Design and Management. Dordrecht (Netherlands): Microcosm Press/Kluwer Academic Publishers

2001.

[29] L. M. Sauter, "Satellite constellation design for mid-course ballistic missile intercept," Master of Science USAF academy, Massachusetts Institute of Technology, Boston, 2002.

[30] D. Mortari, Wilkins, P.M., and Bruccoleri, C., "On Sun-Synchronous Orbits and Associated Constellations," presented at the 6-th DCSSS Conference, Riomaggiore, Italy, 2004.

[31] D. Mortari, Wilkins, M.P., and Bruccoleri, C. , "The Flower Constellations," The Journal of the Astronautical Sciences, vol. 52, Nos. 1 and 2, pp. 107-127, January-June 2004.

[32] D. Mortari and M. P. Wilkins, "Flower constellation set theory. Part I: Compatibility and phasing," Aerospace and Electronic Systems, IEEE Transactions on, vol. 44, pp. 953-962, 2008.

[33] C. Bruccoleri, "Flower Constellation Optimization and Implementation," Doctor of Philosophy, Aerospace Engineering, Texas A\&M University, Austin, 2007.

[34] M. Zayan, Eltohamy,F, "Orbits Design for Remote Sensing Satellite," NileSat Company, Egypt. 
[35] O. M. O. Abdelkhalik, "Remote sensing satellites orbits Design and control," Master of Science, Aerospace Engineering Department, Cairo university, Giza, Egypt, 2000.

[36] M. W. Lo, "Applications of ergodic theory to coverage analysis," presented at the AAS/AIAA Astrodynamics Specialist Conference, Big Sky, MT, 2003. 